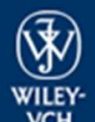

Advanced Synthesis \& Catalysis

\title{
Transition Metal-Free Direct C-H (Hetero)arylation of Heteroarenes: A Sustainable Methodology to Access (Hetero)aryl-Substituted Heteroarenes
}

\begin{tabular}{|r|l|}
\hline Journal: & Advanced Synthesis \& Catalysis \\
\hline Manuscript ID: & Draft \\
\hline Watey - Manuscript type: & Review \\
\hline Complete List of Authors: & $\begin{array}{l}\text { Rossi, Renzo; Universita' di Pisa, Dipartimento di Chimica e Chimica } \\
\text { Industriale } \\
\text { Lessi, Marco; Universita' di Pisa, Dipartimento di Chimica e Chimica } \\
\text { Industriale } \\
\text { Manzini, Chiara; Universita' di Pisa, Dipartimento di Chimica e Chimica } \\
\text { Industriale } \\
\text { Marianetti, Giulia; Scuola Normale Superiore, Chemistry } \\
\text { Bellina, Fabio; Universita' di Pisa, Dipartimento di Chimica e Chimica } \\
\text { Industriale }\end{array}$ \\
\hline Keywords: & $\begin{array}{l}\text { direct C-H (hetero)arylation, heteroarenes, Regioselectivity, transition } \\
\text { metal-free reactions, sustainable chemistry }\end{array}$ \\
\hline
\end{tabular}


DOI: 10.1002/adsc.201((will be filled in by the editorial staff))

\title{
Transition Metal-Free Direct C-H (Hetero)arylation of Heteroarenes: A Sustainable Methodology to Access (Hetero)aryl-Substituted Heteroarenes
}

\author{
Renzo Rossi, ${ }^{\mathrm{a}, *}$ Marco Lessi, ${ }^{\mathrm{a}}$ Chiara Manzini, ${ }^{\mathrm{a}}$ Giulia Marianetti, ${ }^{\mathrm{b}}$ and Fabio Bellina ${ }^{\mathrm{a}, *}$ \\ a Dipartimento di Chimica e Chimica Industriale, University of Pisa, via G. Moruzzi, 3 - 56124 Pisa, Italy \\ Phone: (+39) 050-2212111; fax: (+39) 05040834; e-mail: renzo371@alice.it; fabio.bellina@unipi.it \\ b Scuola Normale Superiore, Piazza dei Cavalieri 7 - 56126 Pisa, Italy
}

Dedicated to the memory of Fausto Calderazzo

Received: ((will be filled in by the editorial staff))

\begin{abstract}
In recent years, environmental and economic reasons have motivated the development of transition metalfree carbon-carbon bond forming reactions and some excellent reviews have covered this research area of particular interest for pharmaceutical industry. However, none of these reviews has been specifically dedicated to summarize and discuss the results achieved in the rapidly growing field of the transition metal-free direct (hetero)arylation reactions of heteroarenes. This review, which covers the literature from 2008 to 2014 , aims to provide a thorough insight of the synthetic and mechanistic aspects of these atom economical and environmental benign reactions also highlighting their advantages and possible disadvantages compared to conventional methods for the synthesis of arylheteroarenes and biheteroaryls via transition metal-catalyzed reactions.

1. Introduction

2. Direct (Hetero)arylation of Heteroarenes with (Hetero)aryl Halides or Pseudohalides

3. Direct (Hetero)arylation of Heteroarenes with (Hetero)aryl Iodonium Salts

4. Direct Arylation of Heteroarenes with Anilines Nitrosated in situ or Arylhydrazines

5. Direct Arylation of Benzothiazoles with Aryl Aldehydes

6. Direct (Hetero)arylation of Heteroarenes with (Hetero)arylmetals

7. Conclusions

Keywords: direct C-H (hetero)arylation; heteroarenes; regioselectivity; transition metal-free reactions; sustainable chemistry
\end{abstract}

\section{Introduction}

(Hetero)aryl-substituted heteroarenes are a structural motif present in naturally-occurring substances, ${ }^{[1]}$ biologically-active compounds, ${ }^{[2]}$ agrochemicals, ${ }^{[3]}$ and conjugated polymers. ${ }^{[4]}$ The traditional approach for the synthesis of (hetero)arylsubstituted heteroarenes involves Pd-catalyzed crosscoupling reactions between previously activated substrates, i.e. (hetero)aryl halides or pseudohalides and (hetero)arylmetal derivatives including Grignard 
reagents, organozinc derivatives, organotin compounds, organoboron derivatives, and organosilicon reagents ${ }^{[5]}$ (Scheme 1, eq. a). However, in the last two decades more step-economical and greener alternative methodologies for the synthesis of arylheteroarenes and biheteroaryls including unsymmetrical derivatives have emerged. One of these methodologies, in which the preparation and use of stoichiometric amounts of organometallic reagents is avoided, involves transition metal-catalyzed direct (hetero)arylation reactions of heteroarenes with (hetero)aryl halides or pseudohalides (Scheme 1, eq. b) ${ }^{[6]}$ Unfortunately, this methodology, which is still a very active area of research and development, suffers from some limitations that include poor reactivity of some substrates, lack of regioselectivity of some of these coupling reactions, especially when the heteroarene substrates possess multiple $\mathrm{C}-\mathrm{H}$ acidic bonds or multiple nucleophilic centers, and impossibility to carry out direct (hetero)arylation reactions at certain specific sites. Furthermore, the efficiency and selectivity of the direct (hetero)arylation reactions often depends strictly by the use and nature of supporting ligands, which sometimes are expensive and/or difficult to prepare, as well as of special additives and cocatalysts.

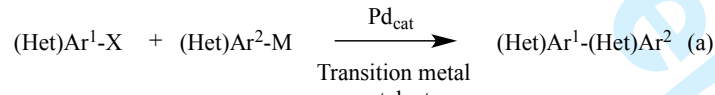

$$
\begin{aligned}
& \text { HetAr }{ }^{1}-\mathrm{H}+\text { (Het)Ar }{ }^{2}-\mathrm{X} \underset{\text { Transition metal }}{\stackrel{\text { catalyst }}{\longrightarrow}} \operatorname{HetAr}^{1}-\left(\mathrm{Het} \mathrm{Ar}^{2} \quad\right. \text { (b) } \\
& \mathrm{HetAr}^{1}-\mathrm{COOH}+(\mathrm{Het}) \mathrm{Ar}^{2}-\mathrm{X} \underset{\text { Transition metal }}{\stackrel{\text { catalyst }}{\longrightarrow}} \operatorname{HetAr}^{1}-(\mathrm{Het}) \mathrm{Ar}^{2} \quad \text { (c) } \\
& \text { (Het)Ar }{ }^{1}-\mathrm{H}+\text { (Het)Ar } \underset{\text { Oxidant }}{\stackrel{\text { catalyst }}{\longrightarrow}} \text { (Het)Ar }{ }^{1} \text {-(Het)Ar }{ }^{2} \text { (d) } \\
& \text { (Het)Ar }{ }^{1}-\mathrm{H}+(\mathrm{Het}) \mathrm{Ar}^{2}-\mathrm{X} \stackrel{\mathrm{h} v}{\longrightarrow} \text { (Het)Ar }{ }^{1} \text {-(Het)Ar }{ }^{2} \text { (e) } \\
& (\mathrm{Het}) \mathrm{Ar}^{1}-\mathrm{H}+(\mathrm{Het}) \mathrm{Ar}^{2}-\mathrm{X} \underset{\begin{array}{c}
\text { strong base }+ \text { ligand } \\
\text { or radical initiator }
\end{array}}{\stackrel{\text { strong base or }}{\longrightarrow}} \operatorname{HetAr}^{1}-(\mathrm{Het}) \mathrm{Ar}^{2} \quad \text { (f) } \\
& \mathrm{HetAr}^{1}-\mathrm{H} \underset{\text { 2) Oxidant }}{\stackrel{\text { 1) }\left(\mathrm{Het} \mathrm{Ar}^{2}-\mathrm{M}\right.}{\longrightarrow}} \operatorname{HetAr}^{1} \text {-(Het)Ar }{ }^{2} \quad \text { (g) }
\end{aligned}
$$

Scheme 1. Methodologies for the synthesis of (hetero)aryl-substituted heteroarenes

Another interesting methodology involves the transition metal-catalyzed decarboxylative crosscoupling reactions of heteroaryl carboxylic acids with (hetero)aryl halides (Scheme 1, eq. c). ${ }^{[7]}$ In these reactions, in which the readily available heteroaryl carboxylic acids are the source of carbon nucleophiles and $\mathrm{CO}_{2}$ is the by-product of the couplings, the regioselectivity is insured by the carboxylic acid functionality.

The transition metal-catalyzed dehydrogenative coupling of two heteroarenes or a heteroarenes with an arene (Scheme 1 , eq d) ${ }^{[8]}$ is another attractive approach to construct (hetero)aryl-substituted heteroarenes. In fact, it allows for superior atom- and step-economic transformations as it does not require preactivation of both coupling partners. However, chemo- and regioselectivity issues limit the broad application of these reactions, which in many cases require the use of stoichiometric amounts of oxidants such as silver or copper salts.

It must also be pointed out that, unfortunately, all the four methodologies illustrated in eqs. a-d of Scheme 1 have some significant drawbacks for their industrial application, especially in the pharmaceutical industry. In fact, they involve the use of catalytic systems which are usually sensitive to moisture and oxygen, are normally quite expensive and sometimes toxic, and require expensive procedures to be completely removed from the final reaction products. ${ }^{[9]}$

Notably, these drawbacks do not characterize the synthesis of (hetero)aryl-substituted heteroarenes through transition metal-free, UV- or visible lightmediated reactions of heteroarenes with aryl halides or pseudohalides as well as of arenes with heteroaryl halides (Scheme 1, eq. e) ${ }^{[10]}$ but this process often suffers from low reaction rates and or low chemical yields.

Finally, in the last decade, environmental and economic concerns have motivated the development of a conceptually different green methodology for the synthesis of arylheteroarenes and unsymmetrical biheteroaryls. In this methodology, which has emerged as a useful alternative to traditional crosscouplings, the synthesis of the target compounds is achieved via transition metal-free direct (hetero)arylation of heteroarenes with (hetero)aryl halides or pseudohalides or (hetero)aryliodonium salts in the presence of a strong base, a combination of a strong base and an organic ligand, or a radical initiator (Scheme 1, eq. f). The seminal study of the transition metal-free direct heteroarylation reactions of heteroarenes with aryl halides was performed ion 2008 by Itami and coworkers ${ }^{[11]}$ and, since then, the literature has been enriched by numerous reports that illustrate various protocols to achieve the inexpensive, high yielding and easy to conduct chemoselective synthesis of a large variety of arylheteroarenes and unsymmetrical biheteroaryls including highly functionalized derivatives.

In this last decade, this methodology has also been joined by some protocols in which (hetero)arylating reagents different from (hetero)aryl halides or pseudohalides have been used. In addition, two-step procedures have been developed that involve the transition metal-free reaction of heteroarenes with (hetero)arylmetals and the subsequent reaction of the resulting compounds with an oxidant (Scheme 1, eq. g). Obviously, these procedures can not be included among those with low economic and environmental 
impact as they involve the synthesis of the organometallic reagents to be used as (hetero)arylating reagents and some of these compounds are water and air sensitive. Nevertheless, it appeared appropriate to include these reactions in this review taking into account of their efficiency and the fact that they do not require a large molar excess of one of the reagents, they operate in the absence of a transition metal catalyst, and given that only one of the reaction partners requires to be activated.

Recently, the transition metal-free carbon-carbon bond forming reactions have been covered by some excellent reviews, ${ }^{[12]}$ but none of them has been specifically devoted to summarize completely and discuss the results achieved in the context of the transition metal-free direct $\mathrm{C}-\mathrm{H}$ (hetero)arylation reactions of heteroarenes. This review with 258 references aims to provide a thorough insight of this subject highlighting the synthetic and mechanistic aspects of these transition metal-free (hetero)arylation reactions as well as the practicality and limitations of the various developed protocols. A comparison between the results achieved using the transition metal-free direct (hetero)arylation reactions of heteroarenes and those obtained by other methods fro the formation of $\mathrm{C}_{\text {(hetero)aryl }}-\mathrm{C}_{\text {heteroaryl }}$ bonds will be also reported.

The review, which covers the literature from 2008 to December 2014, has been organized in the following sections: (i) direct (hetero)arylation of heteroarenes with (hetero)aryl halides or pseudohalides; (ii) direct (hetero)arylation of heteroarenes with (hetero)aryliodonium salts; (iii) direct (hetero)arylation of heteroarenes with anilines nitrosated in situ or arylhydrazines; (iv) arylation of benzothiazoles with aryl aldehydes; and (v) direct (hetero)arylation of (hetero)arenes with (hetero)arylmetals.

However, it should be pointed out that, for reasons of space, this review does not deal with a summary and discussion of the synthesis of (hetero)arylsubstituted heteroarenes via transition metal-free oxidative (dehydrogenative) cross-coupling reactions $^{[13]}$ and via aryl radical additions to heteroarenes involving the use of catalytic amounts of AIBN and over-stoichiometric amounts of $\mathrm{Bu}_{3} \mathrm{SnH}_{1}{ }^{[14]}$ a compound that is very harmful to the environment. Also, the patent literature has not been taken into account.

\section{Direct (Hetero)arylation of Heteroarenes with (Hetero)aryl halides or Pseudohalides}

In 2008, Itami and coworkers reported the first examples of synthesis of arylheteroarenes via intermolecular transition metal-free direct $\mathrm{C}-\mathrm{H}$ arylation of heteroarenes with aryl halides. ${ }^{[1]}$ They discovered that the reaction of 1 equiv of aryl iodides with 40 equiv of electron deficient nitrogen heteroarenes, including pyrazine (1), pyridine (2), pyrimidine (3), piperazine (4) and quinoxaline (5), and 1.5 equiv of sublimed $\mathrm{KO}-t-\mathrm{Bu}$ at $50{ }^{\circ} \mathrm{C}$ under microwave irradiation for $5 \mathrm{~min}$ produced arylheteroarenes in good to excellent yields (Scheme 2). Interestingly, the arylation reactions were carried out in the absence of any amine or bipyridine catalyst such as $N, N^{\prime}$-dimethylethylenediamine or 1,10phenanthroline.

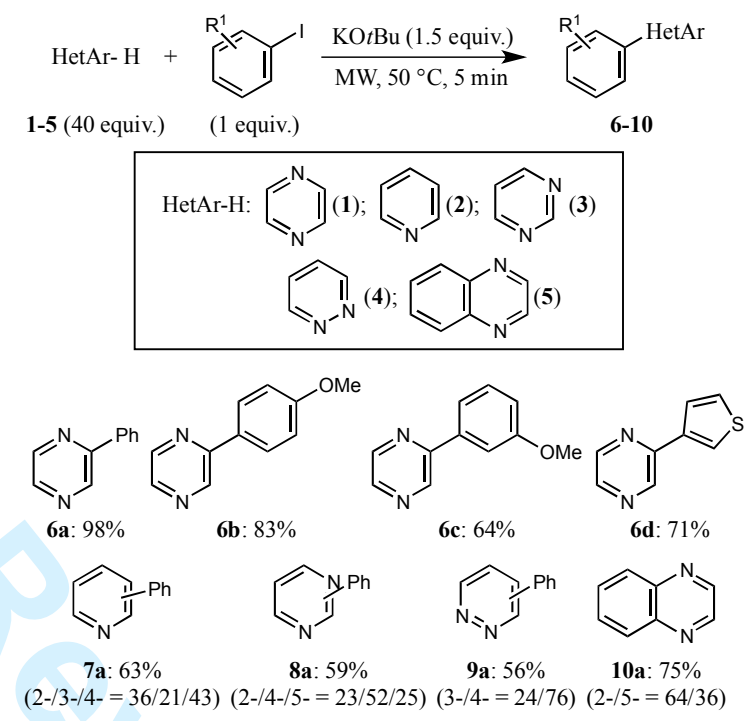

Scheme 2. Synthesis of compounds 6-10 by KO-t$\mathrm{Bu}$-mediated direct arylation of heteroarenes 1-5 with aryl iodides under microwave irradiation

Unfortunately, poor regioselectivity with respect to the heteroarene was observed in the arylation of compounds 2-5 with iodobenzene, but regioisomers with respect to the aryl iodides were not detected in the arylation reactions of pyrazine (1) with 4-iodoand 3-iodoanisole and 3-iodothiophene, which provided compounds $\mathbf{6 b}, \mathbf{6 c}$ and $\mathbf{6 d}$ in 83,64 and $71 \%$ yield, respectively (Scheme 2). This meant that the arylation reactions did not proceed through aryne intermediates. The reaction mechanism was not elucidated, but the radical nature of the reaction was supported by experiments showing that the reaction of pyrazine (1) with iodobenzene in the presence of 1.5 equiv of KO- $t-\mathrm{Bu}$ and 1 equiv of a radical scavenger such as TEMPO, galvinoxyl or acrylonitrile did not gave 2-phenylpyrazine (6a). Itami and coworkers then formulated a plausible mechanism for the $\mathrm{KO}-t$-Bu- 
mediated arylation of $\mathbf{1}$ with iodobenzene in which the initial step was the generation of the radical anion species A by single electron transfer (SET) from KO$t$-Bu to iodobenzene (Scheme 3). ${ }^{[1]}$
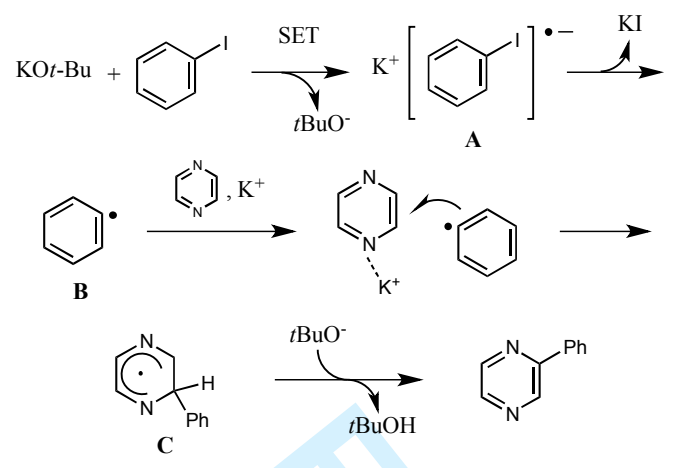

Scheme 3. Plausible mechanism for the of KO-t-Bumediated arylation of pyrazine (1) with iodobenzene

In this mechanism, elimination of KI from $\mathbf{A}$ would provide phenyl radical $\mathbf{B}$, which by addition to pyrazine would generate phenylpyrazyl radical C. Finally, abstraction of hydrogen radical from $\mathbf{C}$ by $t$ butoxide radical would give compound 6 a (Scheme 3). ${ }^{[11]}$

One year after the publication of these results, $\mathrm{Li}$ and Hua reported that pyrazine (1) and pyridine (2) underwent $\mathrm{Cy}_{3} \mathrm{PAuCl}$-catalyzed direct arylation with aryl bromides at $100{ }^{\circ} \mathrm{C}$ in the presence of $\mathrm{KO}-t-\mathrm{Bu}$ to give monoarylated products, which in the case of electron-rich aryl bromides were obtained in moderate to good yields. ${ }^{[15]}$

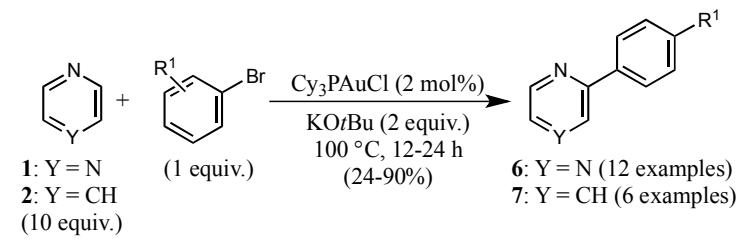

Scheme 4. Gold-catalyzed direct arylation of pyrazine (1) and pyridine (2) with aryl bromides

This method (Scheme 4) also allowed the preparation of compound $6 \mathrm{a}$ in $90 \%$ yield, but in the case of the arylation of pyridine provided mixtures of regioisomers. ${ }^{[15]}$

In the same year, Liu and Yang synthesized compound $\mathbf{6 a}$ and 2-(p-tolyl)pyrazine (6e) in 80 and $82 \%$ yield respectively, by oxygen-promoted, ligand- free $\mathrm{Pd}(\mathrm{OAc})_{2}$-catalyzed Suzuki reaction of 2chloropyrazine (11) with the required arylboronic acids in $50 \%$ aqueous isopropanol at $80{ }^{\circ} \mathrm{C}$ for $40 \mathrm{~min}$ (Scheme 5). ${ }^{[16]}$ Interestingly, a similar protocol allowed the preparation of 2-aryl-substituted pyridines from 2-bromopyridines in excellent yields. ${ }^{[16]}$

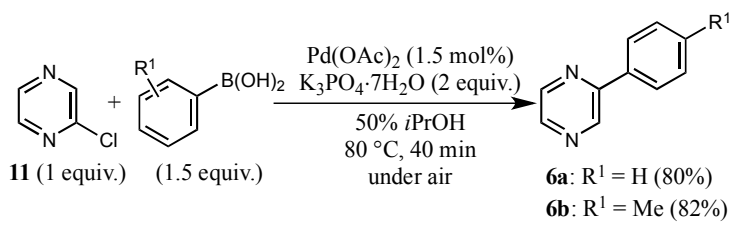

Scheme 5. Ligand-free $\mathrm{Pd}(\mathrm{OAc})_{2}$-catalyzed Suzuki coupling of 2-chloropyrazine (11) with arylboronic acids

More recently, Zhu, Xu and coworkers showed that $p$ toluenesulfonylhydrazide (PTSH) promotes the efficient direct arylation of pyrazine (1) with 4iodoanisole at $110{ }^{\circ} \mathrm{C}$ in the presence of 3 equiv of $\mathrm{KO}-t-\mathrm{Bu}$, but in the absence of any amine or bipyridine catalyst, providing compound $\mathbf{6 b}$ in $90 \%$ yield (Scheme 6). ${ }^{[17]}$ However, a regioisomeric mixture of arylated compounds favouring the ortho product was obtained by the PTSH-initiated direct arylation of pyridine with 4-iodoanisole. ${ }^{[17]}$

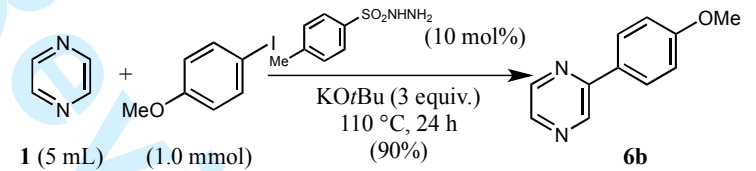

Scheme 6. $\quad p$-Toluenesulfonylhydrazide-initiated direct arylation of pyrazine with 4-iodoanisole

The PTSH-initiated arylheteroarene syntheses were proposed to occur through a chain base-promoted homolytic aromatic substitution involving the aryl radical II, which would be formed by the reaction between deprotonated PTSH and 4-iodoanisole followed by elimination of iodide anion from the resulting radical anion $\mathbf{I}$ (Scheme 7). ${ }^{[17]}$

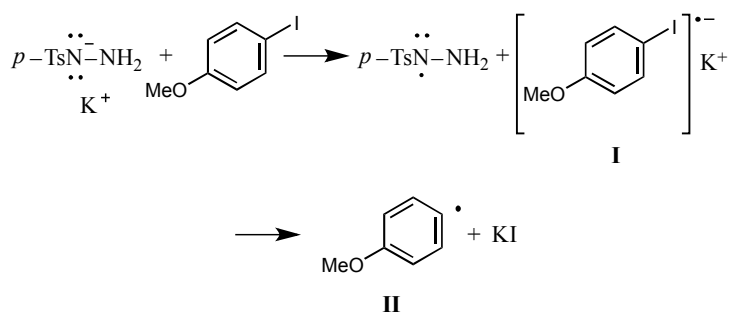


Scheme 7. Proposed mechanism for the formation of p-methoxyphenyl radical II

Notably, the reaction conditions used for the synthesis of $\mathbf{6 b}$ resulted also suitable for the efficient direct arylation of unactivated arenes with aryl iodides, bromides and chlorides. ${ }^{[17]}$

In concluding the treatment of the results achieved so far concerning the transition metal-free $\mathrm{KO}-t-\mathrm{Bu}-$ mediated direct arylation reactions of heteroarenes with (hetero)aryl halides it deserves to be noted that, recently, it was reported that the KO-t-Bu-mediated biaryl coupling reactions do not need to be carried out in the presence of an amine or bipyridine catalyst. ${ }^{[18]}$ In fact, results were obtained suggesting that in KO- $t$ Bu-mediated biaryl couplings carried out employing 1,10-phenanthroline as the catalyst, the alkoxide is destroyed almost immediately. ${ }^{[18]}$

A new interesting transition metal-free method for the direct arylation of electron-rich and electron-poor heteroarenes with aryl chlorides and fluorides was developed by Truong and Daugulis at the beginning of 2011. ${ }^{[19]}$ They found that the reaction between 1.0 equiv of heteroarenes and 1.3-2.5 equiv of aryl halides in THF or a mixture of pentane and THF in the presence of a large molar excess of lithium 2,2,6,6-tetramethylpiperidide (LiTMP) was highly regioselective with respect to the heteroarenes providing cross-coupling products in good to excellent yields. Table 1 illustrates the optimized reaction conditions used for the direct arylation of benzo $[b]$ thiophene (12), benzo $[b]$ furan (13), 2butylfuran (14), 1-methylbenzimidazole (15), 1-
phenyl-1H-pyrrole (16a), 2-methoxypyrazine (17), and 3-methoxypyridine (18). The aryl chlorides which were used in the arylation reactions included derivatives bearing electron-withdrawing or electrondonor substituents, and the aryl fluoride used in the direct arylation of 12 (entry 8, Table 1) contained the electron-withdrawing $t$-butoxycarbonyl group in the $\beta$-position with respect to the $\mathrm{C}-\mathrm{F}$ bond. It is noteworthy that the arylation reactions of heteroarenes 12, 13, 15 and 16a provided C-2 arylated derivatives (entries 1-11,13,14, and 16, Table 1) and that the C-2 arylation of $\mathbf{1 2}$ and $\mathbf{1 3}$ had previously been achieved by treatment of these heteroarenes with aryl bromides in DMA at $100{ }^{\circ} \mathrm{C}$ using a $\mathrm{Pd}(\mathrm{OAc})_{2} / \mathrm{PCy}_{3} \cdot \mathrm{HBF}_{4} /$ pivalic acid catalyst system. ${ }^{[20]}$ On the other hand, 2-aryl-1-phenyl-1 $H$-pyrroles were previously selectively synthesized in high yields by ligand-free $\mathrm{Pd}(\mathrm{OAc})_{2}$-catalyzed direct arylation of 1phenyl-1H-pyrrole (16a) with aryl bromides. ${ }^{[21]}$ Notably, regioselectivity as regards the heteroarenes was also observed for the LiTMP-mediated reactions of the six-membered heteroarene derivatives $\mathbf{1 7}$ and $\mathbf{1 8}$ with chlorobenzene, which gave compounds $\mathbf{2 4}$ and 25 in 55 and $71 \%$ yield, respectively (entries 15 and 16, Table 1). ${ }^{[19]}$ It was also found that the arylation of benzo[b]thiophene (12) with 2chloroanisole and 2-chlorobenzotrifluoride gave the meta-substituted products 19a and 19b, respectively, in good yields (entries 1 and 2, respectively, Table 1). Moreover, both arylation reactions of $\mathbf{1 2}$ with 2chloro- $N, N$-dimethylaniline and 3-chloro- $N, N$ dimethylaniline (entries 4 and 5, respectively, Table 1) produced 3-benzothien-2-yl- $N, N$ dimethylbenzamine (19c) in agreement with a reaction mechanism involving the participation of an aryne intermediate.

Table 1. LiTMP-mediated direct arylation of heteroarenes 12-18 with aryl chlorides and fluorides

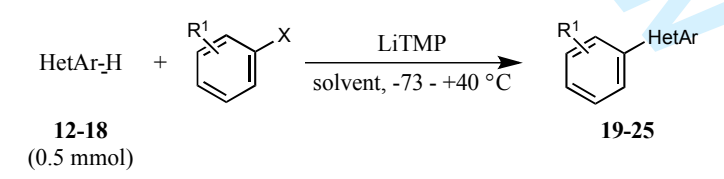

\begin{tabular}{|c|c|c|c|c|c|c|c|c|}
\hline \multirow[b]{2}{*}{ Entry } & \multirow{2}{*}{$\begin{array}{l}\text { HetAr-H } \\
\text { structure }\end{array}$} & \multicolumn{2}{|c|}{ Aryl halide } & \multirow[b]{2}{*}{ LiTMP } & \multirow[b]{2}{*}{ Solvent } & \multirow[b]{2}{*}{ Reaction } & \multicolumn{2}{|c|}{ Product } \\
\hline & & Structure & Mmol & & & & Structure & Yield (\%) \\
\hline 1 & (12) & & 1.35 & 2.1 & THF & $\mathrm{rt} / 1$ & (19a) & 78 \\
\hline 2 & 12 & & 1.0 & 1.8 & THF & $0 / 4$ & $(19 b)$ & 61 \\
\hline
\end{tabular}




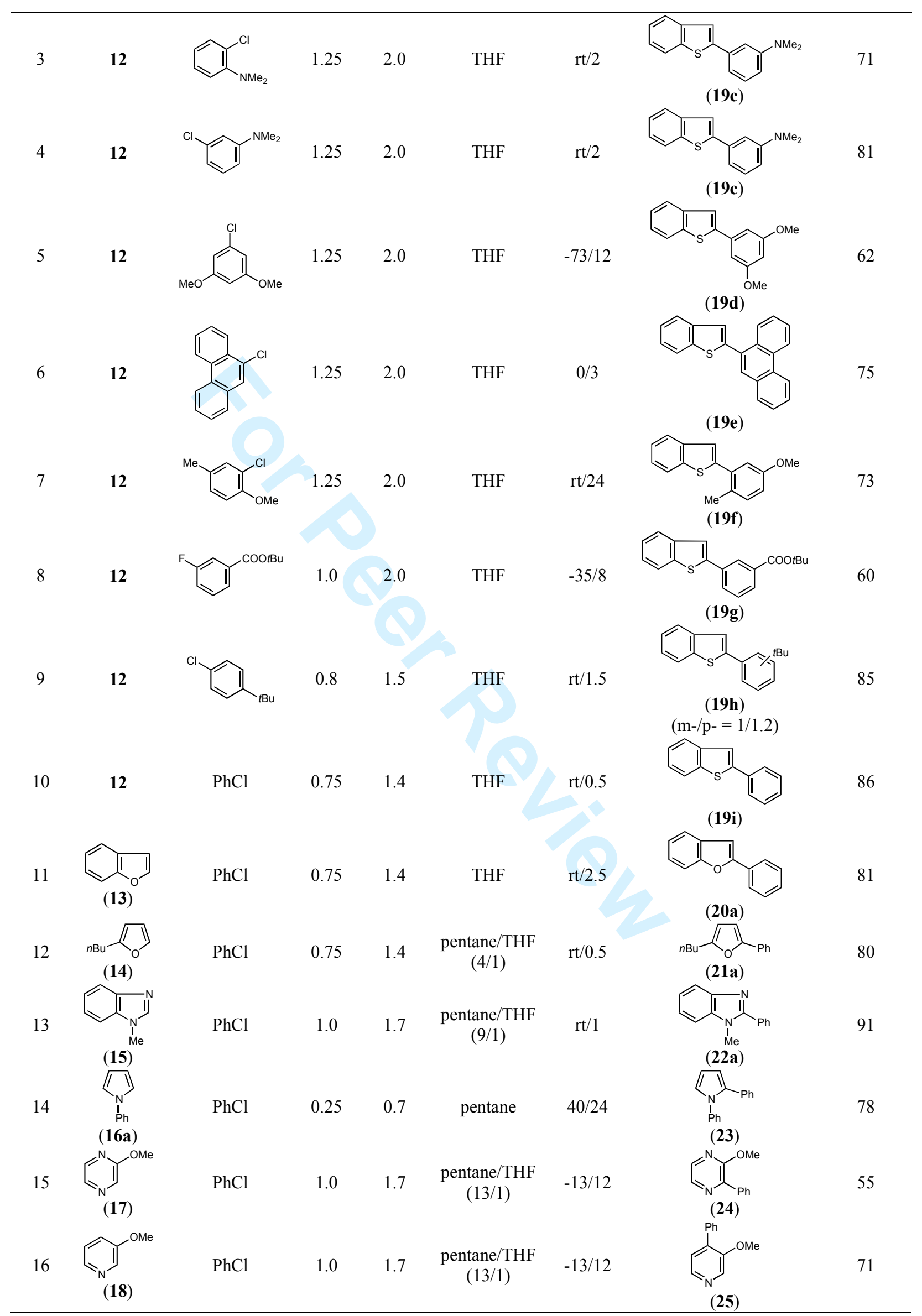




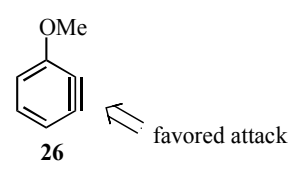

Figure 1. Chemical structure of 3-methoxybenzyne (26)

Truong and Daugulis also carried out a sequential one-pot diarylation of $N$-methylimidazole (27). In particular, they treated a mixture of $\mathbf{2 7}$ and chlorobenzene with LDA in THF at room temperature and found that the subsequent quenching of the reaction mixture with $\mathrm{MeOH}$ and evaporation of the solvents followed by the addition of 2-chloroanisole and LiTMP in THF at room temperature for $2 \mathrm{~h}$ provided the diarylation product $\mathbf{2 8}$ in 50\% yield (Scheme 8). ${ }^{[19]}$

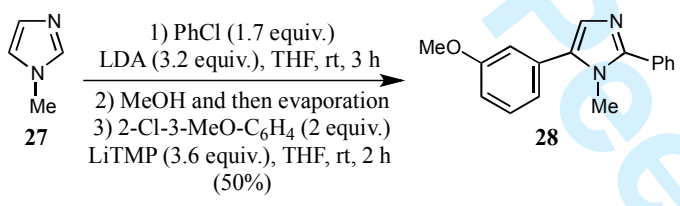

Scheme 8. Synthesis of compound 28 by sequential one-pot diarylation of $\mathrm{N}$-methylimidazole (27).

Again in 2011, Gryko and coworkers conducted a series of interesting studies on the transition metalfree direct arylation of pyrrole derivatives with aryl halides. ${ }^{[23-25]}$ They found that 1 -substituted pyrroles undergo LiO- $t$-Bu-mediated regioselective direct $\mathrm{C}-2$ arylation with aryl iodides in DMF at $145^{\circ} \mathrm{C}$ to give 1-substituted 2-arylpyrroles in satisfactory to good yields (Scheme 9). ${ }^{[23]}$ In all cases complete regioselectivity was observed and higher yields were obtained when aryl iodides bearing an electron-withdrawing substituent were used as arylating reagents.

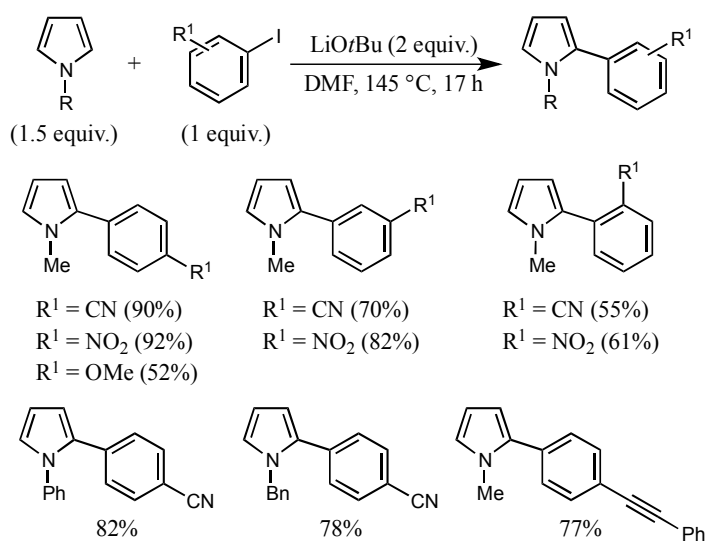

Scheme 9. LiO-t-Bu-mediated direct arylation of 1substituted pyrroles with aryl iodides

In this context, it deserves to be noted that 2-aryl-1substituted pyrroles can also be currently prepared with high regioselectivity by the $\mathrm{Pd}(\mathrm{OAc})_{2} / \mathrm{Cy}_{2} \mathrm{P}-\mathrm{o}-$ biphenyl-catalyzed reaction of $N$-methylpyrrole with electron-rich and electron-poor aryl chlorides in DMA at $125^{\circ} \mathrm{C}$ in the presence of $\mathrm{Na}_{2} \mathrm{CO}_{3},{ }^{[26]}$ by the $\mathrm{Pd}(\mathrm{OAc})_{2} / \mathrm{PCy}_{3} \cdot \mathrm{HBF}_{4} /$ pivalic acid-catalyzed reaction of $\mathrm{N}$-MOM pyrroles with aryl bromides in DMA at $100{ }^{\circ} \mathrm{C}$ in the presence of $\mathrm{K}_{2} \mathrm{CO}_{3},{ }^{[27 a]}$ by the reaction of $\mathrm{N}$-methylpyrroles with 4bromobenzamides using a low loading $(1.0 \mathrm{~mol} \%)$ of $\mathrm{Pd}(\mathrm{OAc})_{2}$ catalyst, ${ }^{[27 \mathrm{~b}]}$ and by treatment of $\mathrm{N}$ tosylpyrrole with electron-poor aryl bromides using $\left[\mathrm{PdCl}\left(\mathrm{C}_{3} \mathrm{H}_{5}\right)\right]_{2}$ as the catalyst and $\mathrm{KOAc}$ as the base. ${ }^{[27 \mathrm{c}]}$

Some limitations of the protocol developed by Gryko and coworkers must however be mentioned. ${ }^{[23]}$ In fact, the reactions illustrated in Scheme 9, although do not involve the use of an expensive catalyst system, require large molar excesses of the heteroarene substrates. Moreover, $\mathrm{NH}$-free pyrrole and its derivatives bearing $\mathrm{N}$ electron-withdrawing substituents such as tosyl or $t$-butoxycarbonyl turned unreactive probably because their lability under the reaction conditions. In addition, an attempt to make direct arylation of benzo $[b]$ thiophene under the reaction conditions used to prepare 1-substituted-2-arylpyrroles failed. Nevertheless, more electron rich heteroarenes like benzo[b]furan, $N$-methylindole and indolizine underwent direct arylation with 4-iodobenzonitrile to give compounds 29,30 and 31 , respectively (Figure 2) in moderate yields. ${ }^{[23]}$ 


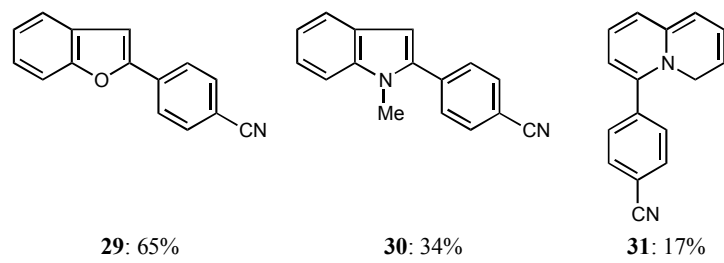

Figure 2. Chemical structures and yields of compounds 29-31

It is also worthy of mention that the LiO-t-Bumediated direct arylation of indolizine turned out to occur selectively at position 5 and that this result was in contrast to what observed for the Pdcatalyzed direct arylation of indolizines with aryl bromides and chlorides, which were found to proceed selectively at position $3^{[28]}$ (Figure 3 ).

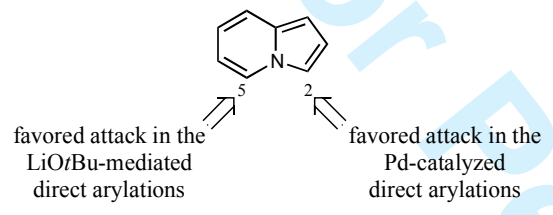

Figure 3. Favored positions of indolizine in transition metal-free LiO- $t$-Bu-mediated direct arylation and in $\mathrm{Pd}$-catalyzed direct arylation.

Gryko and coworkers then demonstrated that the direct C-2 arylation of 1-methyl-, 1-phenyl- and 1benzylpyrrole with aryl iodides could also be performed efficiently at $145{ }^{\circ} \mathrm{C}$ using $\mathrm{LiOH}$ as the base in DMSO, ${ }^{[24]}$ a solvent which was shown to form complexes with $\mathrm{LiOH}^{[29]}$ Under optimized conditions, the LiOH-mediated arylation of 1substituted pyrroles with aryl iodides bearing electron-withdrawing substituents gave 1substituted 2-arylpyrroles in good yields (Scheme $10)$, but the LiOH-mediated reaction of 1methylpyrrole with 4-iodoanisole gave 2-(4methoxyphenyl)-1-methylpyrrole in only $26 \%$ yield. $^{[24]}$
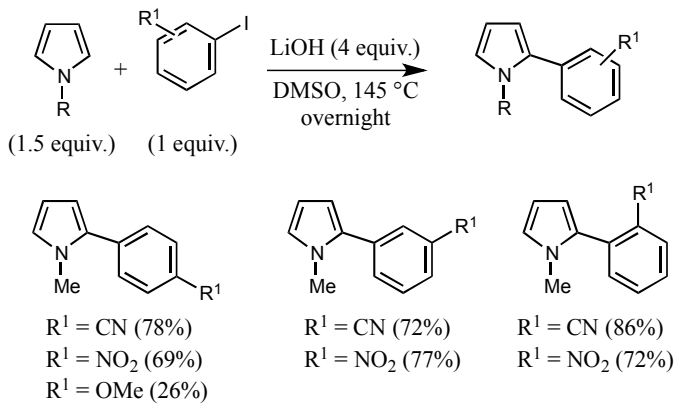

$\mathrm{R}^{1}=\mathrm{NO}_{2}(77 \%)$

$\mathrm{R}^{1}=\mathrm{CN}(86 \%)$ $\mathrm{R}^{1}=\mathrm{NO}_{2}(72 \%)$

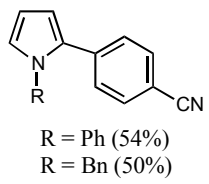

Scheme 10. LiOH-mediated direct arylation of 1substituted pyrroles with aryl iodides

Unfortunately, the yields of many 1-substituted 2arylpyrroles, which were synthesized by $\mathrm{LiOH}-$ mediated direct arylation reactions, turned out to be lower than those of the corresponding compounds obtained through LiO-t-Bu-mediated arylation reactions. Furthermore, it was observed that free $\mathrm{NH}$-pyrrole as well as $\mathrm{N}$-benzoylpyrrole and $\mathrm{N}$ (triisopropylsilyl)pyrrole could not be arylated under the conditions illustrated in Scheme 10. ${ }^{[2]}$

Finally, Gryko and coworkers developed a more environmentally friendly protocol for the synthesis of 1-substituted 2-aryl pyrroles that involved the reaction of 10 equiv of 1 -substituted pyrroles with 1 equiv of aryl iodides, 4 equiv of KOAc and 3 equiv of 1-ethyl-3-methylimidazolium acetate (IL), a commercially available ionic liquid (Scheme 11). ${ }^{[25]}$ Satisfactory yields of the required C-2 arylated heteroarenes were obtained when $\mathrm{N}$ methylpyrrole was reacted with aryl iodides bearing electron-withdrawing substituents, but modest to low yields were obtained in the arylation of pyrroles $N$-substituted with the dimethylamino, [2-(trimethylsilyl)ethoxy]methyl (SEM) or 2pyridyl group. 

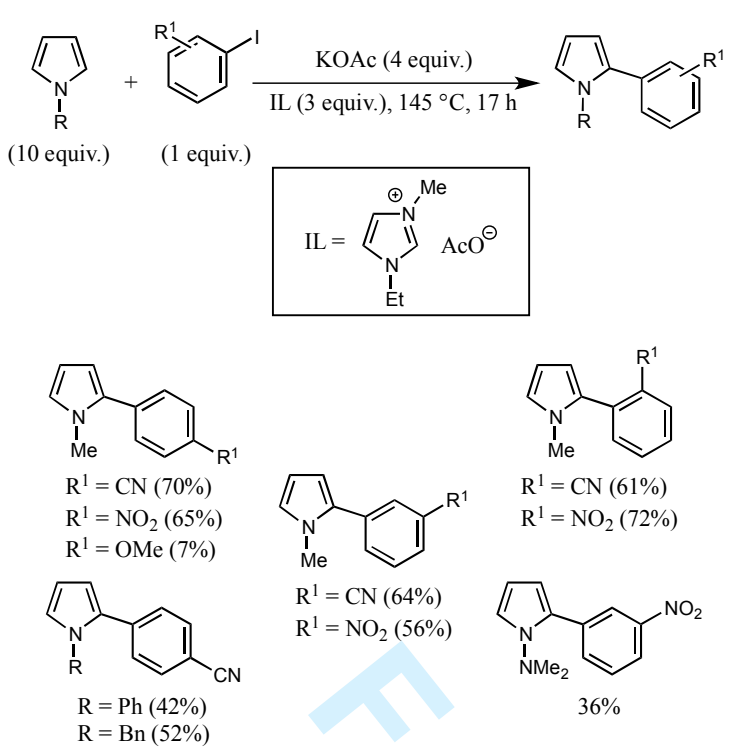

$\mathrm{R}^{1}=\mathrm{CN}(61 \%)$

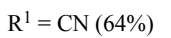

$\mathrm{R}^{1}=\mathrm{NO}_{2}(56 \%)$ $\mathrm{R}^{1}=\mathrm{NO}_{2}(72 \%)$

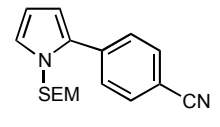

$14 \%$

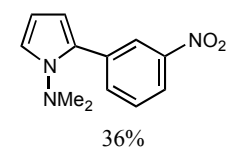

Scheme 11. KOAc-mediated C-2 arylation of 1substituted pyrroles with aryl iodides in 1-ethyl-3methylimidazolium acetate (IL)

It was also made an analysis of 1-ethyl-3methylimidazolium acetate using inductively coupled plasma-atomic emission spectroscopy, and it was found that the concentration of most transition metals in this ionic liquid was less than $5.0 \mathrm{ppm}$. This result led Gryko and coworkers to believe that the arylation reactions in this ionic liquid proceed without the participation of transition metals in the catalytic cycle. Although no direct evidence for the reaction mechanism was obtained, a support to a radical-based mechanism was obtained from the KOAc-mediated reaction of 1-phenylpyrrole with 4-iodobenzonitrile in 1-ethyl3-methylimidazolium acetate in the presence of TEMPO in which the C-2 arylated pyrrole derivative was not produced. ${ }^{[25]}$

It deserves also to be pointed out that no protocol has so far been developed for the base-promoted direct arylation of free NH-pyrrole with aryl halides and that, currently, the synthesis of 2-aryl-1Hpyrroles can be carried out by regioselective $\mathrm{Pd}$ catalyzed reaction of 1-pyrrol-1-ylzinc halide with aryl bromides, which was first developed by Filippini and coworkers ${ }^{[30 a]}$ and later improved by Sadighi and coworkers, ${ }^{[30 \mathrm{~b}]}$ as well as by direct C-2 arylation of free $\mathrm{NH}$-pyrrole with aryl iodides using $10 \% \mathrm{Pd}(\mathrm{OH})_{2} / \mathrm{C}$ as catalyst under phosphane-free conditions $^{[31]}$. In addition, in 2012, Doucet and coworkers described that 2-(4-cyanophenyl)-1Hpyrrole could be prepared in $51 \%$ yield by $\left[\mathrm{PdCl}\left(\mathrm{C}_{3} \mathrm{H}_{5}\right)\right]_{2}$-catalyzed arylation of free $\mathrm{NH}$ pyrrole with 4-bromobenzonitrile in DMA at $130{ }^{\circ} \mathrm{C}$ (Scheme 12). ${ }^{[32]}$

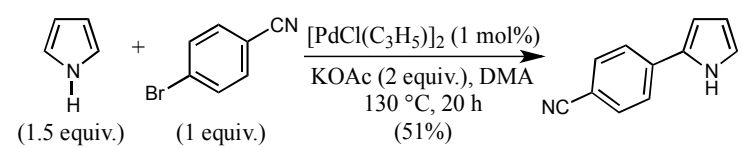

Scheme 12. $\left[\mathrm{PdCl}\left(\mathrm{C}_{3} \mathrm{H}_{5}\right)\right]_{2}$-catalyzed direct $\mathrm{C}-2$ arylation of free NH-pyrrole with 4bromobenzonitrile

In 2014, Daugulis and coworkers, in continuation of their studies made in $2011,{ }^{[19]}$ described a method for the base-promoted arylation of electronrich and electron-deficient heteroarenes with aryl chlorides and aryl triflates. ${ }^{[33]}$ The best results were obtained employing LiTMP or LDA base and, notably, despite the use of these lithium bases, the reactions resulted tolerant of functional groups such as hydroxy and chlorine substituents and the $\mathrm{NH}$ indole group. As shown in Scheme 2, the heteroarene substrates, which were used in the direct arylation reactions, included 1phenylpyrazole (32), 1-methyl-1,2,4-triazole (33), 2,4,6-trichloropyridine $\mathbf{( 3 4 )}$, benzo[b]thiophene (12), 2-methyl-1H-indole (35), 4hydroxybenzo[b]furan (36), (35), 4hydroxybenzo[b]furan (37), 4-methoxypyridine (38), and 2-methoxypyridine (39). 
Table 2. Base-mediated direct arylation of heteroarenes 12, 32-39 with aryl chlorides or triflates.

\begin{tabular}{|c|c|c|c|c|c|c|c|c|c|c|}
\hline \multirow[t]{2}{*}{ Entry } & \multicolumn{2}{|c|}{ HetAr-H } & \multicolumn{2}{|c|}{$\begin{array}{c}\text { (Pseudo)aryl } \\
\text { halide }\end{array}$} & \multicolumn{2}{|c|}{ Base } & \multirow[t]{2}{*}{ Solvent } & \multirow{2}{*}{$\begin{array}{c}\text { Reaction } \\
\text { conditions } \\
{ }^{\circ} \mathrm{C} / \mathrm{h}\end{array}$} & \multicolumn{2}{|c|}{ Product } \\
\hline & Structure & $\mathrm{mmol}$ & Structure & $\mathrm{mmol}$ & Structure & $\mathrm{mmol}$ & & & Structure & Yield (\%) \\
\hline 1 & $\begin{array}{c}\mathrm{Ph} \\
(\mathbf{3 2})\end{array}$ & 0.25 & PhOTf & 0.75 & LiTMP & 1.25 & THF & $-78 / 18$ & (40) & 55 \\
\hline 2 & $\begin{array}{l}\mathrm{Me} \\
(\mathbf{3 3})\end{array}$ & 0.25 & PhOTf & 0.75 & LDA & 1.25 & THF & $-78 / 18$ & (41) & 50 \\
\hline 3 & (34) & 0.25 & PhOTf & 1.0 & LiTMP & 1.50 & $\begin{array}{c}\mathrm{Et}_{2} \mathrm{O} / \mathrm{THF} \\
(40 / 1)\end{array}$ & $-78 / 18$ & (42) & 54 \\
\hline 4 & 12 & 0.50 & & 0.25 & LiTMP & 1.0 & $\begin{array}{c}\mathrm{Et}_{2} \mathrm{O} / \mathrm{THF} \\
(40 / 1)\end{array}$ & $-78 / 48$ & (43a) & 66 \\
\hline 5 & 12 & 0.25 & & 0.50 & LiTMP & 0.85 & THF & $-85 / 12$ & $(43 b)$ & 53 \\
\hline
\end{tabular}


Advanced Synthesis \& Catalysis

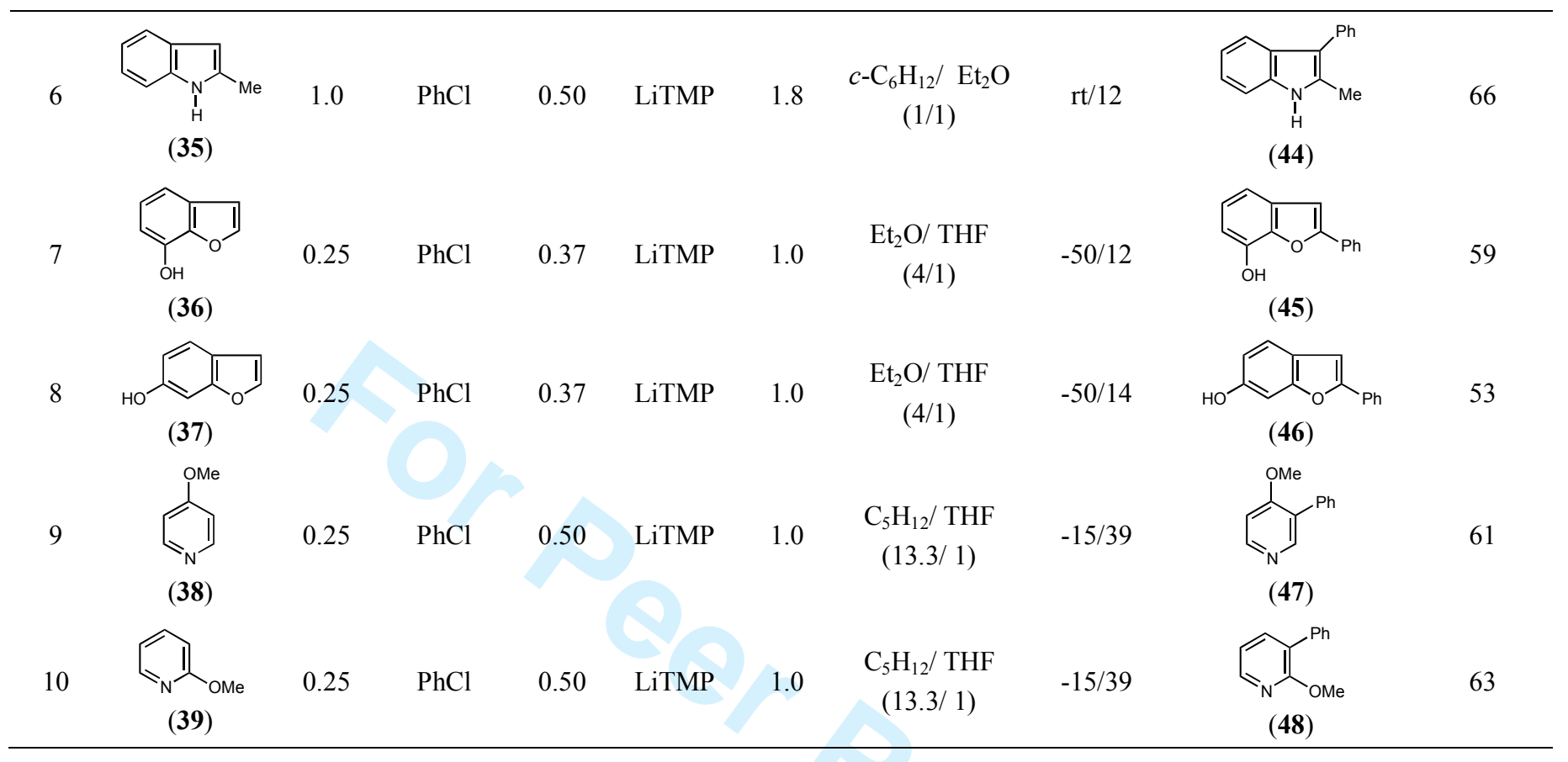


The arylation reactions, which were used for the regioselective synthesis of compounds 40-42, 43a,b and 44-48, were typically run at $-15 \div-85^{\circ} \mathrm{C}$, but the arylation of 2-methyl- $1 H$-indole (35) (entry 6 , Table 2) was carried out at room temperature. Interestingly, the LiTMP-mediated arylation of benzo $[b]$ thiophene (12) with $o$-trimethylsilylphenyl triflate gave selectively the ortho-substituted product $43 \mathrm{a}$ in $66 \%$ yield (entry 4 , Table 2 ) and the LiTMP-mediated reaction of $\mathbf{1 2}$ with 3chlorophenyl triflate turned out chemoselective giving rise to 2-(3-chlorophenyl) benzo $[b]$ thiophene $(\mathbf{4 3 b})$ in $53 \%$ yield (entry 5 , Scheme 2). On the other hand, a diarylation reaction occurred when 2,4,6-trichloropyridine (34) was reacted with a large molar excess of phenyl triflate. The reaction (entry 3, Scheme 2) provided 3,5-diphenyl-2,4,6-trichloropyridine (42) in 54\% yield. Notably, C-3 monoarylation reactions occurred when pyridines $\mathbf{3 8}$ and $\mathbf{3 9}$ were reacted with 2.0 equiv of chlorobenzene in the presence of 4 equiv of LiTMP and the resulting compounds, 47 and 48, respectively, which are not easily accessible via other direct arylation methods, were obtained in good yields (entries 9 and 10, respectively, Table 2). ${ }^{[33]}$ It was also found that the LiTMP-mediated reaction of 2,3-dimethyl- $1 \mathrm{H}$ indole (49) with chlorobenzene in a mixture of cyclohexane and $\mathrm{Et}_{2} \mathrm{O}$ at room temperature gave 2,3-dimethyl-3-phenylindole (50) in $64 \%$ yield (Scheme 13). ${ }^{[33]}$

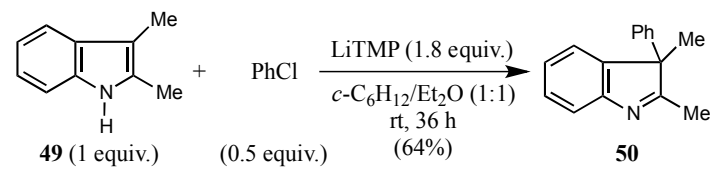

Scheme 13. Synthesis of 2,3-dimethyl-3phenylindole (50).

Daugulis and coworkers then expanded the scope of the methodology illustrated in Scheme 2 for the synthesis of compounds 40-42, 43a,b and 44-48. In particular, they developed a general and efficient method (Scheme 14) to access functionalized arylsubstituted heteroarenes of general formula $\mathbf{D}$ that consisted in the electrophilic trapping of the heteroaryllithium intermediates $\mathbf{C}$, which were generated by addition of heteroaryllithiums $\mathbf{A}$ to arynes B. The latter highly reactive intermediates were in turn generated by the reaction of LiTMP with aryl halides or triflates (Scheme 14).

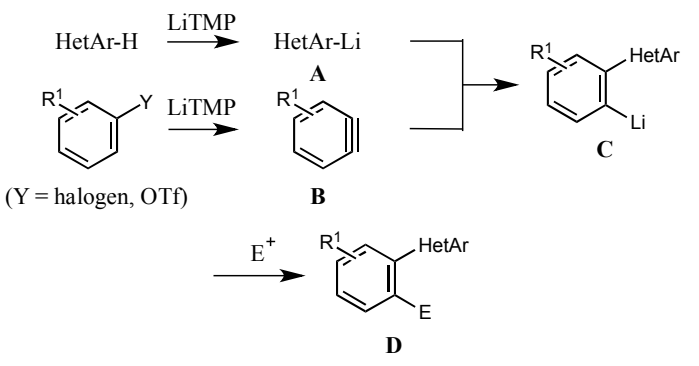

Scheme 14. Electrophilic trapping of the organolithium intermediates $\mathbf{C}$, generated in the reaction of arynes $\mathbf{B}$ with heteroaryllithiums $\mathbf{A}$

The general procedure that was developed consisted in adding a solution of a mixture of a heteroarene and an aryl halide or triflate in THF or a mixture of THF and $\mathrm{Et}_{2} \mathrm{O}$ to LiTMP. Reaction of the resulting heteroaryllithium $\mathbf{A}$ with an aryne $\mathbf{B}$, which was generated at the same time from an aryl halide or triflate followed by electrophilic trapping of the resulting organolithium derivative $\mathbf{C}$ gave the required compound $\mathbf{D}$. Table 3 summarizes the experimental conditions used to prepare a wide variety of compounds of general formula $\mathbf{D}$ starting from $0.25 \mathrm{mmol}$ of heteroarenes $\mathbf{1 2}, \mathbf{1 3}$ and $\mathbf{1 8}$. 
Table 3. LiTMP-mediated arylation of heteroarenes $\mathbf{1 2}, \mathbf{1 3}$ and $\mathbf{1 8}$ with aryl halides or triflates, followed by electrophilic trapping of the resulting heteroaryllithiums.

\begin{tabular}{|c|c|c|c|c|c|c|c|c|c|c|c|}
\hline \multirow[b]{2}{*}{ Entry } & \multirow{2}{*}{ HetAr-H } & \multicolumn{2}{|c|}{ (Pseudo)aryl halide } & \multirow{2}{*}{ Solvent } & \multirow{2}{*}{$\begin{array}{c}\text { Reaction } \\
\text { conditions } \\
{ }^{\circ} \mathrm{C} / \mathrm{h}\end{array}$} & \multicolumn{2}{|c|}{ Electrophile } & \multirow{2}{*}{ Solvent } & \multirow{2}{*}{$\begin{array}{l}\text { Reaction conditions } \\
\text { of step } 2\end{array}$} & \multicolumn{2}{|c|}{ Product } \\
\hline & & Structure & mmol & & & Structure & mmol & & & Structure & Yield(\%) \\
\hline 1 & $\overbrace{(12)}$ & PhOTf & 0.5 & $\begin{array}{c}\mathrm{Et}_{2} \mathrm{O} / \mathrm{THF} \\
(30 / 1)\end{array}$ & $-78 / 12$ & $\mathrm{I}_{2}$ & 1.25 & $\begin{array}{c}\mathrm{Et}_{2} \mathrm{O} / \mathrm{THF} \\
(4 / 1)\end{array}$ & $-78 / 1$ & $(43 c)$ & 66 \\
\hline 2 & 12 & PhOTf & 0.5 & $\begin{array}{c}\mathrm{Et}_{2} \mathrm{O} / \mathrm{THF} \\
(30 / 1)\end{array}$ & $-78 / 12$ & $\mathrm{CBr}_{4}$ & 1.25 & $\begin{array}{c}\mathrm{Et}_{2} \mathrm{O} / \mathrm{THF} \\
(4 / 1)\end{array}$ & $-78 / 2$ & (43d) & 79 \\
\hline 3 & 12 & PhOTf & 0.5 & $\begin{array}{c}\mathrm{Et}_{2} \mathrm{O} / \mathrm{THF} \\
(30 / 1)\end{array}$ & $-78 / 12$ & $\mathrm{CCl}_{4}$ & 1.25 & $\begin{array}{c}\mathrm{Et}_{2} \mathrm{O} / \mathrm{THF} \\
(4 / 1)\end{array}$ & $-78 / 2$ & $(43 \mathrm{e})$ & 69 \\
\hline 4 & 12 & PhOTf & 0.5 & $\begin{array}{c}\mathrm{Et}_{2} \mathrm{O} / \mathrm{THF} \\
(30 / 1)\end{array}$ & $-78 / 12$ & $\left(\mathrm{PhSO}_{2}\right)_{2} \mathrm{NF}$ & 1.25 & $\begin{array}{c}\mathrm{Et}_{2} \mathrm{O} / \mathrm{THF} \\
(4 / 1)\end{array}$ & $-78 / 2$ & (43f) & 50 \\
\hline
\end{tabular}




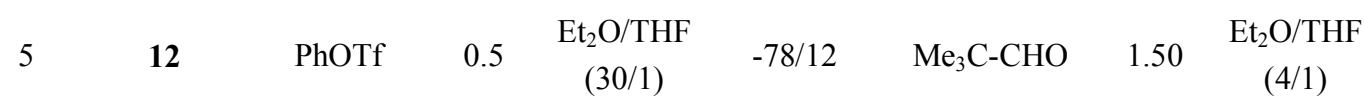

$-78 / 2$

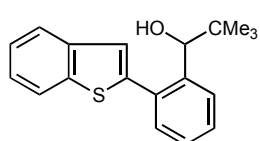

75

(43g)

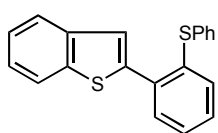

(43h)

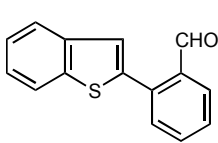

(43i)

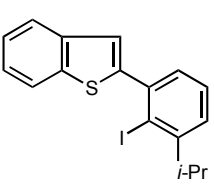

(43f)

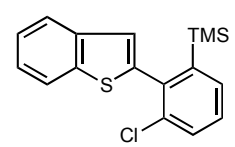

(43k)

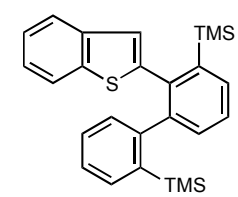

(43I)

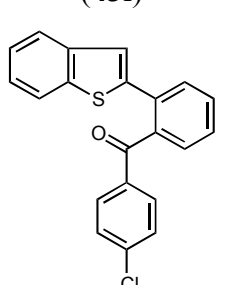

(43m)

12 PhTOf

$\mathrm{Et}_{2} \mathrm{O} / \mathrm{THF}$

$-78 / 12$

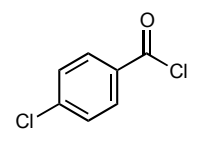

$\mathrm{Et}_{2} \mathrm{O}$

$-78 / 2$ 
Advanced Synthesis \& Catalysis

\begin{tabular}{|c|c|c|c|c|c|c|c|c|c|c|}
\hline 12 & 12 & PhOTf & 0.5 & $\begin{array}{c}\mathrm{Et}_{2} \mathrm{O} / \mathrm{THF} \\
(30 / 1)\end{array}$ & $-78 / 12$ & $\mathrm{MeOCOCl}$ & 1.50 & $\mathrm{Et}_{2} \mathrm{O}$ & $-78 / 2$ & 67 \\
\hline 13 & 12 & PhOTf & 0.5 & $\begin{array}{c}\mathrm{Et}_{2} \mathrm{O} / \mathrm{THF} \\
(30 / 1)\end{array}$ & $-78 / 12$ & $\mathrm{ClPPh}_{2}$ & 1.50 & $\mathrm{Et}_{2} \mathrm{O}$ & $-78 / 2$ & 48 \\
\hline 14 & 12 & & 0.5 & $\begin{array}{c}\mathrm{Et}_{2} \mathrm{O} / \mathrm{THF} \\
(10 / 1)\end{array}$ & $-35 / 24$ & $\mathrm{Me}_{3} \mathrm{C}-\mathrm{CHO}$ & 1.50 & $\mathrm{Et}_{2} \mathrm{O}$ & $-35 / 0.03$ & 77 \\
\hline 15 & (13) & PhOTf & 0.5 & $\begin{array}{c}\mathrm{Et}_{2} \mathrm{O} / \mathrm{THF} \\
(30 / 1)\end{array}$ & $-78 / 24$ & $\mathrm{Me}_{2} \mathrm{~N}-\mathrm{CHO}$ & 1.50 & $\mathrm{Et}_{2} \mathrm{O}$ & $-78 / 0.03$ & 62 \\
\hline 16 & (18) & $\mathrm{PhCl}$ & 0.5 & $\begin{array}{c}\mathrm{Et}_{2} \mathrm{O} / \mathrm{THF} \\
(10 / 1)\end{array}$ & $-45 / 36$ & $\mathrm{I}_{2}$ & 1.50 & $\begin{array}{c}\mathrm{Et}_{2} \mathrm{O} / \mathrm{THF} \\
(4 / 1)\end{array}$ & -78 & 53 \\
\hline
\end{tabular}


Commenting on the results achieved in the direct arylation of benzo $[b]$ thiophene (12) with aryl triflates and 2-bromoisopropylbenzene followed by trapping of the resulting heteroaryllithiums with electrophiles it can be pointed out that compounds 43c-f, $43 \mathbf{j}$ and $43 \mathbf{k}$, which were obtained in good yields in entries $1-4,7$ and 8 of Table 3 , were suitable for further functionalization by transition metal-catalyzed cross-coupling reactions. It also deserves to be highlighted that the LiTMP mediated arylation of $\mathbf{1 2}$ with a slight molar excess of $O$-trimethylsilylphenyl triflate followed by trapping with $\mathrm{CCl}_{4}$ provided compound $43 \mathrm{k}$ in $59 \%$ yield (entry 9, Table 3). On the other hand, the LiTMP mediated arylation of $\mathbf{1 2}$ with 2.4 equiv of $O$-trimethylsilylphenyl triflate allowed trapping of the first aryne addition product 53 (Figure 4) with another molecule of the same aryne affording compound $\mathbf{4 3 1}$ in $71 \%$ yield (entry 10 , Table 3 ).

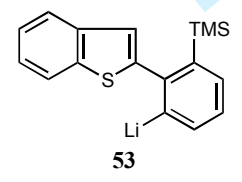

Figure 4. Chemical structure of compound 53.

Notably, the protocol used to prepare compounds 43c-p from benzo[b]thiophene (12) (entries 1-14, Table 3) resulted applicable to the C-2 arylation of benzo[ $b]$ furan (13) allowing the regioselective synthesis of compound $\mathbf{5 1}$ in $62 \%$ yield (entry 15 , Table 3). This result is remarkable since the Pdcatalyzed direct arylation of $\mathbf{1 3}$ at $\mathrm{C}-2$ has been frequently found to be non-selective providing mixtures of 2- and 3-monoarylated and 2,3bisarylated products. ${ }^{[34]}$ Nevertheless, Doucet and coworkers recently demonstrated that a wide variety of 2-arylbenzo[b]furans can be regioselectively synthesized in good yields by $\mathrm{PdCl}_{2}(\mathrm{MeCN})_{2}$-catalyzed direct $\mathrm{C}-2$ arylation of benzo $[b]$ furan with arylsulfonyl chlorides in dioxane at $140{ }^{\circ} \mathrm{C}$ for $40 \mathrm{~h}$ in the presence of $\mathrm{Li}_{2} \mathrm{CO}_{3}$ as the base. ${ }^{[35]}$

Daugulis and coworkers also found that the sixmembered heteroarene $\mathbf{1 8}$ was capable to be involved in the LiTMP-mediated direct arylation with subsequent electrophilic trapping of the resulting heteroaryllithium intermediate. In fact, the LiTMP-mediated reaction of 3-methoxypyridine (18) with chlorobenzene followed by trapping with iodine gave 4-(2-iodophenyl)-3-methoxypyridine (52) in $53 \%$ yield (entry 16 , Table 3 ). ${ }^{[33]}$
The reactivity of (2-(benzo[b]thiophen-2yl)phenyl)lithium (54) (Figure 5), which was generated from 12, phenyl triflate and LiTMP, was then further investigated.

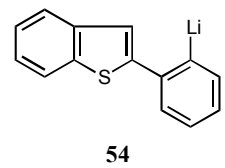

Figure 5. Chemical structure of compound 54.

It was thus established that transmetalation of $\mathbf{5 4}$ with $\mathrm{CuCN} \cdot 2 \mathrm{LiCl}$ followed by the addition of an electrophile resulted in a functionalized product of general formula 43. Scheme 15 summarizes the good results obtained in the synthesis of compounds $\mathbf{4 3 q}-\mathbf{t}$ according to this protocol. ${ }^{[33]}$

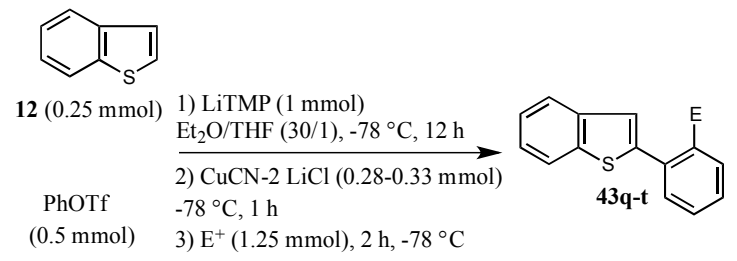

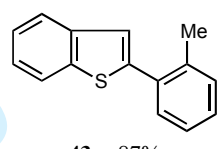

43q: $87 \%$

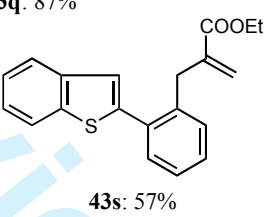

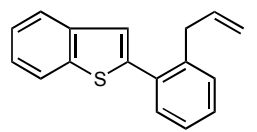

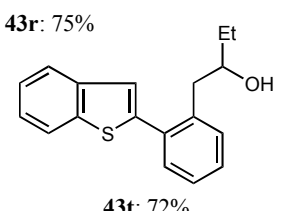

Scheme 15. Synthesis of 2-arylbenzo[b]thiophenes 43q-t

Finally, Daugulis and coworkers investigated the arylation of benzo $[b]$ thiophene (12) with hetarynes that were generated from the corresponding heteroaryl bromides or triflates, and found that treatment of $\mathbf{1 2}$ with 4.0 equiv of 2-bromopyridine and 6.0 equiv of LiTMP in $\mathrm{Et}_{2} \mathrm{O}$ at $5{ }^{\circ} \mathrm{C}$ gave 2benzothiophen-2-ylpyridine (56) in $42 \%$ yield (eq. a, Scheme 16). Similar reaction conditions were then used to prepare compound $\mathbf{5 6}$ in $50 \%$ yield from 12, 4-bromopyridine and LiTMP (eq. b, Scheme 16). It was also found that the LiTMPmediated reaction of $\mathbf{1 2}$ with 5-butyl-2-thienyl triflate gave selectively, although in a modest yield, compound $\mathbf{5 7}$ in which the benzothiophen-2-yl 
group was at the $\beta$-position of thiophene (eq. c, Scheme 16). ${ }^{[33.36]}$

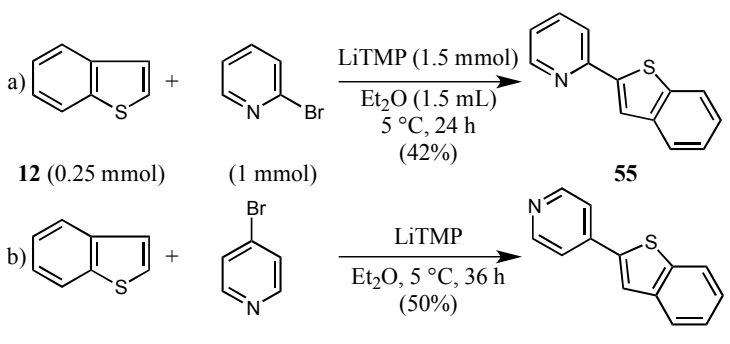

12

56

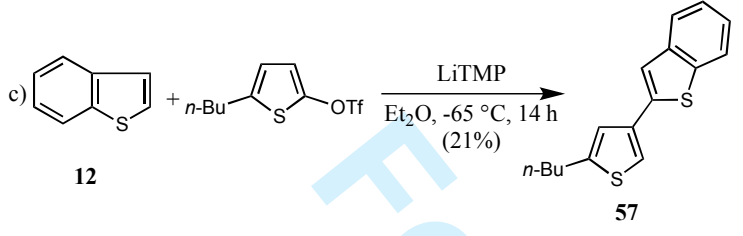

Scheme 16. LiTMP-mediated C-2 heteroarylation reactions of benzo $[b]$ thiophene (12).

In the last decade, efficient transition metalcatalyzed direct arylation reactions have also been frequently carried out using $N$-heterocyclic carbenes (NHCs) as ancillary ligands. ${ }^{[37]}$ However, in 2012, Chen, Ong and coworkers demonstrated that amino-linked $N$-heterocyclic carbenes are able to mediate the direct arylation of pyridine with aryl iodides in the absence of transition metal based compounds. ${ }^{[38]}$ During the optimization process for the direct arylation of pyridine (2) with aryl iodides it was found that the amino-linked NHC, which was obtained by the reaction of imidazolium salt 1$\boldsymbol{t}$-Bu-Im (Figure 6) with $\mathrm{NaO}-t$-Bu, was more effective the NHC 1-t-Bu (Figure 6).
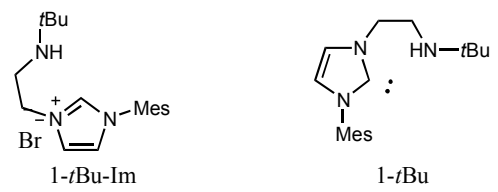

Figure 6. Chemical structure of 1-t-Bu-Im and the amino-NHC 1-t-Bu.

The arylation reactions, which were carried out by treatment of $4 \mathrm{~mL}$ of pyridine (2) with $0.5 \mathrm{mmol}$ of aryl iodides, $1.5 \mathrm{mmol}$ of $\mathrm{NaO}-t-\mathrm{Bu}$ and $20 \mathrm{~mol} \%$ 1-t-Bu-Im at $110{ }^{\circ} \mathrm{C}$ for $4-48 \mathrm{~h}$, gave satisfactory to good yields of regioisomeric mixtures of 2-, 3and 4-arylpyridines using both electron-rich and electron-poor aryl iodides. ${ }^{[38]}$ As shown in Scheme 17, the 2-aryl-substituted pyridines were generally the prevailing regioisomers and the 4-arylated derivatives were always the minor components.

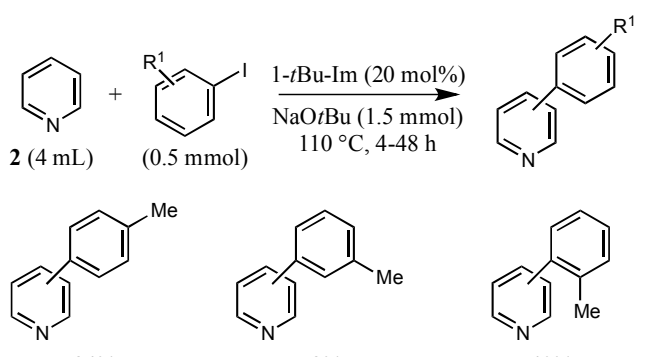

$84 \%$
$(2-/ 3-/ 4-=2.5 / 2.1 / 1)$

$78 \%$
$(2-/ 3-/ 4-=2.8 / 2.3 / 1)$

$40 \%$
$(2-/ 3-/ 4-=2.5 / 1.4 / 1)$
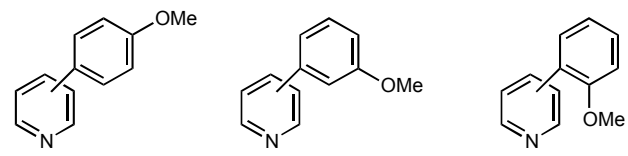

$87 \%$

$70 \%$

$(2-/ 3-/ 4-=2.4 / 2.7 / 1)$

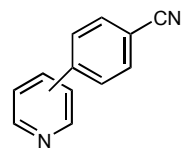

$53 \%$
$(2-/ 3-/ 4-=$ n.d. $)$

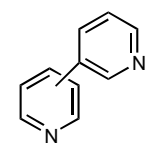

$50 \%$

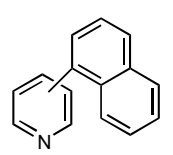

$67 \%$

$(2-/ 3-/ 4-=3.1 / 2.2 / 1)$

$(2-/ 3-/ 4-=3.2 / 1.9 / 1)$

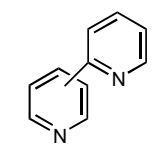

$46 \%$

$(2-/ 3-/ 4-=2.3 / 1.5 / 1)$

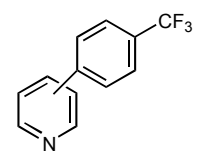

$33 \%$

$(2-/ 3-/ 4-=3 / 3 / 1)$

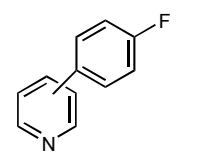

$77 \%$

$(2-/ 3-/ 4-=3.2 / 3.1 / 1)$

Scheme 17. 1-t-Bu-Im-catalyzed direct arylation of pyridine (2) with aryl iodides in the presence of $\mathrm{NaO}-t-\mathrm{Bu}$.

In order to get information about the mechanism of these arylation reactions, some experiments were performed by Chen, Ong and coworkers. A competition experiment in which pyridine (2) and pyridine- $_{5}$ (58) were used in a 1-t-Bu-Imcatalyzed reaction with 4-iodotoluene (Scheme 18) revealed small kinetic isotope effects, indicating that the step of the $\mathrm{C}-\mathrm{H}$ bond breaking was not the rate limiting step. It was also found that a $\mathbf{1 - t}-\mathbf{B u}-$ Im-catalyzed reaction of pyridine with 4iodotoluene in the presence of $\mathrm{NaO}-t-\mathrm{Bu}$ and 1.0 equiv of the radical scavenger TEMPO did not produce the required mixture of regioisomers of $p$ tolylpyridine. 


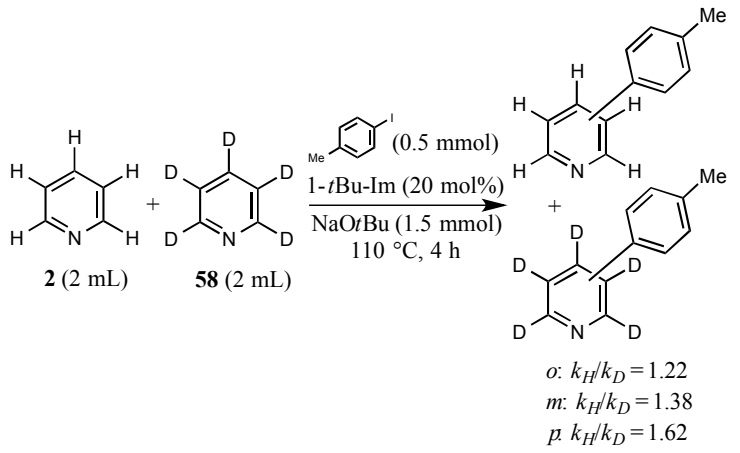

Scheme 18. Kinetic isotope effect experiment using pyridine and pyridine- $\mathrm{d}_{5}$.

Finally, using electron paramagnetic resonance (EPR) the first spectroscopic evidence was obtained that corroborated that the 1-t-Bu-Imcatalyzed reactions involve a single electron transfer mechanism. On the basis of these experiments and previous literature data ${ }^{[39,40]}$ Chen, Ong and coworkers proposed the reaction mechanism depicted in Scheme 19.

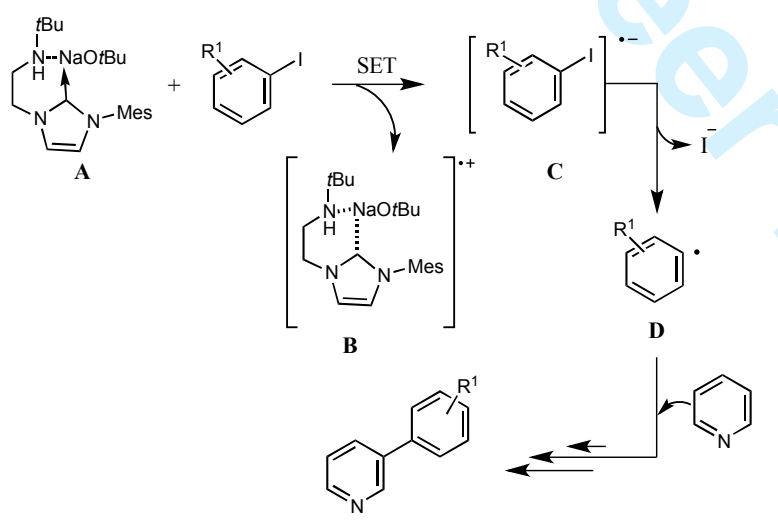

Scheme 19. Plausible mechanism for the 1-t-BuIm-catalyzed direct arylation of pyridine with aryl iodides

It involves a single electron transfer from the adduct $\mathbf{A}$ to the aryl iodides which gives a new NHC radical cation $\mathbf{B}$ and aryl radical anions $\mathbf{C}$. The latter would provide aryl radicals $\mathbf{D}$, which then would react with pyridine to give the required arylated pyridines. ${ }^{[38]}$ Interestingly, a similar reaction mechanism was proposed for the 1-t-BuIm-catalyzed direct arylation of benzene with aryl iodides. ${ }^{[38]}$

More recently, $\mathrm{Zhu}, \mathrm{Xu}$ and coworkers reported that $p$-toluenesulfonylhydrazide (PTSH) promotes the direct arylation of pyridine (2) with 4- iodoanisole in the presence of KO-t-Bu at $110{ }^{\circ} \mathrm{C}$ to give in $85 \%$ yield a mixture of $o-, m$ - and $p$-(4methoxy)phenylpyridine in a $3.2: 1.8: 1.0$ ratio, respectively (Scheme 20). ${ }^{[17]}$ Also in this case, pyridine was employed as the substrate and the solvent.

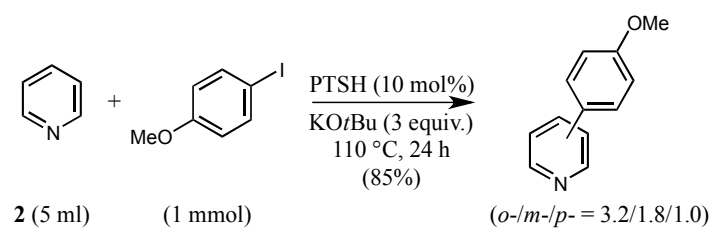

Scheme 20. PTSH-promoted direct arylation of pyridine (2) with 4-iodoanisole.

A further protocol for the metal-free direct arylation of pyridine and other six-membered nitrogen heteroarenes with aryl iodides was recently described by Sanjit Kumar and coworkers. ${ }^{[41]}$ They reported that the radical initiator (E)-2,2'-azobis (2,4dimethylamino)valeronitrile (AMVN) (Figure 7) is able to efficiently promote the direct arylation of pyridine (2), pyrimidine (3), 4-methoxypyridine (38), 3-methylpyridine (59), and pyridazine $(\mathbf{6 0})$ with both electron-neutral and electron-rich aryl iodides in the presence of $\mathrm{KO}-t-\mathrm{Bu}$ at $110^{\circ} \mathrm{C}$.

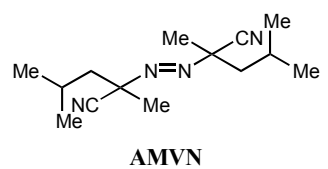

Figure 7. Chemical structure of AMVN

The cross-coupling reactions, which were carried out by treating $3 \mathrm{~mL}$ of heteroarene with $1.0 \mathrm{mmol}$ of aryl iodides, $19-21 \mathrm{~mol} \%$ AMVN and 4.0 equiv of $\mathrm{KO}-t-\mathrm{Bu}$ at $110{ }^{\circ} \mathrm{C}$ for $3-8 \mathrm{~h}$, provided arylsubstituted heteroarenes in good to excellent yields (Scheme 21). Unfortunately, also in this case, all couplings of pyridine (2) and 3-methylpyridine (59) produced mixtures of regioisomers, but the direct arylation reactions of 4-methoxypyridine (38) with iodobenzene and 4-iodoanisole gave selectively $\mathrm{C}$ 2 -arylated derivatives in 55 and $73 \%$ yield, respectively (Scheme 21). 


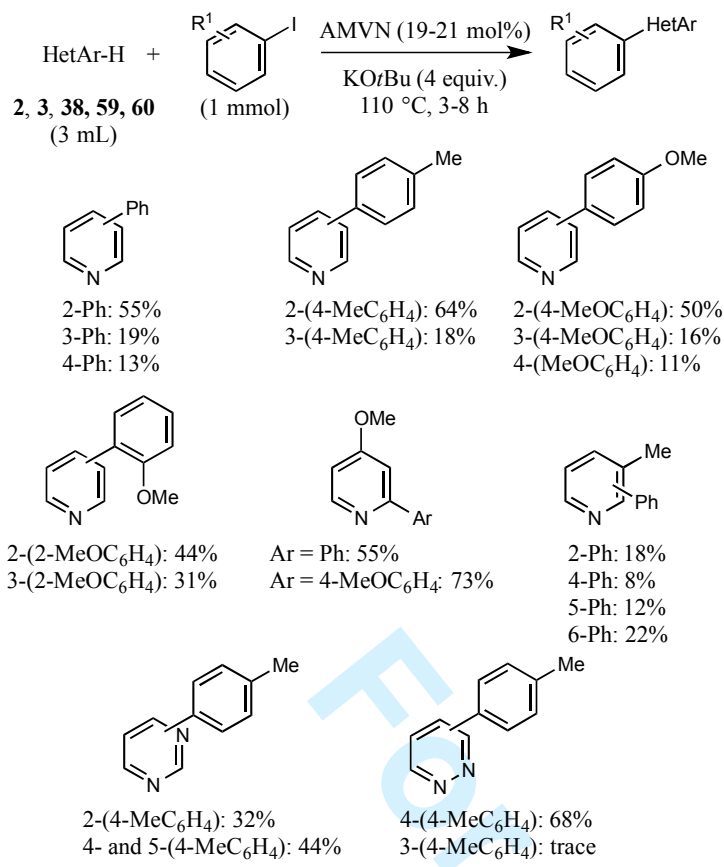

Scheme 21. AMVN-initiated direct arylation of six-membered heteroarenes with aryl iodides in the presence of KO-t-Bu.

Furthermore, the AMVN-initiated reaction of pyridazine (60) with 4-iodotoluene gave 4-( $p$ tolyl)pyridazine in $68 \%$ yield together with a trace amount of the 3 -arylated derivative ${ }^{[41]}$ Notably, the direct arylation of the six-membered heteroarenes $\mathbf{2}$, 3, 38, 59 and 60 allowed the efficient crosscoupling of unactivated arenes with aryl iodides and for the latter reactions a spectroscopic evidence suggesting the involvement of radical intermediates was obtained. ${ }^{[41]}$

Finally, in 2013, in the context of a study on the use of phenylhydrazine as initiator for the direct arylation via base-promoted aromatic substitution, Curran, Studer and coworkers found that the reaction of 112 equiv of pyrazine (1) with 1.0 equiv of 4-iodoanisole, 3.0 equiv of $\mathrm{KO}-t-\mathrm{Bu}$ and 0.2 equiv of phenylhydrazine at $100{ }^{\circ} \mathrm{C}$ for $24 \mathrm{~h}$ gave 2-(4-methoxyphenyl)pyrazine in $82 \%$ yield (Scheme 22) ${ }^{[42]}$ In this reaction, phenylhydrazine, a highly toxic compound, ${ }^{[43]}$ was added in two batches with $3 \mathrm{~h}$ interval.

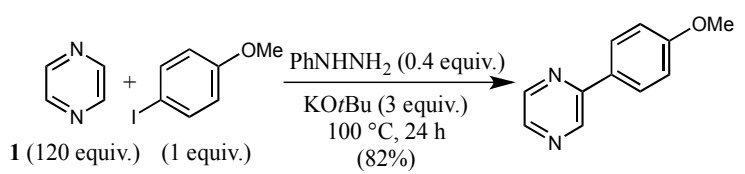

Scheme 22. Phenylhydrazine-initiated deirect arylation of pyrazine (1) with 4-iodoanisole.

The reaction was proposed to occur via a mechanism (Scheme 23) in which the intermediate radical $\mathbf{C}$ would be formed by electron transfer from deprotonated phenylhydrazine to 4iodoanisole resulting in generation of the intermediate radical anion $\mathbf{A}$ and hydrazinyl radical B. Radical anion A would then undergo fragmentation to deliver aryl radical $\mathbf{C}$ and $\mathrm{KI} .{ }^{[42]}$

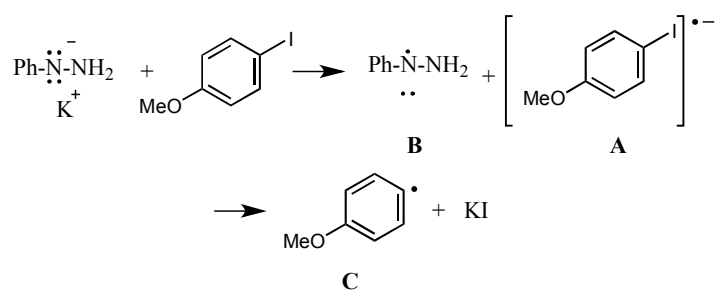

Scheme 23. Proposed mechanism for the formation of the intermediate radical $\mathbf{C}$.

\section{Direct (Hetero)arylation of Heteroarenes with (Hetero)aryl Iodonium Salts}

(Hetero)aryliodonium salts are a kind of non-toxic and stable highly electrophilic compounds that represent a viable alternative to traditional arylating reagents and have found numerous applications in organic synthesis. ${ }^{[44]}$ In recent years, (hetero)aryl iodonium salts have also used as arylating reagents in transition metal-free direct (hetero)arylation reactions of heteroarenes. In 2009, Kita and coworkers reported that $\alpha$-thienyliodonium salts $\mathbf{6 2}$, which were prepared in situ from 3-substituted or 3,4-disubstituted thiophenes and commercially available [hydroxyl(tosyloxy)iodo]benzene (HTIB) (61) in 1,1,1,3,3,3-hexafluoro-2-propanol (HFIP), were able to perform the regioselective C-2 arylation of five-membered heteroarenes at room temperature in the presence of bromotrimethylsilane (TMSBr) affording 2-(2thienyl)heteroarenes 63 in good yields (Scheme 24). ${ }^{[45]}$ Notably, these regioselective reactions, which occurred efficiently under mild experimental conditions in the absence of any transition metal, did not require the use of a large molar excess of heteroarenes and were found to 
tolerate functional groups such as COOMe and the free $\mathrm{NH}$ group of pyrrole.
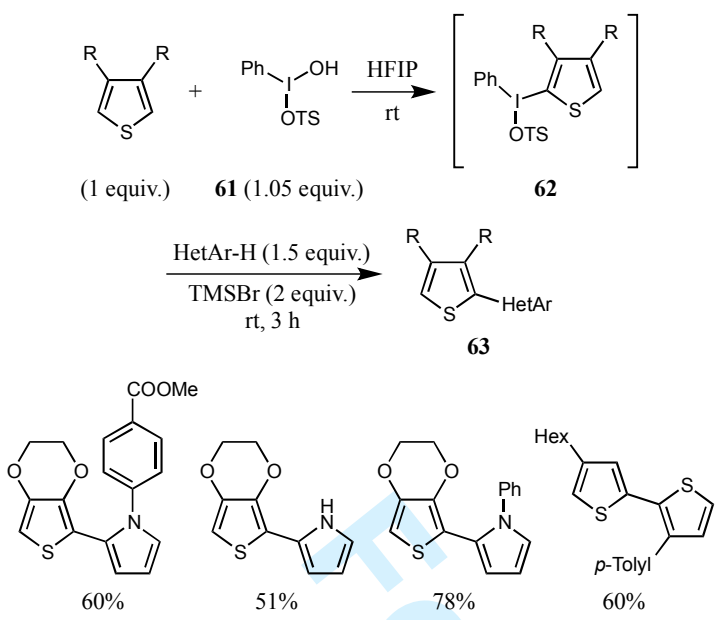

Scheme 24. Synthesis of 2-(2-thienyl)heteroarenes 63.

Kita and coworkers also found that the trivalent iodine(III) reagent, which was generated from $N$ phenylpyrrole (16a) and HITB (61), was able to react with free NH-pyrrole (16b) in HFIP in the presence of TMSBr to provide bipyrrole 64 in $42 \%$ yield (Scheme 25). ${ }^{[45 a]}$

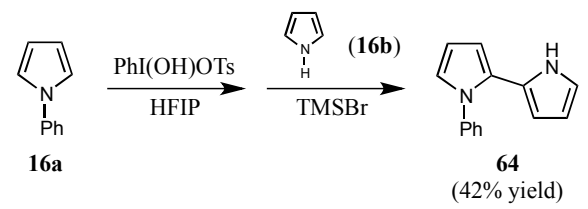

Scheme 25. Synthesis of bipyrrole 64 .

A mechanism was then proposed for the reactions leading to 2-(2-thienyl)heteroarenes 63 (Scheme 26).

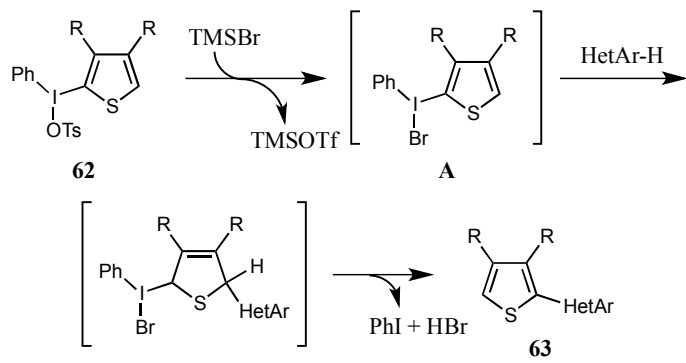

Scheme 26. Possible mechanism for the synthesis of compounds 63 .
It involved: i) the TMSBr-promoted activation in HFIP of the iodonium salts 62, which are usually inert towards heteroarenes; ii) a formal hydroarylation reaction involving the resulting salts $\mathbf{A}$ and the heteroarenes; and iii) elimination of iodobenzene and $\mathrm{HBr}$ to give the required compounds $63 \cdot{ }^{[45 a]}$ Interestingly, a protocol similar to that developed to prepare compounds 63 was used for the efficient and regioselective synthesis of 2-thienyl-substituted arenes starting from iodonium salts $\mathbf{6 2}$ and methoxy-substituted $\operatorname{arenes}^{[45 a]}$

In 2010. in continuation of their studies, Kita and coworkers developed a new synthetic route to head-to-tail linked thiophenes that was based on a selective coupling through the use of an iodonium(III) salt. ${ }^{[456]}$ They found that the reaction of 2 equiv of 3-alkoxythiophenes with 1 equiv of HITB (61) on HFIP at room temperature, followed by the addition of a solution of 2.0 equiv of TMSBr in HFIP produced regioselective access to 3,4'dialkoxy-2,2'-bithiophenes in good yields (Scheme 27).
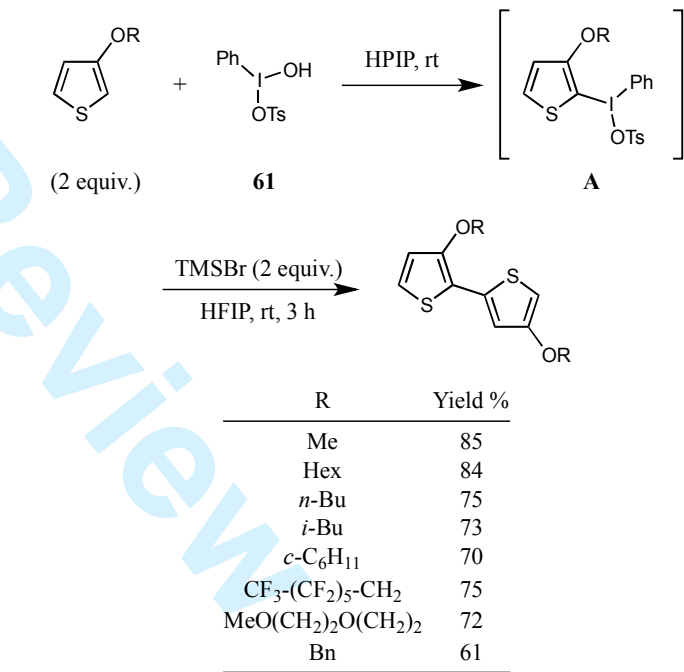

Scheme 27. Synthesis of 3,4'-dialkoxy-2,2'bithiophenes via the intermediate iodonium(III) tosylates A.

In fact, the reaction between 3-alkoxythiophenes and $\mathbf{6 1}$ provided the iodonium(III) tosylates $\mathbf{A}$ which were found to react regioselectively at the 5position of 3-alkoxythiophenes to give 3,4'dialkoxy-2,2'-bithiophenes. Notably, similar experimental conditions turned out to be suitable for the high yielding oxidative coupling of 3- 
arylthiophenes, including sterically hindered substrates, to $3,4^{\prime}$ '-diaryl-2,2'-bithiophenes. ${ }^{[45 b]}$

One year after the publication of the above mentioned results, Ackermann and coworkers investigated the transition metal-free direct arylation of indoles with diaryliodonium salts, ${ }^{[46]}$ a class of solid, crystalline arylating reagents. In this study they discovered that the reaction of $0.5 \mathrm{mmol}$ of indoles, including $N$-alkyl substituted and free $\mathrm{NH}$ derivatives, with $1.0 \mathrm{mmol}$ of diaryliodonium tosylates in $2 \mathrm{~mL}$ of DMF at $100{ }^{\circ} \mathrm{C}$ for $22 \mathrm{~h}$ provided regioselectively 3 -arylated indoles in moderate to good yields (Scheme 28). ${ }^{[46]}$

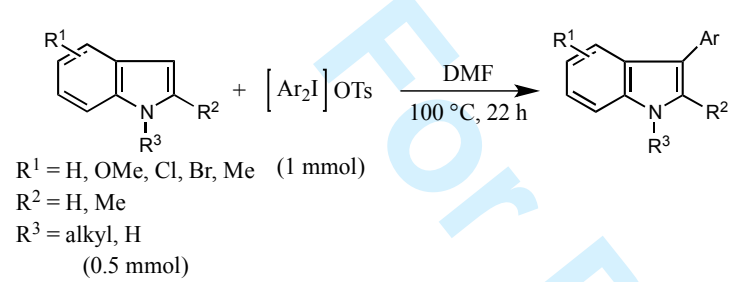

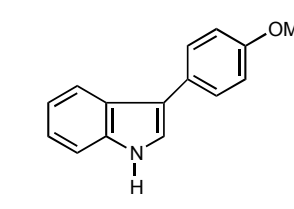

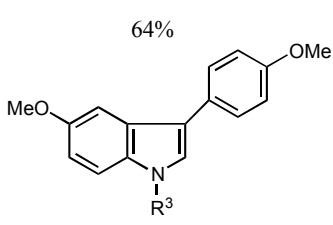

$\mathrm{R}^{3}=\mathrm{Me}: 64 \%$

$\mathrm{R}^{3}=n-\mathrm{Bu}: 65 \%$ $\mathrm{R}^{3}=n$-Oct: $70 \%$ $\mathrm{R}^{3}=n$-Dec: $72 \%$ $\mathrm{R}^{3}=\mathrm{H}: 60 \%$
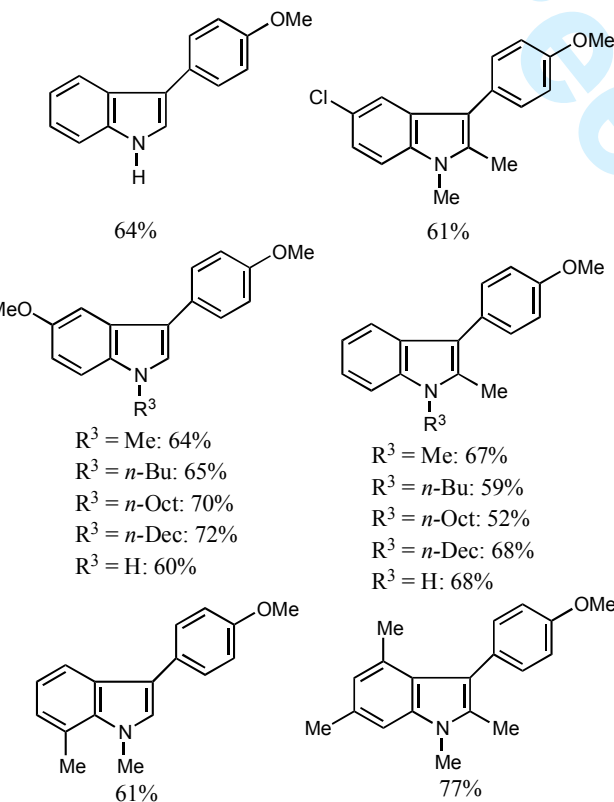
Me

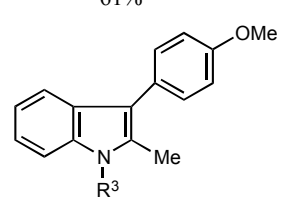

$\mathrm{R}^{3}=\mathrm{Me}: 67 \%$$$
\mathrm{R}^{3}=n-\mathrm{O}
$$$$
\mathrm{R}^{3}=n \text {-Dec: } 68 \%
$$

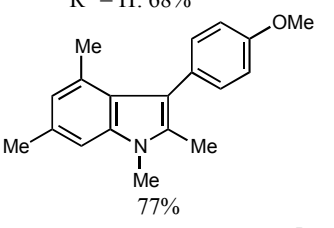<smiles>[Li]c1ccc(-c2c[nH]c3ccc(Br)cc23)cc1</smiles>

$\mathrm{R}^{1}=$ OMe: $63 \%$ $\mathrm{R}^{1}=\mathrm{H}: 62 \%$

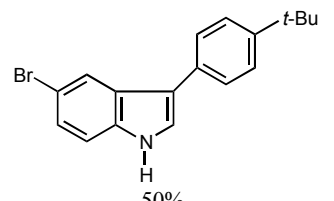
$\mathrm{R}^{3}=\mathrm{H}: 68 \%$
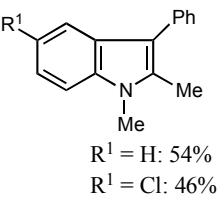

Scheme 28. Direct regioselective C-3 arylation reaction of indoles with diaryliodonium tosylates
Notably, these arylation reactions, which were found to tolerate the presence of $\mathrm{Cl}$ and $\mathrm{Br}$ substituents on the heteroarene substrate, also allowed the synthesis of highly substituted indole derivatives. It was also found that when an unsymmetrically substituted diaryliodonium salt was employed as the arylating reagent a product was obtained resulting from the preferential transfer of the less sterically hindered aromatic moiety of the iodonium salt (Scheme 29). ${ }^{[46]}$

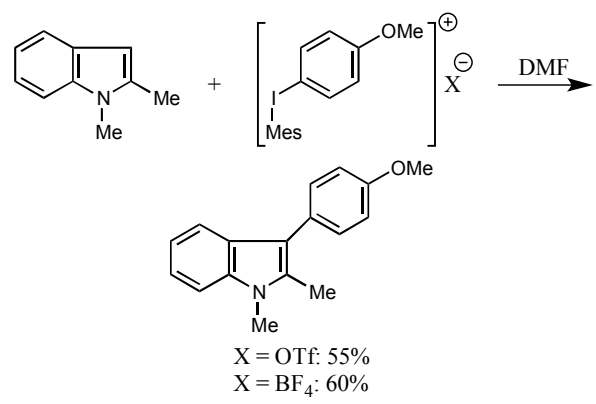

Scheme 29. Direct C-3 arylation of an indole derivative with unsymmetrically-substituted diaryliodonium salts.

It was then performed an intermolecular competition experiment in which 3.0 equiv of 5methoxy- $1 H$-indole and 3 equiv of $1 H$-indole were reacted with 1.0 equiv of bis(4methoxyphenyl)iodonium tosylate. This experiment gave a result (Scheme 30$)^{[46]}$ that was in close correlation with Mayr's nucleophilicity parameter. $^{[47]}$

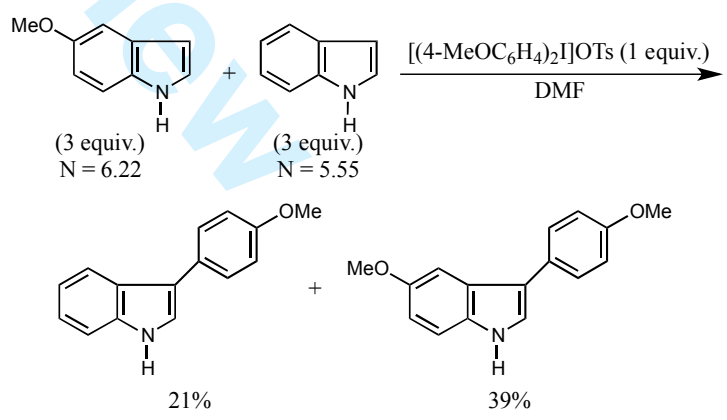

Scheme 30. Intermolecular competition experiment.

It deserves also to be pointed out that the protocol outlined in Scheme 28 for the transition metal-free direct C-3 arylation of indoles with diaryliodonium tosylates, because of its complete regioselectivity, chemoselectivity, high yields and the absence of a catalyst system, competes favourably with the 
literature procedures to access 3-arylated indoles via Pd-catalyzed direct arylation of indoles with aryl halides, ${ }^{[48 a-e]}$ benzoic acids, ${ }^{[48 f, g]}$ and cyclohexanones. ${ }^{[48 \mathrm{~h}]}$ It is also worth mentioning the versatility of the direct arylation reactions with unsymmetrical diaryliodonium salts allowed access to pentasubstituted pyrroles via direct diarylation of a 1,2,5-trisubstituted pyrrole at the 3 and 4 positions. Ackermann and coworkers reported in fact that the reaction of 2,5-dimethyl-1- $n$ octylpyrrole with 2.0 equiv of (mesityl)( $p$ tolyl)iodonium triflate in DMF at $100{ }^{\circ} \mathrm{C}$ delivered 2,5-dimethyl-3,4-bis( $p$-tolyl)-1- $n$-octylpyrrole in $52 \%$ yield (Scheme 31$).{ }^{[46]}$

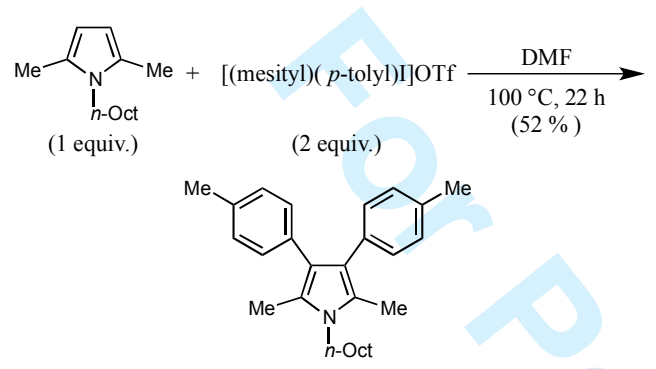

Scheme 31. Direct diarylation of 2,5-dimethyl-1-noctylpyrrole

It should be noted that, in 2011, pentasubstituted pyrroles were synthesized in modest yields by Wagner and Sanford via $\mathrm{PdCl}_{2}\left(\mathrm{MeCN}_{2}\right.$-catalyzed sequential diarylation of 1,2,5-trisubstituted pyrrole derivatives with diaryliodonium tetrafluoroborates in DCE at $84{ }^{\circ} \mathrm{C} .{ }^{[49]}$

More recently, Ackermann and coworkers investigated the late-stage diversification of functionalized peptides through transition metalfree direct $\mathrm{C}-\mathrm{H}$ arylation of indole-containing peptides with diaryliodonium salts. ${ }^{[50]}$ At the outset of this study, the direct arylation of indole-3acetamides of general formula $\mathbf{6 5}$ with diphenyliodonium tosylate was examined and it was found that under optimized conditions a mixture of 1.0 equiv of compounds $\mathbf{6 5}$ with 1.5 equiv of diphenyliodonium tosylate in DMF at $100{ }^{\circ} \mathrm{C}$ for $17 \mathrm{~h}$ gave regio- and stereoselectively 2phenyl-substituted derivatives $\mathbf{6 6}$ in good to excellent yields (Scheme 32).

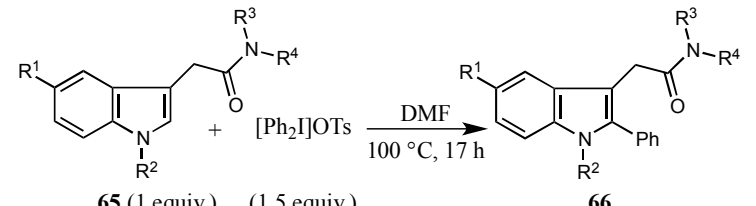

$\mathbf{6 5}$ ( 1 equiv. $) \quad$ ( 1.5 equiv. $)$

66<smiles>[R][R15](=S)NC(=O)Cc1c(-c2ccccc2)n(C)c2ccc([R16])cc12</smiles>

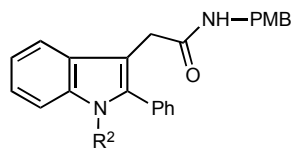

$\mathrm{R}^{1}=\mathrm{Br}: 56 \%$

$\mathrm{R}^{1}=\mathrm{Me}: 91 \%$ $\mathrm{R}^{1}=$ OMe: $87 \%$

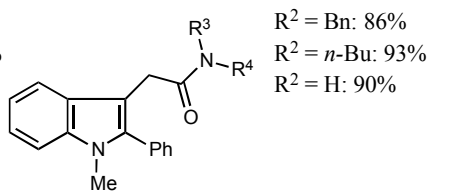

$\mathrm{R}^{3}=\mathrm{R}^{4}=\mathrm{H}: 76 \%$

$\mathrm{R}^{3}=\mathrm{H} ; \mathrm{R}^{4}=c-\operatorname{Pr}: 98 \%$ $\mathrm{R}^{3}=\mathrm{R}^{4}=$ Me: $96 \%$

Scheme 32. Direct arylation of indole-3-acetamides $\mathbf{6 5}$ with diphenyliodonium tosylate.

These optimized reaction conditions were then used for the arylation of the indole moiety of dipeptide 2(1H-indol-3-yl)acetyl-Phe-Gly-OEt (67) with various diaryliodonium tosylates (Scheme 33).

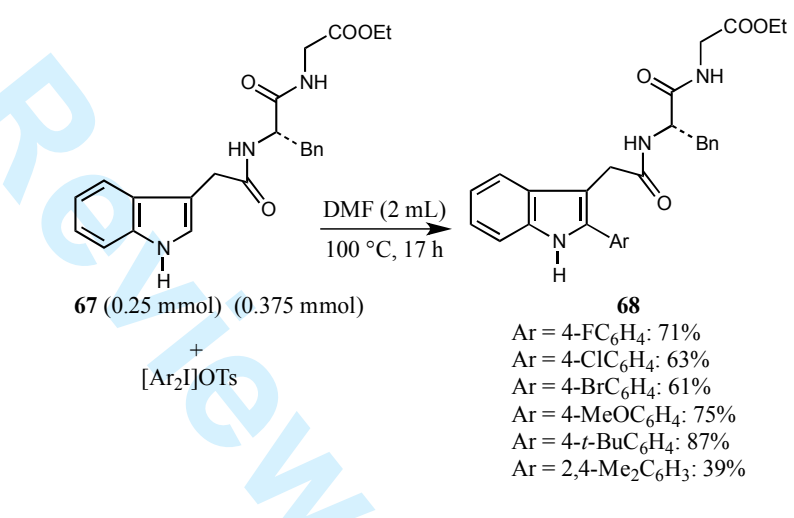

Scheme 33. Direct C-2 arylation of the indole moiety of dipeptide 67 .

The reactions, which resulted tolerating halogen containing motifs, furnished the $\mathrm{C}-2$ arylated compounds 68 in modest to good yields. ${ }^{[50]}$ Notably, the optimized reaction conditions of Scheme 33 also allowed the regioselective direct $\mathrm{C}-\mathrm{H}$ arylation of tripeptide 69, enantiomerically pure peptides such as compound 70, and dipeptides such as $\mathbf{7 1}$ (Figure 8) in good yields. 


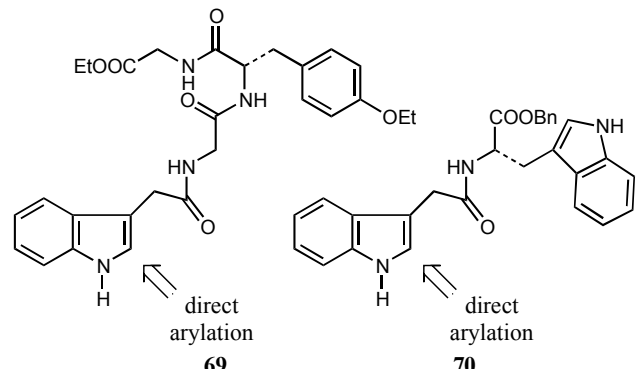

69

70

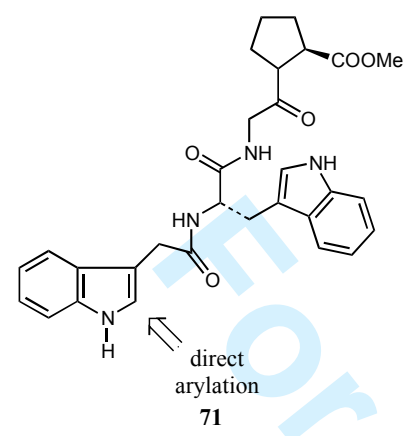

Figure 8. Chemical structures of compounds 69-71.

Interestingly, the arylation reactions of compounds 70 and 71 turned out to be bioorthogonal since they occurred exclusively at their indole-3-acetamide moiety.

Informations about the mechanism of these $\mathrm{C}-\mathrm{H}$ arylations were then obtained from the reaction of $\mathrm{N}$-(4-methoxybenzyl)-2-(1-methyl- $1 H$-indol-3-

yl)acetamide (65a) with diphenyliodonium tosylate that occurred in good to excellent yields when it was carried out in the presence of 1.5 equiv of a radical scavenger such as TEMPO or BHT (Scheme 34). In fact, these results indicated that a SET-type radical reaction was not operative. ${ }^{[50]}$

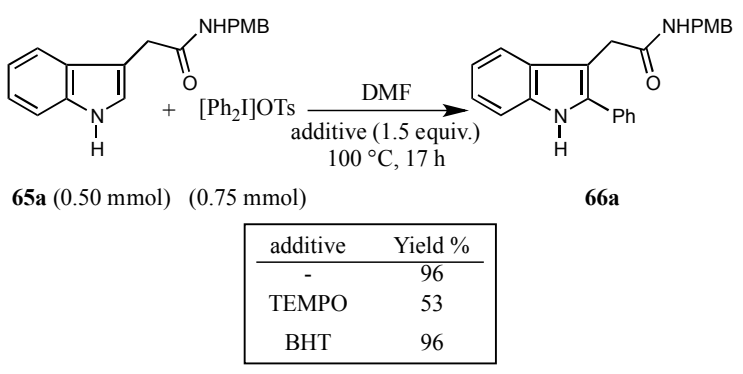

Scheme 34. Direct arylation of compound 65a with diphenyliodonium tosylate in the presence of radical scavengers.
In 2012, Zhang, $\mathrm{Yu}$ and coworkers developed a new method for the transition metal-free highly chemo- and regioselective $\mathrm{C}-2$ arylation of free $\mathrm{NH}$-pyrrole and $N$-methylpyrrole. ${ }^{[51]}$ It involved the reaction of a large molar excess of these heteroarenes with diaryliodonium bromides or triflates at $80{ }^{\circ} \mathrm{C}$ under air for $10 \mathrm{~h}$ in the presence of $\mathrm{NaOH}$ (Scheme 35). This base, in a preliminary screening, proved preferable to $\mathrm{K}_{3} \mathrm{PO}_{4}, \mathrm{Na}_{2} \mathrm{CO}_{3}$, $\mathrm{K}_{2} \mathrm{CO}_{3}$ and $\mathrm{KOH}$ as well as to organic bases such as TMEDA and $\mathrm{Et}_{3} \mathrm{~N}$. The iodonium salts used in these reactions were synthesized via oxidation of arenes or aryl iodides with $m$ CPBA. ${ }^{[52]}$

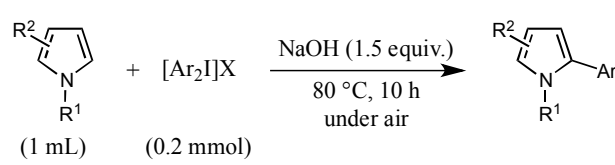

\begin{tabular}{ccccc} 
X & $\mathrm{R}^{1}$ & $\mathrm{R}^{2}$ & $\mathrm{Ar}$ & Yield \% \\
\hline OTf & $\mathrm{H}$ & $\mathrm{H}$ & $\mathrm{Ph}$ & 78 \\
$\mathrm{Br}$ & $\mathrm{H}$ & $\mathrm{H}$ & $4-\mathrm{ClC}_{6} \mathrm{H}_{4}$ & 91 \\
$\mathrm{Br}$ & $\mathrm{H}$ & $\mathrm{H}$ & $4-\mathrm{BrC}_{6} \mathrm{H}_{4}$ & 65 \\
$\mathrm{Br}$ & $\mathrm{H}$ & $\mathrm{H}$ & $4-\mathrm{FC}_{6} \mathrm{H}_{4}$ & 93 \\
OTf & $\mathrm{H}$ & $\mathrm{H}$ & $4-\mathrm{MeC}_{6} \mathrm{H}_{4}$ & 71 \\
$\mathrm{Br}$ & $\mathrm{H}$ & $\mathrm{H}$ & $4-i-\mathrm{PrC}_{6} \mathrm{H}_{4}$ & 50 \\
$\mathrm{Br}$ & $\mathrm{H}$ & $\mathrm{H}$ & $3-\left(\mathrm{NO}_{2}\right) \mathrm{C}_{6} \mathrm{H}_{4}$ & 84 \\
$\mathrm{Br}$ & $\mathrm{H}$ & $\mathrm{H}$ & $3-(\mathrm{EtOOC}) \mathrm{C}_{6} \mathrm{H}_{4}$ & 76 \\
$\mathrm{Br}$ & $\mathrm{H}$ & $\mathrm{H}$ & $2-\mathrm{Me}-5-\left(\mathrm{NO}_{2}\right) \mathrm{C}_{6} \mathrm{H}_{3}$ & 83 \\
OTf & $\mathrm{H}$ & $\mathrm{H}$ & $3,4-\mathrm{Me}_{2} \mathrm{C}_{6} \mathrm{H}_{3}$ & 73 \\
OTf & $\mathrm{H}$ & $\mathrm{H}$ & $2,4-\mathrm{Me}_{2} \mathrm{C}_{6} \mathrm{H}_{3}$ & 73 \\
OTf & $\mathrm{H}$ & $\mathrm{H}$ & $2,4,6-\mathrm{Me}_{3} \mathrm{C}_{6} \mathrm{H}_{2}$ & 12 \\
OTf & $\mathrm{H}$ & $2-\mathrm{Me}$ & $\mathrm{Ph}$ & 67 \\
OTf & $\mathrm{H}$ & $2,4-\mathrm{Me}$ & $\mathrm{Ph}_{2}$ & 53 \\
OTf & $\mathrm{Me}$ & $\mathrm{H}$ & $\mathrm{Ph}^{2}$ & 69 \\
\hline
\end{tabular}

Scheme 35. NaOH-mediated C-2 arylation of pyrroles with diaryliodonium salts.

The arylation reactions provided 2-arylpyrroles generally in good to excellent yields, but the $\mathrm{NaOH}-$ mediated arylation of free NH-pyrrole with bis(2,4,6trimethylphenyl)iodonium triflate gave the required 2-arylated heteroarene in only $12 \%$ yield. Poor yields were also obtained when the arylations were carried out without the use of $\mathrm{NaOH}$. Besides, only a trace of $\mathrm{C}$-arylation product was obtained in the $\mathrm{NaOH}$-mediated arylation of 2,5-dimethyl- $1 \mathrm{H}$ pyrrole with diphenyliodonium triflate (Scheme 36 ).

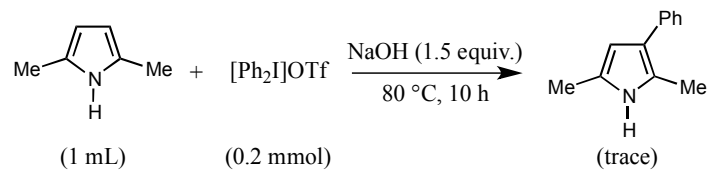

Scheme 36. Attempted NaOH-mediated Carylation of 2,5-dimethyl-1H-pyrrole with diphenyliodonium triflate. 
Intramolecular competition experiments involving free NH-pyrrole and iodonium triflates bearing two different aryl groups were also carried out and, as depicted in Scheme 37, it was found that the less electron-rich groups, phenyl in eq. a) and 4chlorophenyl in eq. b), were favoured as arylating reagents.

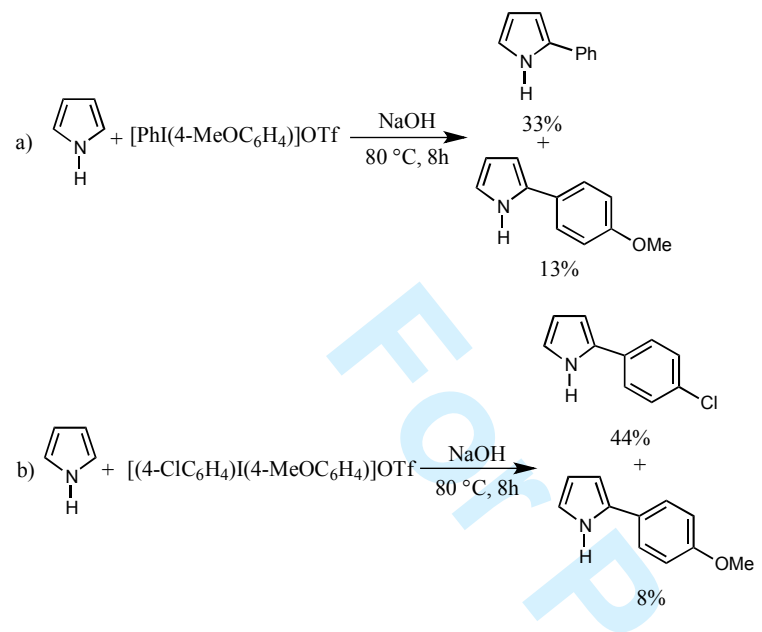

Scheme 37. Intramolecular experiments

It was also noted that even the $\pi$-electron deficient heteroarenes pyrazine (1) and pyridine (2) underwent efficient $\mathrm{NaOH}$-mediated direct arylation with diphenyliodonium triflate at $80{ }^{\circ} \mathrm{C}$ for $10 \mathrm{~h}$ under air. Pyrazine gave 2-phenylpyrazine in $71 \%$ yield and pyridine provided a mixture of $o-$, $m$ - and $p$-coupling products in 58\% yield.

Finally, to get information about the mechanism of these $\mathrm{NaOH}$-mediated arylation reactions, free $\mathrm{NH}-$ pyrrole was reacted with diphenyliodonium triflate in the presence of $\mathrm{NaOH}$ and 1.0 equiv of TEMPO and, in sharp contrast to what found by Ackermann and coworkers in the reaction of indole-3acetamides 65 with diaryliodonium salts in the presence of a radical scavenger, ${ }^{[50]}$ the arylation reaction was found to produce only a trace of 2phenylpyrrole (Scheme 38).

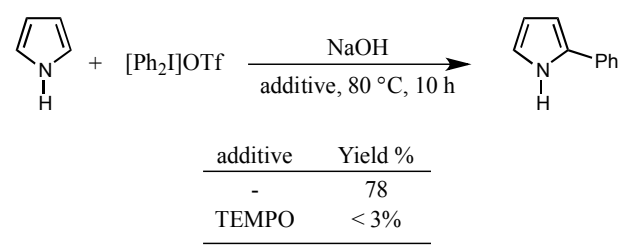

Scheme 38. Radical trapping experiment
This result was consistent with an aryl radical mechanism that was proposed to involve the steps shown in Scheme 39.

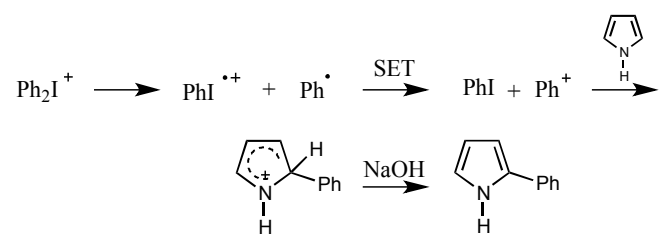

Scheme 39. Proposed mechanism for the $\mathrm{NaOH}$ mediated C-2 arylation of free NH-pyrrole with a diphenyliodonium salt.

In this mechanism, which was formulated taking into account that diaryliodonium salts are able to provide aryl radicals via decomposition, ${ }^{[52]}$ phenyl radical would become phenyl cation via a single electron transfer. A subsequent electrophilic attack on the C-2 position of free NH-pyrrole would lead to 2-phenylpyrrole. ${ }^{[51]}$

\section{Direct Arylation of Heteroarenes with Anilines Nitrosated In Situ or Arylhydrazines}

Arenediazonium salts are strong oxidizing agents which decompose to the corresponding aryl radicals when reduced by ascorbic acid (AA) (vitamin C) (Figure 9). ${ }^{[53]}$

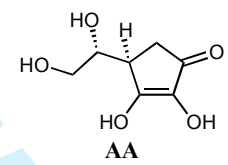

Figure 9. Chemical structure of ascorbic acid (AA)

In 2014, taking into account of these properties, Crisóstomo, Martin and Carrillo ${ }^{[54]}$ employed ascorbic acid as a radical initiator in a transition metal-free direct arylation of heteroarenes with arenediazonium salts, which were generated in situ from the corresponding anilines by treatment with $t$-butyl nitrite in $\mathrm{MeCN} .{ }^{[55]}$ The heteroarenes used as substrates included furan, furan derivatives, thiophene, tert-butyl $1 H$-pyrrole-1-carboxylate, and pyridine- $N$-oxide. At the outset of this study, it was found that treatment of a large excess of furan with 4-chlorobenzenediazonium tetrafluoroborate and 0.1 equiv of AA in DMSO at room temperature for $12 \mathrm{~h}$ gave 2 -(4-chlorophenyl)furan in $58 \%$ yield 
(Scheme 40) and that in the absence of $\mathbf{A A}$ the required 2-arylfuran was obtained in only $9 \%$ yield. ${ }^{[54]}$

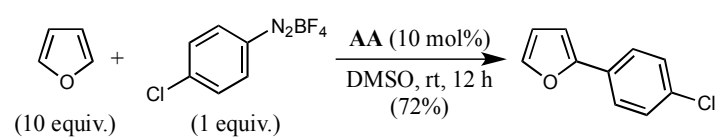

Scheme 40. Ascorbic acid (AA) initiated direct C-2 arylation of furan with 4-chlorobenzene-diazonium tetrafluoroborate.

Interestingly, five years before the publication of these results, Obushak and coworkers had reported that the reaction of 4-nitrobenzenediazonium chloride with 1.8 equiv of furfurol and 1.0 equiv of AA in a $2: 1$ mixture of acetone and water at 20 $25^{\circ} \mathrm{C}$ gave 5-(4-nitrophenyl)furan-2-carbaldehyde in $15 \%$ yield (Scheme 41$).{ }^{[56]}$

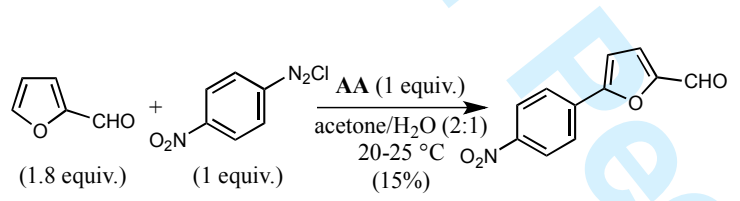

Scheme 41. AA-initiated direct arylation of furfurol with 4-nitrobenzenediazonium chloride.

However, since arenediazonium salts are generally unstable at temperature above $5-10{ }^{\circ} \mathrm{C}$ and may detonoate when dry, Crisóstomo, Martin and Carrillo thought more convenient to carry out the direct arylation of furan with arenediazonium salts generated in situ from the corresponding anilines. ${ }^{[54]}$ The new protocol that they developed for the regioselective synthesis of 2-arylfurans, including derivatives bearing functional groups such as $\mathrm{COOH}$, halogens and $\mathrm{NO}_{2}$, involved the addition of 1.5 equiv of $t$-butyl nitrite to a solution of 10 equiv of furan, 1.0 equiv of anilines and 10 mol \% AA at room temperature (Scheme 42). After $12 \mathrm{~h}$ the reaction provided 2-arylfurans in yields ranging from 33 to $80 \%$. In agreement with the occurrence of a radical reaction controlled by the SOMO-HOMO interaction, ${ }^{[57]}$ higher yields were obtained when anilines bearing electronwithdrawing substituents were used as reagents.
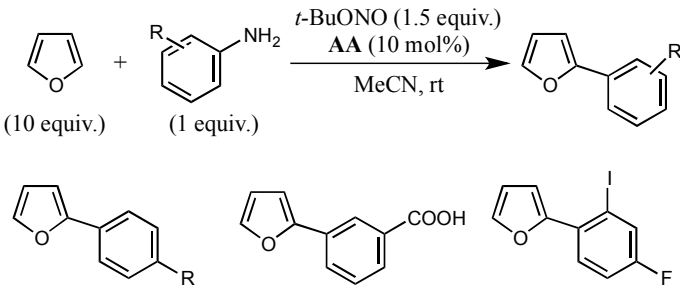

$\mathrm{R}=\mathrm{Cl}: 71 \%$

$\mathrm{R}=\mathrm{NO}_{2}: 76 \%$

$\mathrm{R}=\mathrm{COOH}: 80 \%$

$\mathrm{R}=\mathrm{H}: 33 \%$

$\mathrm{R}=$ COOEt: $64 \%$

$\mathrm{R}=\mathrm{Me}: 37 \%$

$\mathrm{R}=$ OMe: $31 \%$
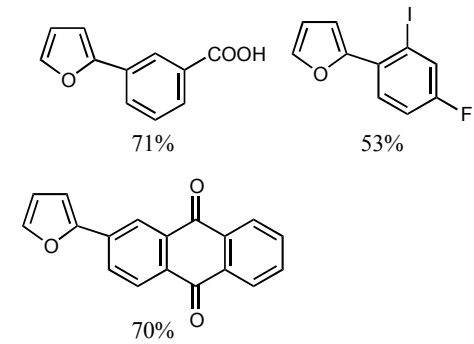

Scheme 42. AA-initiated direct C-2 arylation of furan with anilines nitrosated in situ.

Notably, a protocol very similar to that illustrated in Scheme 42 for the C-2 arylation of furan enabled the efficient direct $\mathrm{C}-2$ arylation of other heteroarenes allowing the synthesis of compounds 72, 73, 74, 75 and 76 in 67, 71, 66, 61 and 47\% yield, respectively (Figure 10).

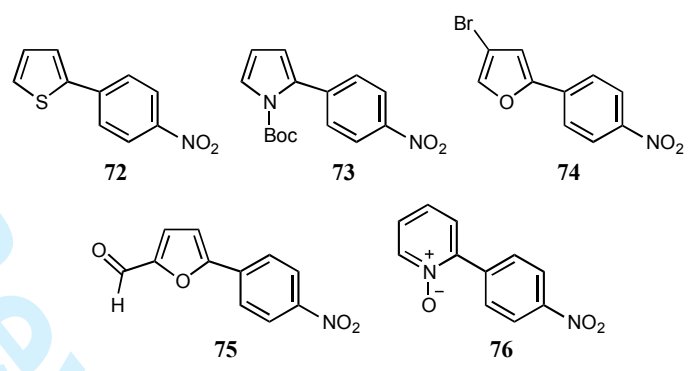

Figure 10. Chemical structures of compounds 7276.

The usefulness of compound $\mathbf{7 5}$ was then demonstrated by means of a synthesis on a gram scale of dantrolene (78) from this furan derivative and 1-aminohydantoin hydrochloride (77) (Scheme 43). ${ }^{[54]}$

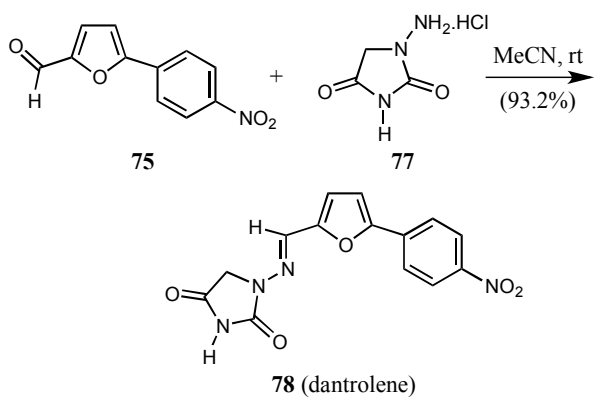

Scheme 43. Synthesis of dantrolene (78). 
Dantrolene (78) is an efficient $\mathrm{Ca}^{2+}$-regulating drug for the treatment of porcine and human hyperthermia ${ }^{[58]}$ and is a skeletal muscle relaxant which acts as an inhibitor of the enzyme acetylcholinesterase. $^{[59]}$

A tentative mechanism for the AA-initiated direct C-2 arylation of furan was also proposed (Scheme 44). ${ }^{[54]}$

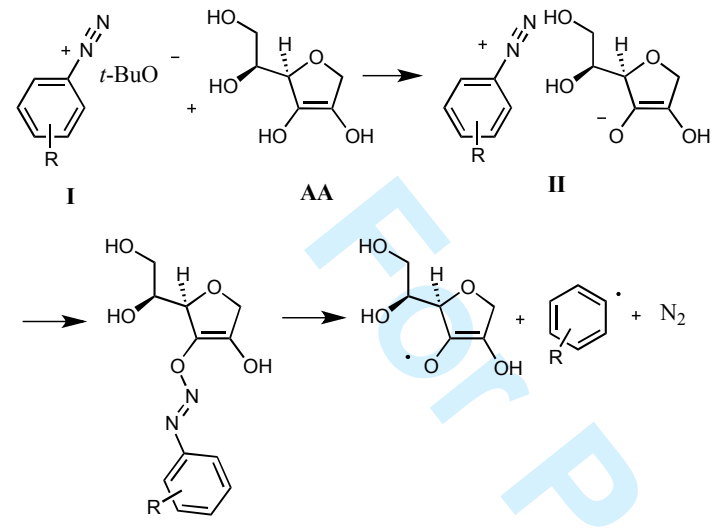

III<smiles>CCC(C)C</smiles>

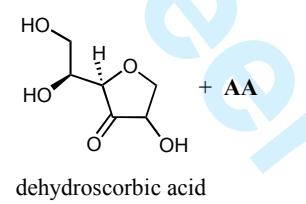

IV
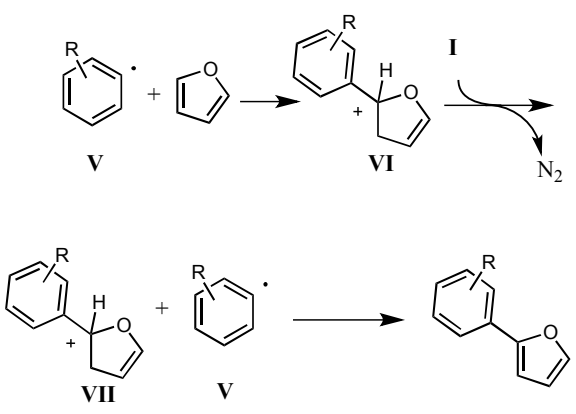

Scheme 44. Plausible mechanism for the AAinitiated direct C-2 arylation of furan.

In the first step of this mechanism $\mathbf{A A}$ would protonate the diazonium salt I leading to the diazonium salts II. Ascorbate then would reduce the diazonium cation by SET to provide diazoether III, which would generate nitrogen, ascorbyl radical IV and aryl radical V. Ascorbyl radical would undergo dismutation into dehydroascorbic acid and AA, which could reduce another arenediazonium ion. On the other hand, the reaction between furan and aryl radical $\mathbf{V}$ would give radical $\mathbf{V I}$, which by losing an electron would reduce another molecule of I to give cation VII, which is the direct precursor to the direct $\mathrm{C}-2$ arylation product. ${ }^{[54]}$

Again in 2014, Kuang and coworkers developed an unprecedented method for the direct arylation of pyridines with arylhydrazine hydrochlorides at room temperature, in air and in the absence of a base or a catalyst. ${ }^{[60]}$ As shown in Scheme 45, under optimized conditions, arylpiridines were synthesized in moderate to high yields but with minimal regioselectivity by treating $2 \mathrm{~mL}$ of pyridine (2) with $0.2 \mathrm{mmol}$ of arylhydrazine hydrochlorides at room temperature for $24 \mathrm{~h}$. Notably, the yields of the arylation reactions did not appear to be significantly dependent on the electronic nature of the substituents of the arylhydrazines and their position on the phenyl group of these substances.

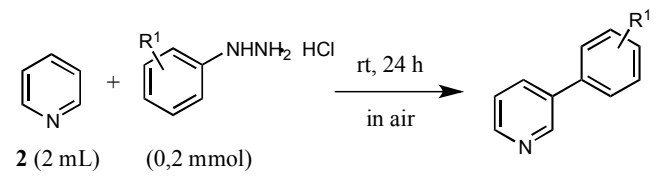

$53 \%$

$(2-/ 3-=2 / 1)$

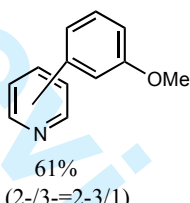

$(2-/ 3-=2-3 / 1)$

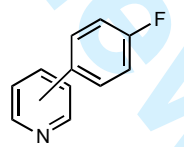

$63 \%$

$(2-/ 3-=2-4 / 1)$

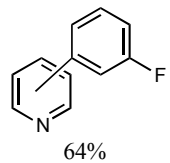

(2-/3-=2-8/1)

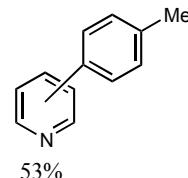

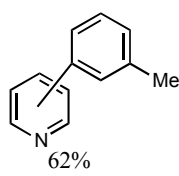

$(2-/ 3-=2-3 / 1)$

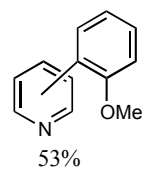

(2-/3-=2-3/1)
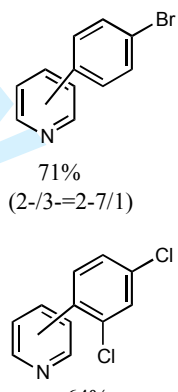

$(2-/ 3-=2 / 1)$
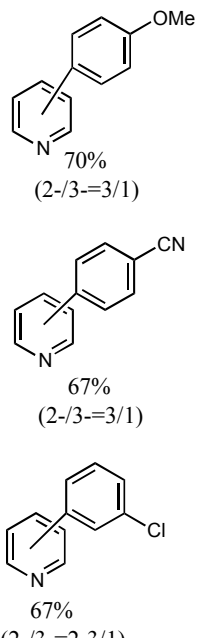

$(2-/ 3-=2-3 / 1)$

$(2-/ 3-=2-6 / 1)$

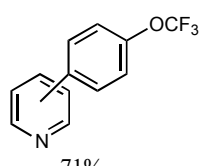

Scheme 45. Direct arylation of pyridine (2) with arylhydrazine hydrochlorides.

Good yields, but minimal regioselectivity were also obtained in the reaction of monomethyl-substituted pyridines with arylhydrazine hydrochlorides bearing an electron-donating or and electronwithdrawing group into the para-position (Scheme 
46). On the contrary, the arylation reaction of 3,5dimethylpyridine with 4-methoxyphenylhydrazine hydrochloride occurred selectively providing the desired C-2 arylation product in $43 \%$ yield (Scheme 46). ${ }^{[60]}$

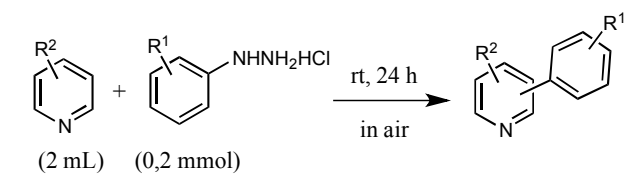<smiles>Cc1ccncc1-c1ccc(C#N)cc1</smiles><smiles>COc1ccc(-c2cnccc2C)cc1</smiles><smiles>Cc1ccncc1-c1ccc(Cl)cc1Cl</smiles>
$(2-/ 3=2 / 1)$

$$
52 \%
$$
$(2-/ 3=2-6 / 1)$ $57 \%$ $(2-/ 3=2-1 / 1)$

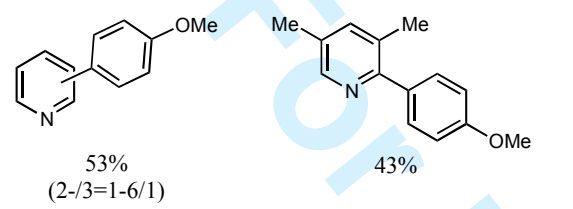

Scheme 46. Direct arylation of methyl-substituted pyridines with arylhydrazine hydrochlorides.

It was also found that the developed arylation protocol was suitable for the arylation of other electron-poor heteroarenes such as quinoline. In fact, treatment of this heteroarene with 4methoxyphenylhydrazine hydrochloride gave 2-(4methoxyphenyl)quinoline in $46 \%$ yield (Scheme 47) together with a trace amount of the corresponding $\mathrm{C}-3$ regioisomer.

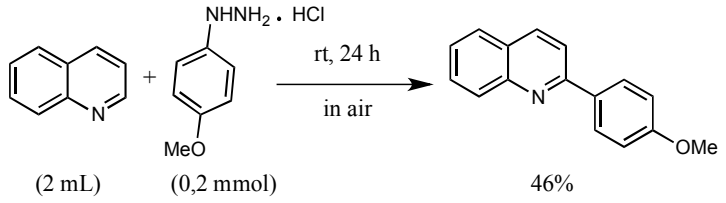

Scheme 47. Regioselective synthesis of 2-(4methoxyphenyl)quinoline.

Finally, some experiments were carried out to get information about the reaction mechanism. It was found that trace amounts of the desired arylation products were obtained when pyridine was reacted with phenylhydrazine instead of phenylhydrazine hydrochloride as well as when the reaction of pyridine with phenylhydrazine hydrochloride was carried out in the presence of 1 equiv of TEMPO. Moreover a kinetic isotope effect experiment in which pyridine and pyridine- $\mathrm{d}_{5}$ were reacted with 4-methoxyphenylhydrazine hydrochloride showed that no significant $\mathrm{KIE}$ value $\left(k_{H} / k_{D}=1.12\right)$ was obtained (Scheme 48).

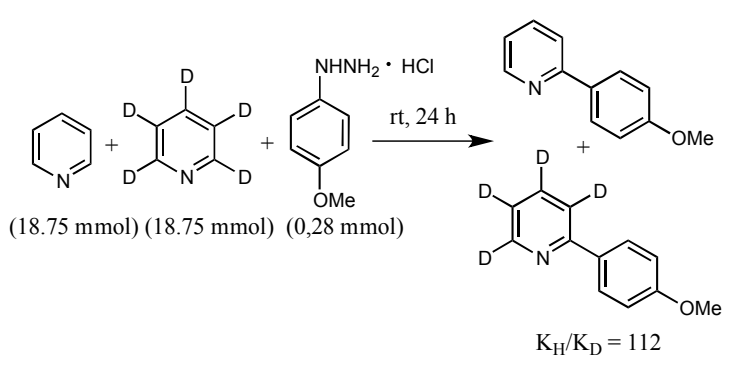

Scheme 48. Kinetic isotope effect experiment using pyridine, pyridine- $\mathrm{d}_{5}$ and 4methoxyphenylhydrazine hydrochloride.

These results taken together literature data ${ }^{[61]}$ allowed Kuang and coworkers to formulate the possible reaction mechanism depicted in Scheme 49. The first step of this mechanism would entail that arylhydrazine hydrochlorides disproportionate into hydrazyl radical $\mathbf{A}$ and aryl radicals $\mathbf{B}$. The latter would then react with protonated pyridine to form radical cations $\mathbf{C}$, which in turn would be reoxidized by dioxygen producing the required arylation products. ${ }^{[60]}$
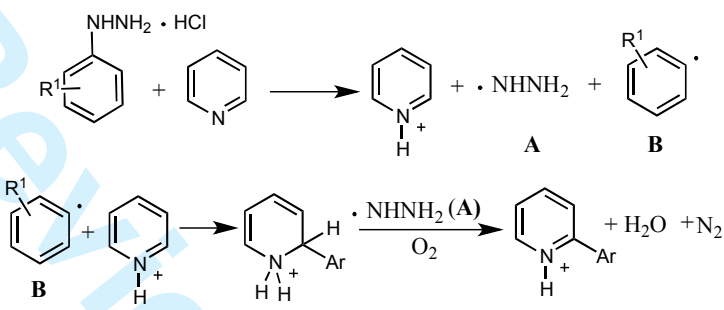

Scheme 49. Possible mechanism for the direct arylation of pyridine with arylhydrazine hydrochlorides.

However, it should be noted that this mechanism does not take into account the fact that arylhydrazines, which are readily formed from the corresponding hydrochlorides by treatment with a base such as pyridine, are easily oxidized under mild conditions by various oxidants including dioxygen from air to give unstable aryldiazenes $\mathbf{D}$ and that these intermediate decompose to dinitrogen and aryl radicals (Scheme 50) ${ }^{[62]}$ which are able to perform arylation reactions. ${ }^{[63]}$ 


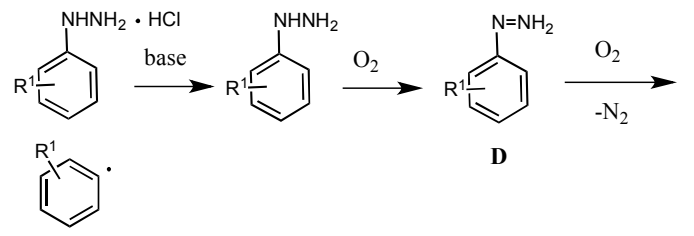

Scheme 50. Formation of aryl radicals from arylhydrazines.

\section{Direct Arylation of Benzothiazoles with Aryl Aldehydes}

2-Arylbenzothiazoles include highly important derivatives in medicinal chemistry. ${ }^{[64]}$ Efficient approaches to this class of heteroarenes involve Pdcatalyzed direct arylation reactions of benzothiazoles with aryl halides ${ }^{[65]}$ or arylboronic acids, ${ }^{[66]} \mathrm{Ni}$-catalyzed arylations of benzothiazoles with aryl halides ${ }^{\left[{ }^{[6]}\right.}$ or arylsilicon reagents, ${ }^{[68]}$ and Fe-catalyzed oxidative decarbonylative reactions of benzothiazoles with aryl aldehydes ${ }^{[69]}$ a class of compounds that, in 2010, $\mathrm{Li}$ and coworkers employed in the Rh-catalyzed oxidative decarbonylative coupling of aryl $\mathrm{C}-\mathrm{H}$ bonds of 2arylpyridine derivatives. ${ }^{[70]}$

In order to avoid the use of organic solvents and the potential metal contamination of the arylation products caused by the transition metal catalysts or the organometallic reagents, Cui and coworkers recently investigated the direct arylation of benzothiazoles with aryl aldehydes in neat water under metal free conditions and found that 2arylbenzothiazoles were obtained in moderate to good yields by the KI-catalyzed reaction of benzothiazoles with a small molar excess of aryl aldehydes in neat water at $100{ }^{\circ} \mathrm{C}$ for $8 \mathrm{~h}$ using $t$ butylhydroperoxide (TBHP) as an oxidant (Scheme 51). ${ }^{[71]}$

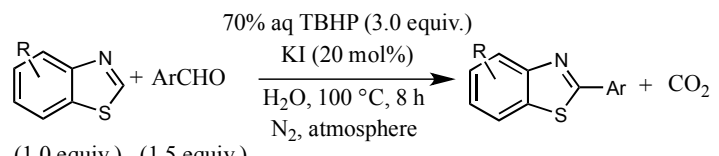

(1.0 equiv.) (1.5 equiv.)
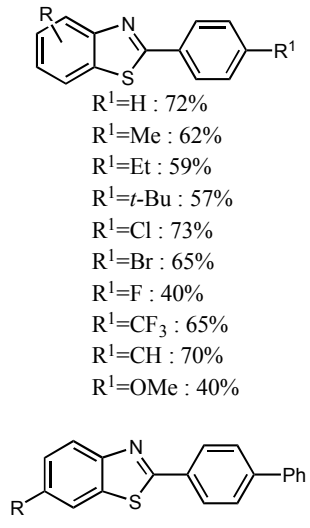

$\mathrm{R}^{1}=\mathrm{Cl}: 75 \%$

$\mathrm{R}^{1}=\mathrm{Me}: 79 \%$

$\mathrm{R}^{1}=\mathrm{OMe}: 63 \%$

$\mathrm{R}^{1}=\mathrm{OEt}: 54 \%$

$\mathrm{R}^{1}=\mathrm{NO}_{2}: 36 \%$

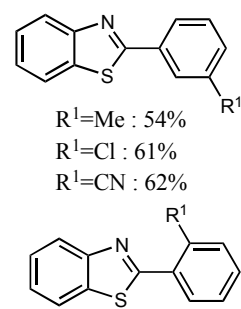

$\mathrm{R}^{1}=\mathrm{Me}: 58 \%$

$\mathrm{R}^{1}=\mathrm{OMe}: 46 \%$

$\mathrm{R}^{1}=\mathrm{Cl}: 72 \%$

$\mathrm{R}^{1}=\mathrm{F}: 42 \%$

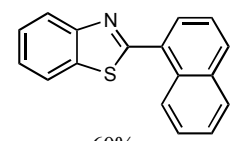

$60 \%$

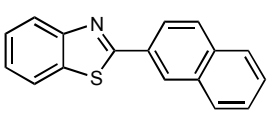

$47 \%$
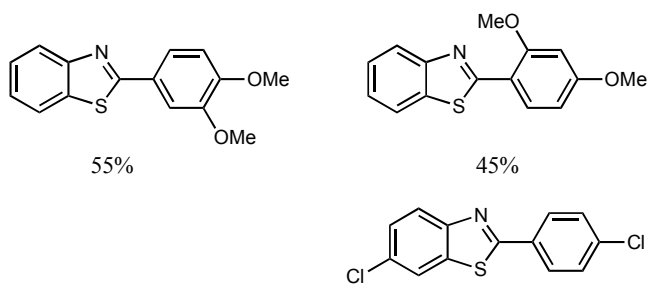

$58 \%$

Scheme 51. KI-catalyzed arylation of benzothiazoles with aryl aldehydes using aqueous TBHP as the oxidant.

TBHP appeared to be the oxidant of choice and other peroxides such as $t$-butyl peroxybenzoate, di$t$-butyl peroxide and $m$-chloroperbenzoic acid were found to disfavour the arylation reaction. It was also found that the best results were obtained by performing the reactions under a nitrogen atmosphere and that the yields decreased operating under the air and oxygen atmospheres. As shown in Scheme 51, under the optimal conditions a wide variety of substituted benzaldehydes gave 2-arylsubstituted benzothiazoles in $36-79 \%$ yields. No significant effect for benzaldehydes was observed and satisfactory yields were in general obtained in reactions involving benzothiazoles bearing both electron-donating and electron-withdrawing substituents. However, the arylation of 6nitrobenzothiazole with benzaldehyde gave the 
required C-2 arylation product in only $36 \%$ yield. ${ }^{[71]}$

Attention was also paid to elucidate the possible mechanism of the KI-catalyzed reactions depicted in Scheme 51. In an experiment it was found that the KI-catalyzed arylation of benzothiazole with $\alpha$ ${ }^{13} \mathrm{C}$-benzaldehyde yielded ${ }^{13} \mathrm{C}$-labeled 2phenylbenzothiazole as the major product (Scheme 52). ${ }^{[71]}$

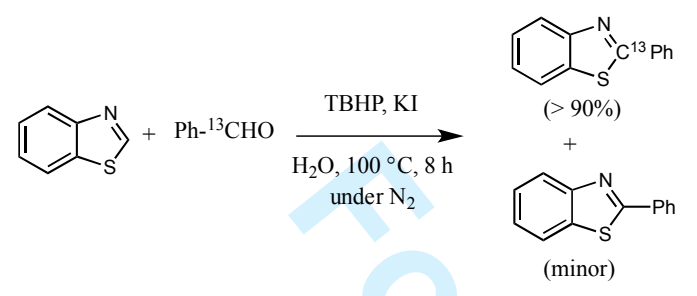

Scheme 52. KI-catalyzed reaction of benzothiazole with $\alpha-{ }^{13} \mathrm{C}$-benzaldehyde.

This result indicated that the reaction did not involve a decarbonylative or decarboxylative pathway, but could proceed through a ring-opening mechanism as in the case of the $\mathrm{Pd}(\mathrm{OAc})_{2} / \mathrm{PPh}_{3}$ catalyzed direct arylation of benzoxazoles with iodobenzene in DMF in the presence of $\mathrm{Cs}_{2} \mathrm{CO}_{3}{ }^{[72]}$ In addition, since benzothiazole remained unchanged under the standard conditions in the absence of aryl aldehydes, the latter compounds were proposed to permit the ring-opening process involving benzothiazole. It was also found that treatment of 2-methylbenzothiazole with benzaldehyde under the standard conditions gave no reaction product (Scheme 53), this indicating that the carbon at position 2 in benzothiazole is oxidized to $\mathrm{CO}_{2}$ in the arylation reaction and that the methyl group at $\mathrm{C}-2$ of benzothiazole hinders such an oxidation.

$$
\underset{\mathrm{S}}{\stackrel{\mathrm{TBHP}, \mathrm{KI}}{\longrightarrow} \underset{\mathrm{H}_{2} \mathrm{O}, 100^{\circ} \mathrm{C}, \mathrm{N}_{2}}{\longrightarrow}} \text { no reaction }
$$

Scheme 53. Treatment of 2-methylbenzothiazole with benzaldehyde under the standard conditions used for the C-2 arylation of benzothiazoles

Finally, a further experiment showed that the arylation of benzothiazole with benzaldehyde was hampered by the addition of TEMPO. Based on these results, Cui and coworkers proposed the mechanism depicted in Scheme 54 for the
TBHP/KI-promoted arylation of benzothiazole with benzaldehyde.

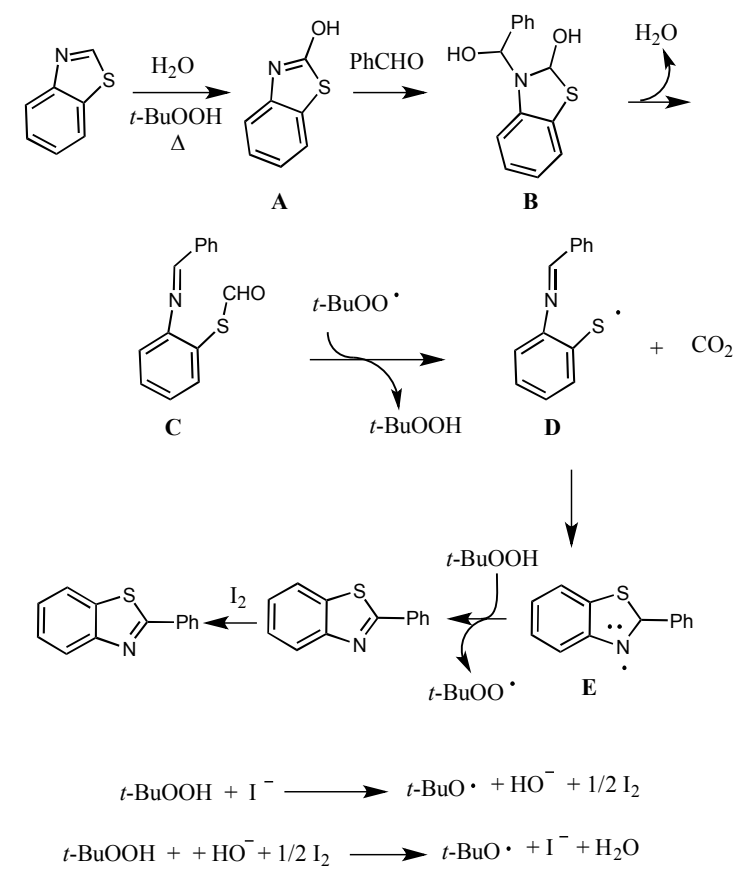

Scheme 54. Proposed mechanism for the TBHP/KI-promoted arylation of benzothiazole with benzaldehyde in neat water.

In the first step of this mechanism benzothiazole would react with water in the presence of TBHP to give 2-hydroxy-2,3-dihydrobenzothiazole (A). The subsequent reaction of $\mathbf{A}$ with benzaldehyde would give hemiaminal $\mathbf{B}$, which by loss of water would provide the Schiff base $\mathbf{C}$. The reaction of $\mathbf{C}$ with $t$ butyl peroxyl radical would give $\mathrm{CO}_{2}$ and the arylsulfanylradical D able to undergo cyclization, which would provide 2-phenyl-2,3dihydrobenzothiazole $(\mathbf{F})$ via the intermediate $\mathbf{E}$. The cyclization reaction of $\mathbf{D}$ would occur by a mechanism similar to that proposed for the 4methoxyTEMPO-catalyzed aerobic oxidative synthesis of 2-substituted benzothiazoles, benzoxazoles and benzimidazoles. ${ }^{\text {[73]- }}$ Oxidation of F by iodine finally would provide 2phenylbenzothiazole. In this mechanism molecular iodine would be formed through the reaction of TBHP with the iodide anions ${ }^{[74]}$ and $t$-butylperoxyl radical would be obtained by the reaction of TBHP with molecular iodine and hydroxyl anion. ${ }^{[71]}$ 


\section{Direct (Hetero)arylation of Heteroarenes with (Hetero)arylmetals}

Over the past decade, transition metal-catalyzed direct arylation reactions of $\mathrm{C}-\mathrm{H}$ bonds of heteroarene rings with (hetero)arylmetals were used to synthesize a wide variety of (hetero)arylsubstituted heteroarenes. ${ }^{[75]}$ Nevertheless, significant attention was also paid to the development of two-step processes for the transition metal-free ortho-arylation of heteroarenes that involve the addition of (hetero)arylmetals to heteroarene derivatives.

In the period 2007-2010, Olsson, Almqvist and coworkers developed two different protocols ( $A$ and $B$ ) for the transition metal-free regioselective synthesis of 2-arylpyridines from pyridine- $N$ oxides and aryl Grignard reagents (Scheme 55). ${ }^{[76,77]}$ These protocols turned out to be effective alternatives to the syntheses of these heteroarene derivatives by $\mathrm{Pd}(\mathrm{OAc})_{2} / \mathrm{P}(t-\mathrm{Bu})_{3} \cdot \mathrm{HBF}_{4}$-catalyzed direct arylation of pyridine- $N$-oxides with aryl bromides followed by deoxygenation, ${ }^{[78]}$ by $\mathrm{Cu}(\mathrm{acac})$-catalyzed direct arylation of pyridine $N$ oxides with arylboronic esters, ${ }^{[79]}$ or by $\mathrm{Fe}(\mathrm{acac})$ catalyzed cross-coupling reaction of pyridines with arylboronic acids in the presence of $\mathrm{K}_{2} \mathrm{~S}_{2} \mathrm{O}_{8}$ and $n$ $\mathrm{Bu}_{4} \mathrm{NBr}$ in $\mathrm{CH}_{2} \mathrm{Cl}_{2} /$ water $^{[80]}$ In protocol $A$ 2arylpyridines were obtained in $63-86 \%$ yield by sequential addition of arylmagnesium chlorides to pyridine $\mathrm{N}$-oxides in THF at $25^{\circ} \mathrm{C}$ and hydrolysis of the resulting reaction mixtures followed by treatment with acetic anhydride at $120{ }^{\circ} \mathrm{C}$ for $1-4$ min under microwave irradiation. ${ }^{[76]}$

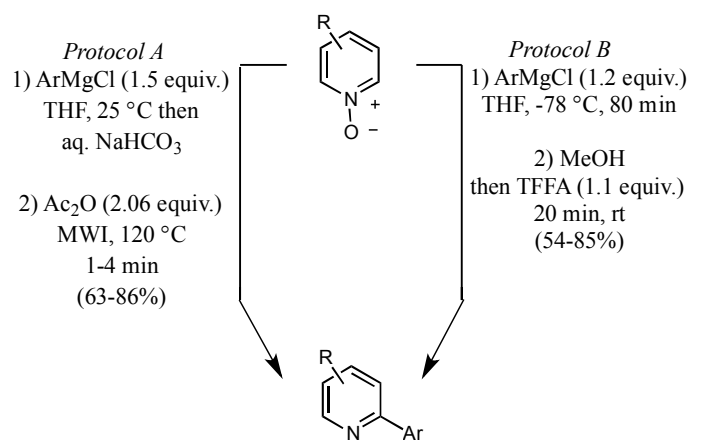

Scheme 55. Regioselective synthesis of 2-arylsubstituted pyridines from pyridine- $N$-oxides via two two-step protocols ( $A$ and $B$ ) involving the addition of aryl Grignard reagents to the substrates
Figure 11 shows the chemical structures and yields of the compounds synthesized using this protocol.
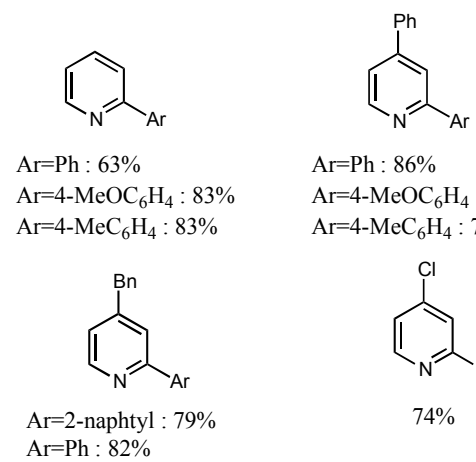

$\mathrm{Ar}=\mathrm{Ph}: 86 \%$ $\mathrm{Ar}=4-\mathrm{MeOC}_{6} \mathrm{H}_{4}: 75 \%$ $\mathrm{Ar}=4-\mathrm{MeC}_{6} \mathrm{H}_{4}: 73 \%$

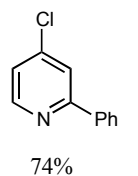
$\mathrm{Ar}=\mathrm{Ph}: 82 \%$

Figure 11. Chemical structures and yields of 2-aryl substituted pyridines synthesized using protocol $A$.

It is interesting that this two step-protocol worked well also with 2 -substituted pyridine $N$-oxides allowing the preparation of 2-methyl-6phenylpyridine with complete regioselectivity in $87 \%$ yield from 2-methylpyridine- $N$-oxide (Scheme 56). ${ }^{[76]}$

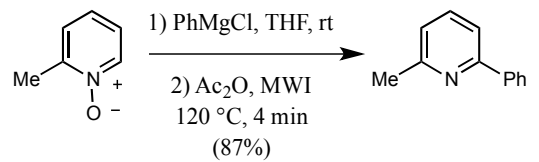

Scheme 56. Synthesis of 2-methyl-6phenylpyridine.

Evidence was also obtained that protocol $A$, except in the case of 3-methylpyridine $N$-oxide, involves the formation of 2,4-dienal oxime intermediates DOI from pyridine- $N$-oxides and aryl Grignard reagents (Scheme 57). ${ }^{[76]}$

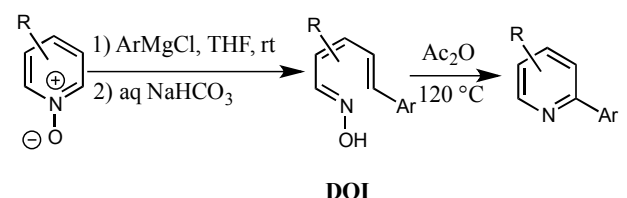

Scheme 57. Formation of 2-arylpyridines from 2,4dienal oxime intermediates.

Olsson, Almqvist and coworkers also discovered that by exchanging $\mathrm{Ac}_{2} \mathrm{O}$ for $\mathrm{DMF}$ in the second step of protocol A, 2-aryl-substituted pyridine $\mathrm{N}$ oxides were obtained and that these compounds were suitable to undergo addition of a second 
arylmagnesium halide to give 2,6-diaryl-substituted pyridines after a subsequent microwave-mediated reaction with $\mathrm{Ac}_{2} \mathrm{O}$. Scheme 58 shows the application of this procedure for the high yielding syntheses of 4-(benzyloxy)-2,6-diphenylpyridine (80) and 4-(benzyloxy)-2-phenyl-6-( $p$ tolyl)pyridine (81) from 4-(benzyloxy)pyridine $N$ oxide (79). ${ }^{\text {176] }}$

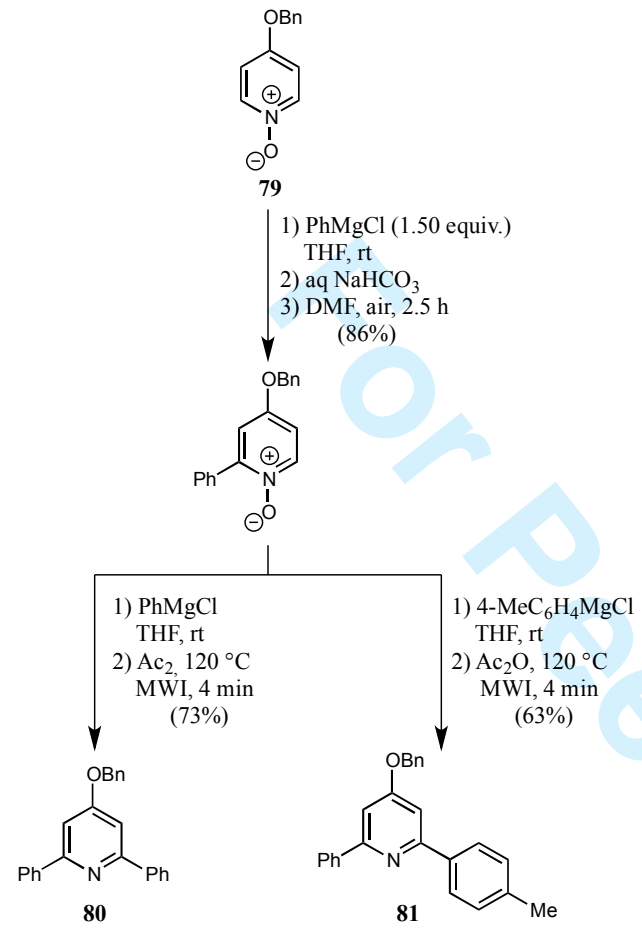

Scheme 58. Regioselective synthesis of 2,6diarylpyridines $\mathbf{8 0}$ and $\mathbf{8 1}$.

As shown in Scheme 55, the second protocol (protocol $B$ ) developed by Olsson, Almqvist and coworkers for the regioselective synthesis of 2aryl-substituted pyridines involved addition of arylmagnesium halides to pyridine $N$-oxides and treatment of the resulting reaction mixtures, after hydrolysis with $\mathrm{MeOH}$, with trifluoroacetic anhydride (TFFA). ${ }^{[77]}$ Notably, pyridine $N$-oxides bearing an electron-donating or an electronwithdrawing group worked well and the arylation reactions could also be carried out on a gram scale. Figure 12 shows the chemical structures and yields of the 2-arylpyridines synthesized using this protocol thus illustrating that the arylation reactions took place in general with good to high yields. However, when 3-picoline $N$-oxide was reacted according to this protocol, unfortunately, only a trace amount of 3-methyl-2-phenylpyridine was obtained

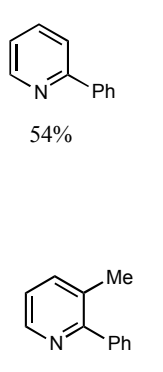

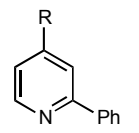

$\mathrm{R}=\mathrm{OBn}: 68 \%$ $\mathrm{R}=\mathrm{OMe}: 66 \%$ $\mathrm{R}=\mathrm{Cl}: 68 \%$ $\mathrm{R}=\mathrm{COOMe}: 63 \%$

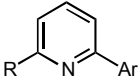

$\mathrm{R}=\mathrm{Me} ; \mathrm{Ar}=\mathrm{Ph}: 62 \%$

$\mathrm{R}=\mathrm{Ph} ; \mathrm{Ar}=\mathrm{Ph}: 85 \%$

$\mathrm{R}=\mathrm{Ph} ; \mathrm{Ar}=4-\mathrm{MeOC}_{6} \mathrm{H}_{4}: 79 \%$ $\mathrm{R}=\mathrm{Ph} ; \mathrm{Ar}=4-\mathrm{FC}_{6} \mathrm{H}_{4}: 79 \%$

Figure 12. Chemical structures and yields of 2arylpyridines synthesized using protocol $B$.

In 2011, Zhang and Duan extended the reaction between aryl Grignard reagents and pyridine $N$ oxides to nitropyridine $N$-oxides and found that treatment of 1.0 equiv of 4-nitropyridine $N$-oxides with 1.2 equiv of arylmagnesium halides in THF at $-60{ }^{\circ} \mathrm{C}$, followed by addition of 1.2 equiv of $2,3-$ dichloro-5,6-dicyano-1,4-benzoquinone (DDQ) provided regioselectively 2-aryl-4-nitropyridine $\mathrm{N}$ oxides in high yields (Scheme 59). ${ }^{[81]}$

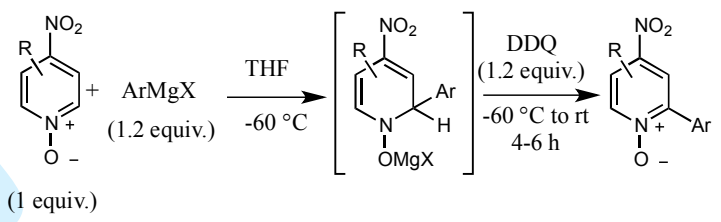

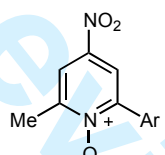

$\mathrm{Ar}=\mathrm{Ph}: 92 \%$

$\mathrm{Ar}=4-\mathrm{MeOC}_{6} \mathrm{H}_{4}: 85 \%$ $\mathrm{Ar}=3-\mathrm{MeOC}_{6} \mathrm{H}_{4}: 82 \%$ $\mathrm{Ar}=2-\mathrm{MeOC}_{6} \mathrm{H}_{4}: 78 \%$ $\mathrm{Ar}=2,3,4-\mathrm{MeOC}_{6} \mathrm{H}_{4}: 76 \%$ $\mathrm{Ar}=1$-naphtyl : $69 \%$ Ar $=2$-thienyl : $79 \%$ Ar=3-pyridyl : 70\% $\mathrm{Ar}=4-(\mathrm{MeOOC}) \mathrm{C}_{6} \mathrm{H}_{4}: 69 \%$

Scheme 59. Regioselective synthesis of 2-aryl-4nitropyridine $\mathrm{N}$-oxides from 4-nitropyridine $\mathrm{N}$ oxides.

This direct arylation protocol, which involves the arylation reaction at the 2- or 6-positions of 4nitropyridine $N$-oxides via the $\mathrm{N} \rightarrow \mathrm{O}$ groupdirected addition of the Grignard reagents, was also found to be suitable for the high yielding C-2 arylation of 4-nitroquinoline $N$-oxide with phenylmagnesium chloride (Scheme 60) ${ }^{[81]}$ 


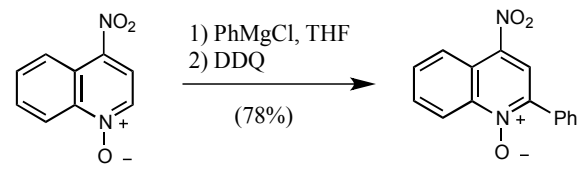

Scheme 60. Synthesis of 4-nitro-2-phenylquinoline $N$-oxide.

Zhang and Duan also investigated the one-pot direct arylation of 3-nitropyridine $\mathrm{N}$-oxide with arylmagnesium halides and found that the reactions furnished 2-(6-)aryl-3-nitropyridine $N$-oxides in excellent yields (Scheme 61). They justified the regioselectivity of these reactions on the basis of the additive electronic effects of the nitro substituent and the $\mathrm{N} \rightarrow \mathrm{O}$ group. ${ }^{[81]}$

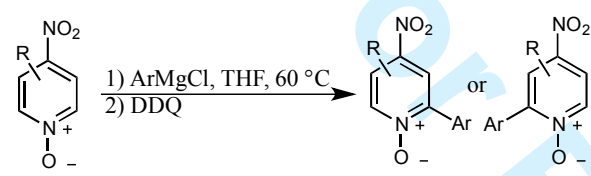

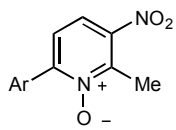

$\mathrm{Ar}=\mathrm{Ph}: 92 \%$ $\mathrm{Ar}=4-\mathrm{MeC}_{6} \mathrm{H}_{4}: 89 \%$ Ar=1-naphtyl : 94\%<smiles>CO[n+]1c([Al])ccc([N+](=O)[O-])c1-c1ccccc1</smiles>

$\mathrm{Ar}=4-\mathrm{MeC}_{6} \mathrm{H}_{4}: 98 \%$ $\mathrm{Ar}=2-\mathrm{MeC}_{6} \mathrm{H}_{4}: 98 \%$ $\mathrm{Ar}=1$-naphtyl : $98 \%$ $\mathrm{Ar}=2$-(MeOOC) $\mathrm{MeC}_{6} \mathrm{H}_{4}: 91 \%$

Scheme 61. Synthesis of 2-(6-)aryl-3-nitropyridine $\mathrm{N}$-oxides from 3-nitropyridine $\mathrm{N}$-oxides.

Finally, Zhang and Duan highlighted the synthetic potential of the one-pot arylation of 4-nitropyridine $\mathrm{N}$-oxides by a total synthesis of caerulomycins E (86) and A (87), two natural products first isolated from Streptomyces caeruleus ${ }^{[82]}$ that feature a unique 2,2'-bipyridine core structure. As shown in Scheme 62, the synthesis of $\mathbf{8 6}$ was carried out in four steps starting from commercially available 2methyl.4-nitropyridine $N$-oxide (82).
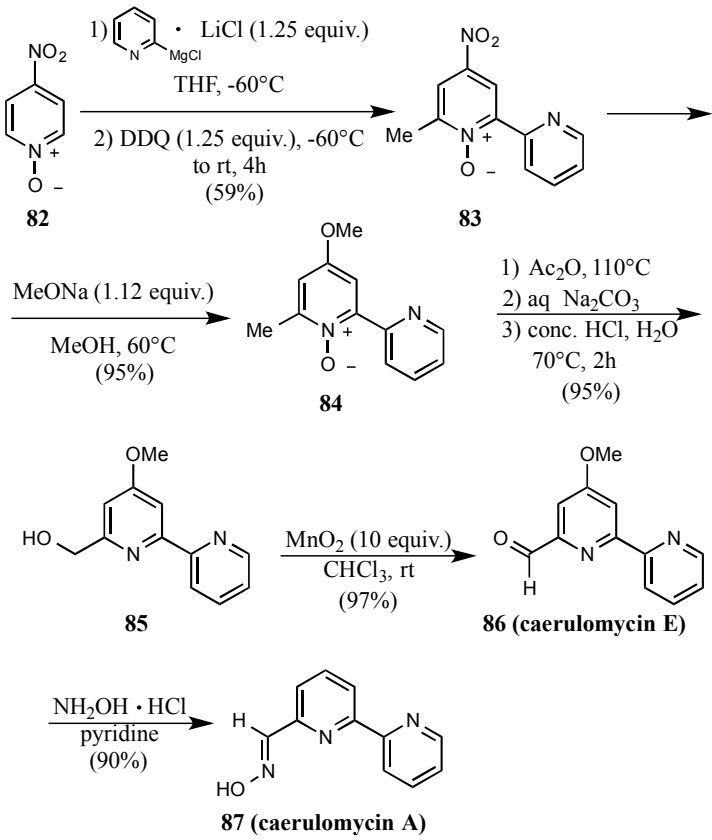

Scheme 62. Synthesis of caerulomycins E (86) and A (87).

Thus, 2-pyridylMgCl-LiCl, which was prepared from 2-bromopyridine and $i$ - $\mathrm{PrMgCl}$ according to Knochel's method ${ }^{[83]}$ and titrated before use, ${ }^{[84]}$ was added to compound $\mathbf{8 2}$ and the resulting compound was treated with DDQ to give 2-(2-pyridyl)pyridine $\mathrm{N}$-oxide $\mathbf{8 3}$ in $59 \%$ yield. The corresponding 4 methoxy derivative $\mathbf{8 4}$, which was obtained by treatment of $\mathbf{8 3}$ with $\mathrm{MeONa}$ in $\mathrm{MeOH}$, was then converted into compound $\mathbf{8 5}$ by the reaction with $\mathrm{Ac}_{2} \mathrm{O}$ at $110{ }^{\circ} \mathrm{C}$ followed by hydrolysis. Finally, oxidation of 85 with $\mathrm{MnO}_{2}$ in $\mathrm{CHCl}_{3}$ gave caerulomycin E (86) in $53 \%$ total yield. Furthermore, the reaction of $\mathbf{8 6}$ with hydroxylamine hydrochloride in pyridine provided caerulomycin A (87), a compound that was shown to exhibit antimicrobial, antiamoebic and antitumor activities ${ }^{[85]}$ and to suppress immunity by inhibiting $\mathrm{T}$ cell activity. ${ }^{[86]}$

In concluding the presentation of the results of the reactions between pyridine $N$-oxides and arylmagnesium halides it seems also appropriate to point out that in 1971 van Bergen and Kelly, contrary to what was assumed by Kato and Yamanaka ${ }^{[87]}$ demonstrated that these reactions do not give rise to addition products with a 1,2dihydropyridine structure, but instead lead to 5aryl-2Z,4E-pentadienal-syn-oximes which by treatment with $\mathrm{Ac}_{2} \mathrm{O}$ under reflux give 2arylpyridines (Scheme 63). ${ }^{[8]}$ These results therefore anticipated those subsequently reported 
by Olsson and Almqvist, ${ }^{[76]}$ but contrasted with the pathway hypothesized by Zhang and Duan for the reaction between 4-nitropyridine $\mathrm{N}$-oxides and arylmagnesium halides that, according to these authors, would involve the formation of intermediates by means of a 1,2-addition reaction. ${ }^{[81]}$

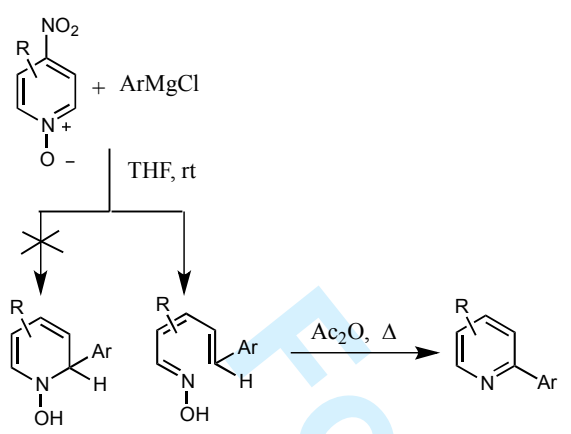

Scheme 63. Course of the reaction between pyridine $N$-oxides and aryl Grignard reagents.

Instead, the method that was developed between 1988 and 1990 by Strekowski and coworkers for the synthesis of 2-chloro-4-(heteroaryl)pyrimidines 90 involved an addition reaction of heteroaryllithium reagents to 2-chloropyrimidines $\mathbf{8 8}^{[89 \mathrm{a}]}$ followed by hydrolysis and dehydrogenation of the resultant dihydropyrimidines $\mathbf{8 9}$ with DDQ. ${ }^{[89 b]}$ Scheme 64 illustrates the reaction conditions used for the synthesis of a wide range of compounds 90.
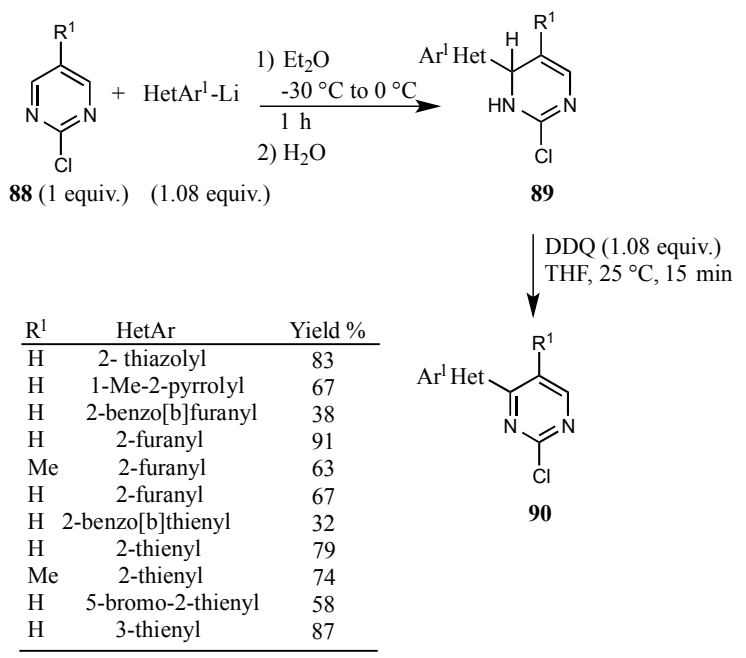

Scheme 64. Synthesis of 2-chloro-4(heteroaryl)pyrimidines 90.
It was also demonstrated that compounds 90 could be converted into 2-chloro-4,6di(heteroaryl)pyrimidines $\mathbf{9 2}$ by addition of heteroaryllithium reagents followed by dehydrogenation of the resulting dihydropyrimidines 91 (Scheme 65). ${ }^{\text {[8b] }}$<smiles>[R]c1cnc(Cl)nc1[GaH]</smiles><smiles>[R]c1c([AlH2])nc(Cl)nc1[AlH2]</smiles>

Scheme 65. Synthesis of 2-chloro-4,6di(heteroaryl)pyrimidines $\mathbf{9 2}$.

In 2013, a more practical method for the orthoarylation of electron deficient $N$-heteroarenes, which was related to that described by Strekowski and coworkers but not required the use of an organic oxidant, ${ }^{[896]}$ was developed by $\mathrm{Da}$ and coworkers. ${ }^{[90]}$ They discovered that heteroarenes including quinolines, isoquinolines, pyridines and quinoxaline undergo efficient direct ortho-arylation by treatment with aryl Grignard reagents in THF and toluene in the presence of TMEDA at $50{ }^{\circ} \mathrm{C}$ for $36 \mathrm{~h}$ and quenching of the reaction mixtures with aq. $\mathrm{NH}_{4} \mathrm{Cl}$ at $0{ }^{\circ} \mathrm{C}$ followed by stirring of the resultant mixtures inn the open air for $12 \mathrm{~h}$ (Scheme 66). This method allowed the preparation of a wide variety of 2-(hetero)arylquinolines 93, including derivatives bearing a bromo substituent at position 3, eight 1-(hetero)arylisoquinolines 94, including four derivatives bearing a bromo substituent at position 5, and two 2-arylpyridines 95. 


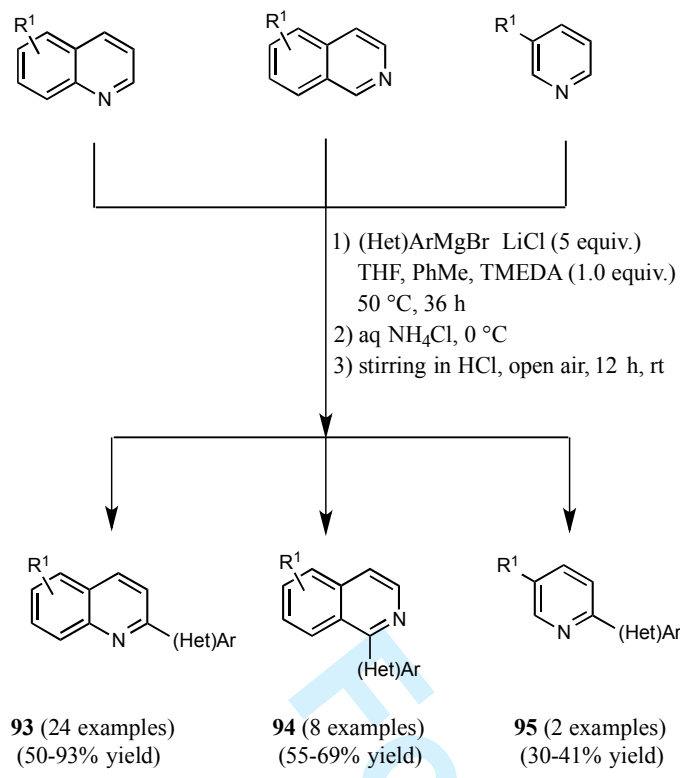

Scheme 66. TMEDA-assisted ortho-arylation of quinolines, isoquinolines and pyridines.

Figure 13 lists the chemical structure and yields of the compounds synthesized according to the protocol depicted in Scheme 66.

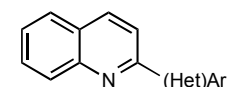

(Het) $\mathrm{Ar}=\mathrm{Ph}: 88 \%$

(Het)Ar $=3-\mathrm{MeC}_{6} \mathrm{H}_{4}: 92 \%$

(Het) $\mathrm{Ar}=2-\mathrm{MeOC}_{6} \mathrm{H}_{4}: 92 \%$

(Het)Ar=3- $\mathrm{MeOC}_{6} \mathrm{H}_{4}: 79 \%$

(Het) $\mathrm{Ar}=4-\mathrm{MeOC}_{6} \mathrm{H}_{4}: 84 \%$

(Het)Ar=2-naphthyl : 64\%

(Het)Ar $=3,5-\mathrm{Me}_{2} \mathrm{C}_{6} \mathrm{H}_{3}: 81 \%$

(Het)Ar $=4-\mathrm{FC}_{6} \mathrm{H}_{4}: 72 \%$

(Het) $\mathrm{Ar}=4-\mathrm{ClC}_{6} \mathrm{H}_{4}: 50 \%$

(Het)Ar=5-benzo[b]furanyl : $71 \%$

(Het)Ar=2-thienyl : $55 \%$

(Het)Ar=3-benzo[ $b]$ thiophenyl : $88 \%$
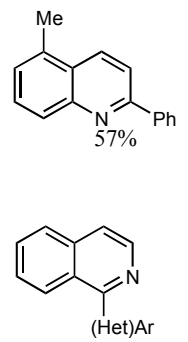

(Het)Ar=Ph : $60 \%$ (Het)Ar=4- $\mathrm{MeC}_{6} \mathrm{H}_{4}: 64 \%$

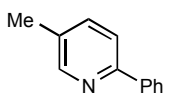

$41 \%$
(Het)Ar $=4-\mathrm{MeC}_{6} \mathrm{H}_{4}: 93 \%$ (Het)Ar=3,5- $\mathrm{Me}_{2} \mathrm{C}_{6} \mathrm{H}_{3}: 81 \%$

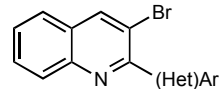

(Het)Ar=Ph : 95\%

(Het) $\mathrm{Ar}=3-\mathrm{MeC}_{6} \mathrm{H}_{4}: 96 \%$ (Het)Ar $=4-\mathrm{MeC}_{6} \mathrm{H}_{4}: 96 \%$ (Het)Ar=2- $\mathrm{MeOC}_{6} \mathrm{H}_{4}: 95 \%$

(Het)Ar=3- $\mathrm{MeOC}_{6} \mathrm{H}_{4}: 89 \%$

(Het)Ar $=4-\mathrm{MeOC}_{6} \mathrm{H}_{4}: 80 \%$

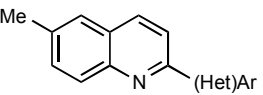

(Het)Ar=Ph : 76\%

(Het) $\mathrm{Ar}=3-\mathrm{MeC}_{6} \mathrm{H}_{4}: ? \%$

(Het)Ar=4- $\mathrm{MeC}_{6} \mathrm{H}_{4}: 80 \%$
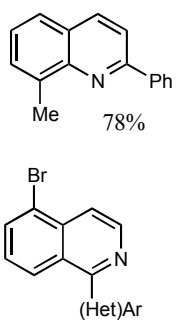

(Het) $\mathrm{Ar}=\mathrm{Ph}: 69 \%$

(Het) $\mathrm{Ar}=3-\mathrm{MeC}_{6} \mathrm{H}_{4}: 65 \%$

(Het) $\mathrm{Ar}=4-\mathrm{MeC}_{6} \mathrm{H}_{4}: 71 \%$

(Het)Ar=3,5- $\mathrm{Me}_{2} \mathrm{C}_{6} \mathrm{H}_{3}: 59 \%$

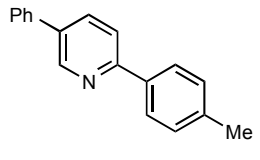

$30 \%$
Figure 13. Chemical structures and yields of the 2(hetero)aryl-substituted heteroarenes synthesized by TMEDA-assisted ortho-arylation reaction of electron-deficient $N$-heteroarenes

As regards the synthesis of 2-(hetero)arylsubstituted quinolines it deserves to be noted that, recently, the highly regioselective synthesis of these compounds was also achieved using nonenvironmentally friendly transition metal-catalyzed protocols including: i) $\mathrm{Pd}(\mathrm{OAc})_{2}$-catalyzed arylation of quinolines with dichlorobenzenes using dioxygen and $\mathrm{Ag}_{2} \mathrm{CO}_{3}$ as the oxidants; ${ }^{[91]}$ ii) the $\mathrm{Ni}(\mathrm{cod})_{2} / \mathrm{PCy}_{3}$-catalyzed reaction of quinolines with arylzinc reagents; ${ }^{[92]}$ and iii) the $\left[\mathrm{RhCl}(\mathrm{CO})_{2}\right]_{2}$ catalyzed direct arylation of quinolines with aryl bromides. ${ }^{[93]}$ Instead, to our knowledge, only one method for the direct arylation of isoquinolines, different from the one illustrated in Scheme 66, has so far been reported in the literature. However, this recently developed method $^{[94]}$ featuring the $\mathrm{Ru}(\mathrm{bpy})_{3} \mathrm{Cl}_{2} \cdot 6 \mathrm{H}_{2} \mathrm{O}$ catalyzed reaction of isoquinolines with arenediazonium tetrafluoroborates in $\mathrm{MeOH}$ containing trifluoroacetic acid under irradiation 
with a fluorescent lamp provides 1arylisoquinolines in yields lower than those obtained using the protocol illustrated in Scheme 66.

Da and coworkers also found that ortho-diarylated quinoxalines could be obtained in good to excellent yields by the reaction of 1.0 equiv of quinoxaline (5) with 3.0 equiv of (hetero)arylmagnesium bromides in a mixture of THF and toluene at $50{ }^{\circ} \mathrm{C}$ in the presence of 1.0 equiv of TMEDA and quenching of the resultant addition products followed by stirring in the open air (Scheme 67). ${ }^{[0]}$

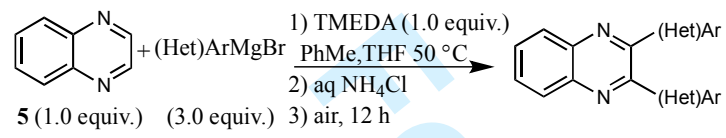

$$
\begin{array}{lc}
\text { (Het)Ar } & \text { Yield \% } \\
\hline \text { 4- } \mathrm{MeC}_{6} \mathrm{H}_{4} & 93 \\
\text { 2-thienyl } & 90 \\
\text { 3-benzo }[b] \text { thienyl } & 82 \\
\hline
\end{array}
$$
Scheme 67. Synthesis of $\quad$ 2,3-
di(hetero)arylquinoxalines.

Again in 2013, Knochel and coworkers described that strongly electron-deficient pyridines bearing an electron-withdrawing group at position 3 can undergo regioselective $\mathrm{C}-4$ arylation in good to excellent yields by treatment with 1.4-1.5 equiv arylmagnesium bromides activated with $\mathrm{LiCl}$ and 1.1 equiv of $\mathrm{BF}_{3} \cdot \mathrm{Et}_{2} \mathrm{O}$ in $\mathrm{THF}$ at $-30{ }^{\circ} \mathrm{C}$ followed by the reaction of the resultant 1,4 -addition product with chloranil (Scheme 68). ${ }^{[95]}$ Notably, these direct arylation reactions exhibited wide functional group tolerance and took place with high to excellent yields even using aryl Grignard reagents bearing synthetically versatile electron-donating or electron-withdrawing groups as well as a bulky Grignard reagent such as 2,4,6trimethylphenylmagnesium bromide. ${ }^{[95]}$

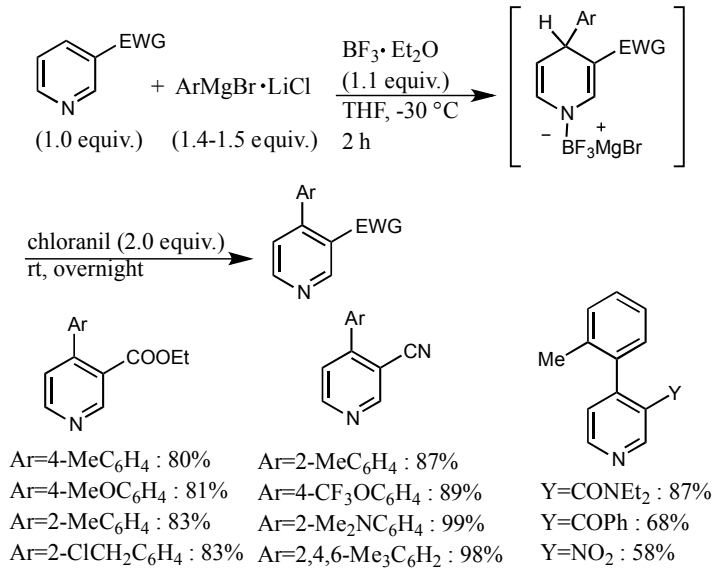

Scheme 68. C -4 arylation of pyridines bearing an electron-withdrawing group at position 3 .

It should be noted that Sames and coworkers had previously found that the regioselective direct C-4 arylation of 3-nitropyridine with (hetero)aryl bromides could be achieved in moderate to good yields using the $\mathrm{Pd}(\mathrm{OAc})_{2} /[\mathrm{P}(n$ $\left.\mathrm{Bu}) \mathrm{Ad}_{2} \mathrm{H}\right] \mathrm{I} / \mathrm{Cs}_{2} \mathrm{CO}_{3} / \mathrm{PivOH} / \mathrm{PhMe}$ system. ${ }^{[96]}$

Knochel and coworkers then used the protocol depicted in Scheme 68 for the synthesis of the fluorescent compound $\mathbf{9 8}$ from 3-cyanopyridine (96) and the dimagnesiated species 97 (Scheme 69). ${ }^{[95]}$

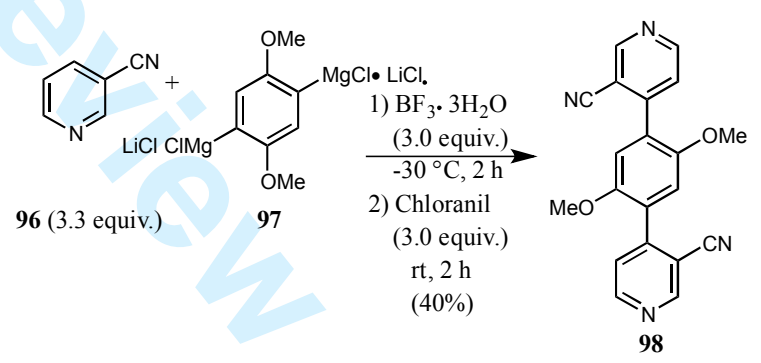

Scheme 69. Synthesis of the fluorescent compound 98.

In addition, they found that the addition of (hetero)aryl Grignard reagents to isonicotinonitrile (99) proceeded at C-2 giving rise to 2-(hetero)aryl4-cyanopyridines in acceptable yields (Scheme 70). ${ }^{[95]}$ 

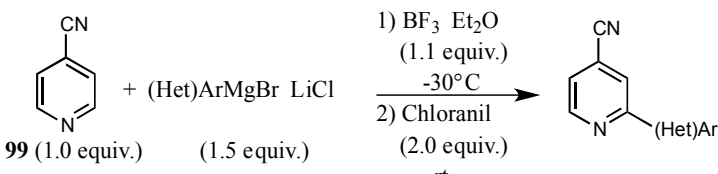

$\mathrm{rt}$

Scheme 70. Synthesis of 2-(hetero)aryl-4cyanopyridines.

More recently, Larionov and coworkers investigated the KO- $t$-Bu-mediated reaction of quinolone $N$-oxides with commercially available pentafluorophenyltrimethylsilane (100) and found that treatment of 8-methoxyquinoline $\mathrm{N}$-oxide (101) with 1.5 equiv of $\mathbf{1 0 0}$ and 1.0 equiv of KO-t$\mathrm{Bu}$ in $\mathrm{THF}$ at $-20^{\circ} \mathrm{C}$ for $50 \mathrm{~min}$ in the presence of $3 \AA$ molecular sieves followed by hydrolysis produced 8-methoxy-2-(perfluorophenyl)quinoline (102) in only $17 \%$ yield (Scheme 71$).{ }^{[97]}$

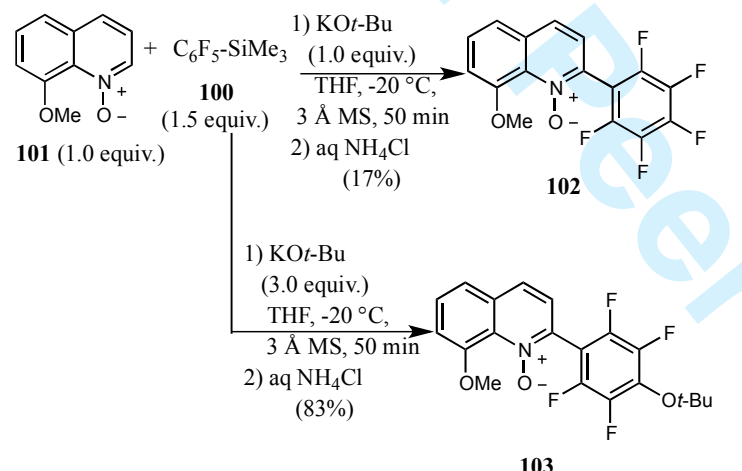

Scheme 71. Synthesis of compounds 102 and 103.

However, the reaction of $\mathbf{1 0 1}$ with 1.5 equiv of $\mathbf{1 0 0}$ and 3.0 equiv of $\mathrm{KO}-t-\mathrm{Bu}$ in THF at $-20{ }^{\circ} \mathrm{C}$ in the presence of $3 \grave{A}$ molecular sieves followed by treatment with aq. $\mathrm{NH}_{4} \mathrm{Cl}$ gave in $83 \%$ yield 2-[4( $t$-butoxy)-2,3,5,6-tetrafluorophenyl]-8methoxyquinoline (103), which derived from an unexpected nucleophilic substitution reaction of the fluoride in the para-position with respect to the 2quinolinyl group by $\mathrm{KO}-t-\mathrm{Bu}$ (Scheme 71). ${ }^{[97]}$ Notably, similar C-2 arylation reactions with concomitant nucleophilic substitution efficiently occurred when quinolone $N$-oxides 104 and 105 (Figure 14) were reacted with 1.5 equiv of $\mathbf{1 0 0}$ and 6.0 equiv of oxygen or sulphur nucleophiles. These reactions allowed the synthesis of compounds $\mathbf{1 0 6}$, 107 and 108 (Figure 14) in 86, 83 and 45\% yield, respectively. ${ }^{[97]}$

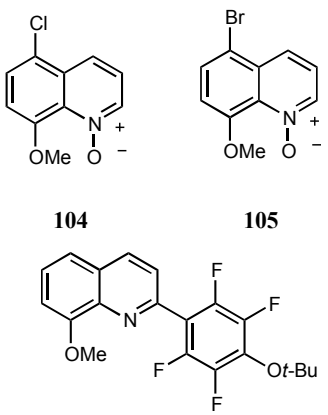

107
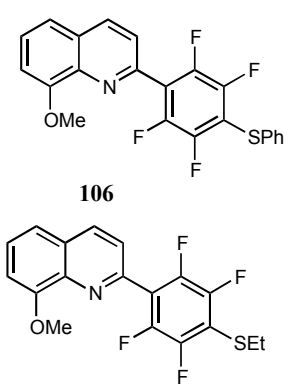

108
Figure 14. Chemical structures of compounds 104108.

In the proposed mechanism of the KO- $t$-Bumediated reaction of quinolone $N$-oxides with pentafluorophenyltrimethylsilane it was hypothesized that the $t$-butoxide anion activates the organosilicon reagent by forming a pentacoordinated silicon reagent that binds to the oxygen atom of the heteroarene substrate. A subsequent transfer of the pentafluorophenyl group to $\mathrm{C}-2$ followed by deprotonation and elimination of trimethylsilyloxide anion would the provide 2pentafluorophenylquinolines (Scheme 72). ${ }^{[97]}$

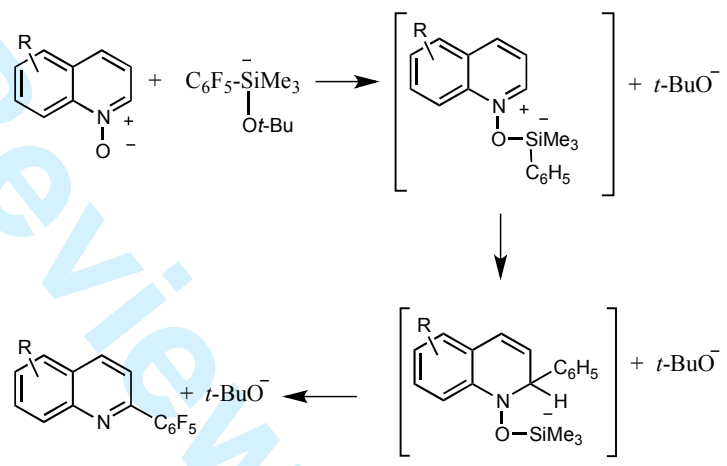

Scheme 72. Presumed mechanism for the KO-t$\mathrm{Bu}$-mediated reaction between quinolone $\mathrm{N}$-oxides and pentafluorophenyltrimethylsilane.

\section{Conclusions}

As shown in this review, several protocols have been identified and developed, especially in the last decade, to achieve the synthesis of (hetero)arylsubstituted electron-rich and electron-deficient heteroarenes through transition metal-free direct C$\mathrm{H}$ (hetero)arylation reactions. ${ }^{[98]}$ These reactions have been found to be generally characterized by efficiency, experimental simplicity, low cost, and, unlike the classical transition metal-catalyzed $\mathrm{C}-\mathrm{C}$ 
bond forming reactions, do not require lengthy and expensive procedures to obtain the required reaction products free of contaminants. However, it must be mentioned that some of these transition metal-free direct arylation protocols are characterized by significant drawbacks. In fact, the regioselectivity of the direct arylation reactions of $\pi$-deficient heteroarenes such as pyridine, pyrimidine and pyrazine, with the exception of the reactions carried out by the use of (hetero)arylmetals, remains an issue. Furthermore, various (hetero)arylation protocols in which (hetero)aryl halides or pseudohalides are the (hetero)arylating reagents require the use of the heteroarenes both as substrates and as solvents and therefore in a very large molar excess with respect to the (hetero)arylating reagents and, unfortunately, in the experimental procedures of these reactions the recovery and recycling of these reagents has been almost never described.

In addition, there are still several unsolved challenges and, among these, the development of general methods for the synthesis of highly functionalized (hetero)aryl-substituted heteroarenes through chemoselective and highly-regioselective transition metal-free direct (hetero)arylation reactions of both electron-rich and electrondeficient heteroarene derivatives with multihalogen substituted (hetero)arene reagents is particularly worthy of mention.

Finally, it deserves also to be noted that for many protocols outlined in this review it has not been established whether the described (hetero)arylation reactions are truly transition metal-free or whether traces of transition metal present in the reactants, bases and/or solvents play a decisive role on the progress of the reactions. ${ }^{[99]}$ This applies in particular for the arylations in which organometallic compounds are used as reaction components.

Nevertheless, it is our belief that in the near future the current pursuit of sustainable chemistry and the potential applications of the transition metal-free direct (hetero)arylation reactions of heteroarenes in pharmaceutical industry can promote studies to significantly improve the scope, regioselectivity and efficiency of these reactions and thoroughly investigate their mechanism.
Renzo Rossi was born in Pisa (Italy) and graduated in Organic Chemistry with first-class honours at the University of Pisa defending a thesis performed under the guidance of Professor Piero Pino. In 1969 he became Assistant Professor and in 1971 he earned the libera docenza in Organic Chemistry. After holding other intermediate positions at the University of Pisa and the Scuola Normale Superiore of Pisa, in 1980 he became Full Professor of Organic Chemistry at the University of Calabria. In 1982, he again joined the University of Pisa where he has held the Chair of Chemistry of Naturally Occurring Compounds. In 1999, the University of Pisa awarded him the Ordine del Cherubino. His current research interests include: i) new catalytic methods for the synthesis of oxygen-containing heterocycles; ii) the preparation of substances which exhibit significant cytotoxicity against human tumor cell lines and antivascular properties; iii) the study of new methodologies for carbon-carbon bond formation that involve the use of organometallic reagents; iv) palladium-catalyzed cross-coupling reactions; v) transition metal-catalyzed direct arylation reactions of substrates with activated $\mathrm{sp}^{3}$-hybridized $\mathrm{C}-\mathrm{H}$ bonds with aryl halides and pseudohalides; vi) the design, development and applications of new, highly chemoand regioselective methods for the transition metalcatalyzed direct $\mathrm{C}$ - and $\mathrm{N}$-arylation reactions of electronrich heteroaromatic systems, including free (NH)-azoles, with aryl halides and pseudohalides, and their application in the synthesis of bioactive natural and unnatural compounds. In recent years, several successful studies have also been performed by his research group in the field of the synthesis and evaluation of the biological properties of insect sex pheromone components, insecticidal carboxyamides, natural phototoxins, and naturally-occurring compounds of marine origin and their structural analogues which are characterized by the $2(5 H)$-furanone ring. Professor Rossi, who has coauthored over 235 research publications and a number of highly cited review articles and patents, is a fellow of the Royal Society of Chemistry and the American Chemical Society. He is a reviewer for several international journals dealing with synthetic organic chemistry and organometallics.

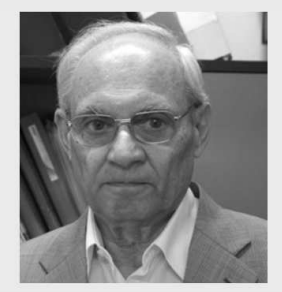

Marco Lessi was born in Livorno (Italy) in 1979. He studied Chemistry at the University of Pisa and received his Laurea Degree with first-class honours in June 2004 defending a thesis performed under the guidance of Professor Dario Pini. In January 2005, he began his PhD fellowship in the laboratory of Professor Pini and received his $\mathrm{PhD}$ degree in 2008, submitting a thesis on the preparation and applications of new insoluble polymer-bound (IPB) enantioselective catalytic systems. The studies were focused on the synthesis of transition 
metal complexes obtained from bisoxazoline and BINOL ligands. In the period January 2008-March 2009, Dr. Lessi worked for Solvay Solexis S.p.A. on the development of new routes for the preparation of highfluorinated low-molecular-weight molecules and oligomers. In March 2009, he re-joined the University of Pisa where he currently cooperates with Professor Bellina. The current research interests of Dr. Lessi involve the development of novel and efficient protocols for highly selective transition metal-catalyzed direct $\mathrm{C}\left(\mathrm{sp}^{3}\right)-\mathrm{H}$ and $\quad \mathrm{C}\left(\mathrm{sp}^{2}\right)-\mathrm{H} \quad$ arylation reactions, and the discovery of new synthetic routes and applications of functionalized ionic liquids obtained from naturally-occurring building blocks.

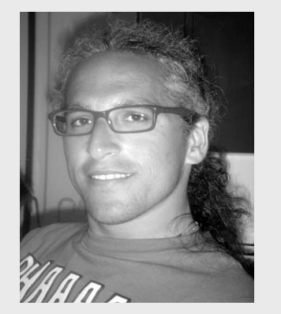

Chiara Manzini was born in Lucca (Italy) in 1986 and graduated in Chemistry with first-class honours at the University of Pisa in 2011. Currently she holds a position as $\mathrm{PhD}$ student at the Department of Chemistry and Industrial Chemistry of the University of Pisa under the guidance of Professor Fabio Bellina. She is currently working on the development and application of new protocols for the selective arylation of $\mathrm{N}$-containing heteroaromatics.

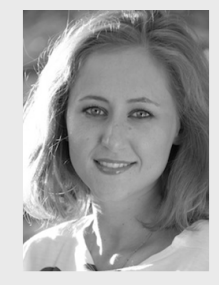

Giulia Marianetti was born in Lucca (Italy) in 1988 and graduated in Organic Chemistry with first-class honours at the University of Pisa in 2013. She currently holds a $\mathrm{PhD}$ scholarship at the Scuola Normale Superiore of Pisa under the supervision of Prof. Fabio Bellina and Prof. Vincenzo Barone. She is currently working on the synthesis and the computational studies of new organic fluorophores.

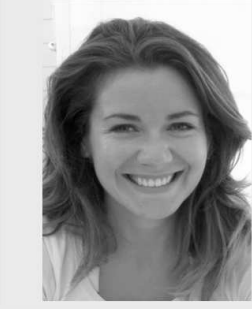

Fabio Bellina was born in Catania (Italy) in 1964. He studied Chemistry at the University of Pisa and received his Laurea Degree with first-class honours in 1990. In 1992, he joined the University of Pisa as an Organic Chemistry Researcher in the Department of Chemistry and Industrial Chemistry. In October 2003, he was appointed by the Faculty of Science of the University of Pisa as an Associate Professor of Organic Chemistry. His research interests were initially mainly devoted to the total synthesis of naturally occurring compounds of biological and/or pharmacological interest and to the synthesis of structural analogues of naturally occurring fungicidal derivatives of agrochemical interest. More recently, Prof. Bellina focused his attention on new and efficient protocols for regioselective transition metalmediated carbon-carbon and carbon-heteroatom bond forming reactions, with a particular interest in the selective functionalization of oxygen-containing unsaturated heterocycles such as $2(5 H)$-furanones and $2(2 H)$-pyranones. Currently, he is working on the development of novel and efficient protocols for the transition metal-catalyzed direct $\mathrm{C}-\mathrm{H}$ and $\mathrm{N}-\mathrm{H}$ bond arylation of heteroarenes, the direct functionalization of active $\mathrm{C}\left(\mathrm{sp}^{3}\right)-\mathrm{H}$ bonds, the alkynylation of (hetero)aromatic scaffolds, and on the application of

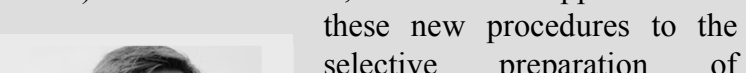
selective preparation of bioactive natural and synthetic compounds and to new organic chromophores.

\section{References}

[1] For representative examples, see: a) H. Zelová, Z. Hanáková, Z. Cermáková, K. Smejkal, S. Dall'Acqua, P. Babula, J. Cvacka, J. Hosek, J. Nat. Prod. 2014, 77, 1297-1303; b) L. C. Patiño C.; C. Muniain, M. E. Knott, L. Puricelli, J. A. Palermo, J. Nat. Prod. 2014, 77, 1170-1178; c) H. Kim, I. Yang, A. S. Patil, S. Kang, J. Lee, H. Choi, M.-S. Kim, S.-J. Nam, H. Kang, J. Nat. Prod. 2014, 77, 2716-2719; d) X. Zhou, H. Huang, Y. Chen, J. Tan, Y. Song, J. Zou, X. Tian, Y. Hua, J. Ju, J. Nat. Prod. 2012, 75, 2251-2255; e) A. Herrmann, H. Hedman, J. Rosén, D. Jansson, B. Haraldsson, K.-E. Hellenäs, J. Nat. Prod. 2012, 75, 1690-1696; f) P. Fu, S. Wang, K. Hong, X. Li, P. Liu, Y. Wang, W. Zhu, J. Nat. Prod. 2011, 74, 1751-1756; g) J. J. Mason, J. Bergman, T. Janosik, J. Nat. Prod. 2008, 71, 1447-1450.

[2] For representative recent examples, see: a) C.-S. Jiang, Y. Fu, L. Zhang, J.-X. Gong, Z.-Z. Wang, W. Xiao, H.-Y. Zhang, Y.-W. Guo, Bioorg. Med. Chem. Lett. 2015, 25, 216-220; b) P. Alper, M. Azimioara, C. Cow, D. Mutnick, V. Nikulin, P.-Y. Michellys, Z. Wang, E. Reding, M. Paliotti, J. Li, D. Bao, J. Zoll, Y. Kim, M. Zimmerman, T. Groessel, T. Tuntland, S. B. Joseph, P. McNamara, H. M. Sedel, R. Epple, Bioorg. Med. Chem. Lett. 2014, 24, 2383-2387; c) C. Sakata, T. Kawasaki, Y. Kato, M. Abe, K.-i. Suzuki, M. Ohmiya, T. Funatsu, Y. Morita, M. Okadi, Thromb. Res. 2013, 132, 56-62; d) W. Sinko, Y. Wang, W. Zhu; Y. Zhang, F. Feixas, C. L. Cox, D. A. 
Mitchell, E. Oldfield, J. A. Mc Cammon, J. Med. Chem. 2014, 57, 5693-5701; e) A. Aguilar, H. Zhou, J. Chen, L. Liu, L. Bai, D. Mc Eachern, C. Y. Yang, J. Meagher, J. Stuckey, S. Wang, J. Med. Chem. 2013, 56, 3048-3067; f) G. D. Reddy, S.-J. Park, H. M. Cho, T.-J. Kim, M. E. Lee, J. Med. Chem. 2012, $55,6438-6444$.

[3] a) M. M. Rahman, G. Liu, K. Furuta, F. Ozoe, Y. Ozoe, J. Pest. Sci. 2014, 39, 133-143; b) V. V. Dabholkar, V. Vijay, N. Shinde, A. Karekar, P. Naik, Heterocycl. Lett. 2013, 3, 525-531; c) M. Gaur, M. Goel, L. Sridhar, T. D. S. Ashok, S. Prabhakar, P. Dureja, P. Raghiathan, S. V. Eswaran, Monatsh. Chem. 2012, 143, 283-288; d) G. P. Lahm, D. Cordova, J. D. Barry, Bioorg. Med. Chem. 2009, 17, 4127-4133; e) Modern Crop Protection Compounds (Eds.; W. Kramer, U. Schirmer), Wiley-VCH, Weinheim, 2007; f) X.-R. Liu, H. Wu, Z.-Y. He, Z.Q. Ma, J.-T. Feng, X. Zhang, Molecules 2014, 19, 14036-14051; g) Y. Xie, H.-W. Chi, A.-Y. Guan, C.L. Liu, H.-J. Ma, D.-L. Cui, J. Agric. Food Chem. 2014, 62, 12491-12496.

[4] For examples, see: a) S. M. Park, Y. Yoon, C. W. Jeon, H. Kim, M. J. Ko, D.-K. Lee, J. Y. Kim, H. J. Son, S.-K. Kwon, Y.-H. Kim, A. S. Kim, J. Polym. Sci. A 2014, 52, 796-803; b) J. Huang, B. Xiao, J. Wang, Y. Wang, X. Peng, X. Miao, Q. Pan, Y. Mo, W. Deng, H. Wu, Y. Cao, Org. Electron. 2014, 15, 2311-2321; c) C. Y. K. Chan, J. W. Y. Lam, C. K. W. Jim, H. H. Y. Sung, J. D.; Williams, B. Z. Tang, Macromolecules 2013, 46, 2494-9506; d) Y. J. Kim, Y.-J. Lee, J.-W. Jang, H. Cha, Y.-H. Kim, S.-K. Kwon, C. E. Park, J. Polym. Sci. A 2013, 51, 47424751; e) Y. Zhang, J. Zou, H.-L. Yip, K.-S. Chen, J. A. Davies, Y. Sun, A. K.-Y. Jen, Macromolecules 2011, 44, 4752-4758; f) W. Elsawy, H. Kang, K. Yu, E. Elbarbary, K. Lee, J.-S. Lee, J. Polym. Sci. A 2010, 52, 2926-2933; g) A. Kira, Y. Shibano, S. Kang, H. Hayashi, T. Umeyama, Y. Matano, H. Imahori, Chem. Lett. 2010, 39, 448-450; h) E. Zhou, L. Yang, S. Liu, W. You, Macromolecules 2010, 43, 1039010396.

[5] For recent reviews on this topic, see: a) K. Manabe, M. Yamaguchi, Catalyst 2014, 4, 307-320; b) J. Koubachi, S. El Kazzouli, M. Bousmina, G. Guillaumet, Eur. J. Org. Chem. 2014, 5119-5138; c) A. R. Kapdi, D. Prajapati, RSC Adv. 2014, 4, 4124541259; d) N. I. Nikishkin, J. Huskens, W. Verboom, Org. Biomol. Chem. 2013, 11, 3583-3602; e) M. J. Mpashahlele, L. G. Lesenyeho, J. Heterocyclic Chem. 2013, 50, 1-16; f) T. J. Delia, J. Heterocyclic Chem. 2013, 50, 735-745; g) R. Rossi, F. Bellina, M. Lessi, Adv. Synth. Catal. 2012, 354, 1181-1255; h) L.-C. Campeau, K. Fagnou, Chem. Soc. Rev. 2007, 36, 1058-1068.

[6] For reviews on this topic, see. a) R. Rossi, F. Bellina, M. Lessi, C. Manzini, L. A. Perego, Synthesis 2014, 46, 2833-2883; b) L. Djakovitch, F.-
X. Felpin, ChemCatChem 2014, 6, 2175-2187; c) R. Rossi, F. Bellina, M. Lessi, C. Manzini, Adv. Synth. Catal. 2014, 356, 17-117; d) A. Lei, H. Zhang, RSC Catalysis Series 2013, 11, 310-327; e) S. Kowalski, S. Allard, Z. Zilberberg, T. Riedl, U. Scherf, Progr. Polym. Sci. 2013, 38, 1805-1814; f) A. Sharma, D. Vacchani, E. Van der Eycken,Chem. Eur. J. 2013, 19, 1158-1168; g) F. Shibahara, T. Murai, Asian J. Org. Chem. 2013, 2, 624-636; h) P. B. Arockiam, C. Bruneau, P. H. Dixneuf, Chem. Rev. 2012, 112, 5879-5918; i) L. Ackermann, A. R. Kapdi, H. K. Potuchi, S. I. Kozhushkov in Handbook of Green Chemistry, Wiley-VCH, Weinheim, Germany, 2012, 7, 259-305; j) Y.-X. Su, L. P. Sun, Mini Rev. Org. Chem. 2012, 9, 87-117; k) M. Livendáhl, A. M. Echavarren, Isr. J. Chem. 2010, 50, 630-651; 1) J. Roger, A. L. Gottumukkala, H. Doucet, ChemCatChem 2010, 2, 20-40; m) O. Daugulis, Top. Curr. Chem. 2010, 292, 57-84; n) F. Bellina, R. Rossi, Tetrahedron 2009, 65, 10269-10310; o) L. Ackermann, R. Vicente, A. R. Kapdi, Angew. Chem. Int. Ed. 2009, 48, 9792-9826; p) F. Bellina, S. Cauteruccio, R. Rossi, Curr. Org. Chem. 2008, 12, 774-790; q) I. J. S. Fairlamb, Chem. Soc. Rev. 2007, 36, 1036-1045; q) T. Satoh, M. Miura, Chem. Lett. 2007, 36, 1173-1193; r) I. V. Seregin, V. Gevorgyan, Chem. Soc. Rev. 2007, 36, 1173-1193; s) D. Alberico, M. E. Scott, M. Lautens, Chem. Rev. 2007, 107, 174-238; t) L.-C. Campeau, R. Stuart, K. Fagnou, Aldrichim. Acta 2007, 40, 35-41.

[7] For recent references on this topic, see: a) A. Suresh, S., Mathusubramian, R. S. Kumaran, G. Manickam, Asian J. Org. Chem. 2014, 3, 604-608; b) F. Chen, N. W. Y. Wong, P. Forgione, Adv. Synth. Catal. 2014, 356, 1725-1730; c) X. Li, D. Zou, F. Leng, C. Sun, J. Li, Y. Wu, Y. Wu, Chem. Commun. 2013, 49, 312314; d) A. Carrër, J.-D. Brion, S. Messaoudi, M. Alami, Adv. Synth. Catal. 2013, 355, 2044-2054; e) S. Messaoudi, J.-D. Brion, M. Alami, Org. Lett. 2012, 14, 1496-1499; f) N. Nandi, Y.-M. Jhou, J.-Y. Lee, B.-C. Kuo, C.-Y. Liu, R.-W. Huang, H. M. Lee, J. Org. Chem. 2012, 77, 9384-9390; g) R. Shang, L. Liu, Science China 2011, 54, 1670-1687; h) F. Zhang, M. F. Greaney, Org. Lett. 2010, 12, 47454747.

[8] For leading references on this topic, see. a) Y. Shang, X. Jie, H. Zhao, W. Su, Org. Lett. 2014, 16, 416419; b) W. Liu, X. Yu, Y. Li, C. Kuang, Chem. Commun. 2014, 50, 9291-9294; c) S.-W. Yang, Y.-X. Su, L.-P. Sun, Tetrahedron 2014, 70, 3730-3734; d) N. J. Willis, J. M. Smith, RSC Adv. 2014, 4, 1105911063; e) R. Odani, K. Hirano, T. satoh, M. Miura, $J$. Org. Chem. 2013, 78, 11045-11052; f) S. Fan, Z. Chen, X. Zhang, Org. Lett. 2012, 14, 4950-4953; g) X. Qin, B. Feng, J. Dong, X. Li, Y. Xue, J. Lan, J. You, J. Org. Chem. 2012, 77, 7677-7783; h) C.-Y. He, Q.-Q. Min, X. Zhang, Organometallics 2012, 31, 1335-1340; i) X. Bugaut, F. Glorius, Angew. Chem. Int. Ed. 2011, 50, 7479-7481; j) C. S. Yeung, V. M. 
Dong, Chem. Rev. 2011, 111, 1215-1292; k) K. Hirano, M. Miura, Chem. Commun. 2012, 48, 10704-10714.

[9] For examples of removal of Pd from the reaction products, see: a J. M. French, J. R. Griffiths, S. T. Diver, Adv. Synth. Catal. 2015, 357, 361-365; b) J. Recho, R. J. G. Black, C. North, J. E. Ward, R. D. Wilkes, Org. Process Res. Dev. 2014, 18, 6726-635; c) J.-P. Huang, X.-X. Chen, S.-X. Gu, L. Zhao,, W.X. Chen, F.-E. Chen, Org. Process Res. Dev. 2010, 14, 939-941; d) K. M. Bullock, M. B. Mitchell, J. F. Toczko, Org. Process Res. Dev. 2008, 12, 896-899; e) C. J. Pink, H.-t. Wong, F. C. Ferreira, A. G. Livingston, Org. Process Res. Dev. 2008, 12, 589595; f) N. Galaffu, S. P. Man, R. D. Wilkes, J. R. H. Wilson, Org. Process Res. Dev. 2007, 11, 406-413.

[10] For typical examples of such methodology, see: a) M. E. Budén, J. F. Guastavino, R. A. Rossi, Org. Lett. 2013, 15, 1174-1177; b) M. Tobisu, T. Furukawa, N. Chatani, Chem. Lett. 2013, 42, 1203-1205; c) J. M. O'Connell, E. Mararty, F. Aldabbagh, Synthesis 2012, 44, 3371-3377; d) A. M. Lisenmeier, C. M. Williams, S. Bräse, J. Org. Chem. 2011, 76, 91279132; e) S. A. Rodríguez, M. T. Baumgartner, Tetrahedron Lett. 2010, 51, 5322-5324; f) V. Nair, D. A. Young, J. Org. Chem. 1984, 49, 4340-4344.

[11] S. Yanagisawa, K. Ueda, T. Taniguchi, K. Itami, Org. Lett. 2008, 10, 4673-4676.

[12] a) R. A. D. Arancon, C. S. K. Lin, C. Vargas, R. Luque, Org. Biomol. Chem. 2014, 12, 10-35; b) V. P. Mehta, P. Punji, RSC Adv. 2013, 3, 11957-11986; c) S. Roscales, A. G. Csáky, Chem. Soc. Rev. 2014, 43, 8215-8225; d) C.-L. Sun, Z.-J. Shi, Chem. Rev. 2014 114, 9219-9280; e) A. B. Bhunia, S. R. Yetra, Chem. Soc. Rev. 2012, 41, 3140-3152; f) E. Shirakawa, T. Hayashi, Chem. Lett. 2012, 41, 130-134; g) S. Yanagisawa, K. Itami, ChemCatChem 2011, 3, 827829; h) I. P. Beletskaya, A. V. Cheprakov, Coll. Czech. Chem. Commun. 2003, 68, 1904-1913.

[13] For leading references on this topic, see: a) Ref. 12d; b) Q. Chen, T. Leon, P. Knochel, Angew. Chem. Int. Ed. 2014, 53, 8746-8750; c) J. Xu, L.-D. Shao, D. Li, X. Deng, Y.-C. Liu, Q.-S. Zhao, C. Xia, J. Am. Chem. Soc. 2014, 136, 17962-17965; d) Ref. 12b; e) X. Chen, X. Cui, F. Yang, Y. Wu, Org. Lett. 2015, 17, 1445-1448; f) D. Beukeaw, K. Udomsasporn, S. Yotphan, J. Org. Chem. 2015, 80, 3447-3454.

[14] a) D. Crich, M. Patel, Tetrahedron 2006, 62, 7824 7837; b) D. C. Harrowven, B. J. Sutton, S. Coulton, Org. Biomol. Chem. 2003, 1, 4047-4057; c) D. Crich, M. Patel, Heterocycles 2004, 64, 499-504.

[15] M. Li, P. Hua, Tetrahedron Lett. 2009, 50, 1478 1481.

[16] C. Liu, W. Yang, Chem. Commun. 2009, 62676269.
[17] Q. Song, D. Zhang, Q. Zhu, Y. Xu, Org. Lett. 2014, 16, 5272-5274.

[18] J. Cuthbertson, V. J. Gray, D. Wilden, Chem. Commun. 2014, 50, 2575-2578.

[19] T. Truong, O. Daugulis, J. Am. Chem. Soc. 2011, 133, 4243-4245.

[20] B, Liegault, D. Lapointe, L. Caron, A. Vlassova, K. Fagnou, J. Org. Chem. 2009, 74, 1826-1834.

[21] J. Roger, H. Doucet, Adv. Synth. Catal. 2009, 351, 1977-1990.

[22] a) G.-Y. J. Im, S. M. Bronner, A. E. Goetz, R. S. Paton, P. H.-Y. Cheong, K. N. Houk, N. K. Gary, J. Am. Chem. Soc. 2010, 132, 17933-17944; b) P. M. Tadross, C. D. Gilmore, P. Bugga, S. C. Virgil, B. M. Stoltz, Org. Lett. 2010, 12, 1224-1227; c) R. Huisgen, J. Sauer, Angew. Chem. Int. Ed. 1960, 72, 91-108.

[23] O. Vakuliuk, B. Koszarna, D. T. Gryko, Adv. Synth. Catal. 2011, 353, 925-930.

[24] O. Vakuliuk, B. Koszarna, D. T. Gryko, Synthesis 2011, 76, 471-483.

[25] O. Vakuliuk, D. T. Gryko, Eur. J. Org. Chem. 2011, 2854-2859.

[26] E. T. Nadres, A. Lazareva, O. Daugulis, J. Org. Chem. 2011, 76, 471-483.

[27] a) Ref. 20; b) L. Chen, C. Bruneau, P. H. Dixneuf, H. Doucet, Chem CatChem 2013, 5, 1956-1963; c) C. B. Bheeter, J. K. Bera, H. Doucet, Tetrahedron Lett. 2012, 53, 509-513.

[28] a) C.-H Park, V. Ryabova, I. V. Seregin, A. W. Sromeck, V. Gevorgyan, Org. Lett. 2004, 6, 11591162 ; b) B. Liu, Z. Wang, N. Wu, M. Li, J. You, J. Lan, Chem. Eur. J. 2012, 18, 1599-1603.

[29] a) Yu. L. Frolov, I. V. Guchik, V. A. Shagun, A. V. Vashchenko, J. Struct. Chem. 2005, 46, 979-984; b) Yu. L. Frolov, I. V. Guchik, V. A. Shagun, A. V. Vashchenko, B. A. Trofimov, J. Struct. Chem. 2003, 44, 977-931.

[30] a) L. Filippini, M. Gusmeroli, A. Riva, Tetrahedron Lett. 1992, 33, 1755-1758; b) R. D. Roeth, N. P. Mankad, E. Calimano, J. P. Sadighi, Org. Lett. 2004, 6, 3981-3983.

[31] F. Jafarpour, S. Rahiminejadan, H. Hazrati, J. Org. Chem. 2010, 75, 3109-3112.

[32] C. B. Bheeter, J. K. Bera, H. Doucet, Tetrahedron Lett. 2012, 53, 509-513.

[33] T. Truong, M. Mesgar, K. K. A. Le, C. Daugulis, J. Am. Chem. Soc. 2014, 136, 8568-8576.

[34] a) A. Ohta, Y. Akita, T. Ohkuwa, M. Chiba, R. Gukunaga, A. Miyafuji, T. Nakata, N. Tani, Y. Aoyagi, Heterocycles 1990, 31, 1951-1958; b) T. 
Dao-Huy, M. Haider, F, Glatz, M. Schnürch, M. D. Mihovilovic, Eur. J. Org. Chem. 2014, 8119-8125.

[35] L. Loukotova, K. Yuan, H. Doucet, Chem CatChem 2014, 6, 1303-1309.

[36] For reviews on the transition metal catalyzed $\beta$ arylation reactions of (benzo)thiophenes, see: a) $\mathrm{K}$. Yuan, H. Doucet, ChemCatChem 2013, 5, 34953496 ; b) J. Roger, A. L. Gottumukkala, H. Doucet, Chem CatChem 2010, 2, 20-40.

[37] For representative examples, see: a) B. B. Touré, B. S. Lane, D. Sames, Org. Lett. 2006, 8, 1979-1982; b) I. Özdemir, Y. Gök, Ö. Özeroglu, M. Kaloglu, H. Doucet, C. Bruneau, Eur. J. Inorg. Chem. 2010, 1798-1805; c) S. Demir, I. Özdemir, H. Arslan, D. VanDerveer, J. Organomet. Chem. 2011, 696, 25892593; d) H. Tao, W. Min, L. Pinhwa, W. Lei, Chin. J. Chem. 2012, 30, 979-984; e) A. R. Martin, A. Chartoire, A. M. Z. Slawin, S. P. Nolan, Beilstein J. Org. Chem. 2012, 8, 1637-1643; f) I. Özdemir, N. Gürbüz, N. Kaloglu, Ö. Dogan, M. Kaloglu, C. Bruneau, H. Doucet, Beilstein J. Org. Chem. 2013, 9, 303-312; g) A. Mariconda, F. Grisi, C. Costabile, S. Falcone, V. Bertolasi, P. Longo, New. J. Chem. 2014, $38,762-769$; h) J. C. Bernhammer, H. V. Huynh, Organometallics 2014, 33, 1266-1275; i) S. Akkoc, Y. Gök, M. Akkurt, M. N. Tahir, Inorg. Chim. Acta 2014, 413, 221-230; j) X.-B. Shen, Y. Zhang, W.-X. Chen, Z.-K. Xiao, T.-T. Hu, L.-X. Shao, Org. Lett. 2014, 16, 1984-1987; k) Z.-S. Gu, W.-X. Chen, L.-X. Shao, J. Org. Chem. 2014, 79, 5806-5811; 1)_S. Guo, H. V. Huynh, Organometallics 2014, 33, 2004-2011; m) S. Akkoc, Y. Gök, Appl. Organomet. Chem. 2014, $28,854-860$.

[38] W.-C. Chen, Y.-C. Hsu, W.-C. Shih, C.-Y. Lee, W.-H. Chuang, Y.-F. Tsai, P.P-Y. Chen, T.-G. Ong, Chem. Commun. 2012, 48, 6702-6704.

[39] A. Studer, D. P. Curran, Angew. Chem. Int. Ed. 2011, 50, 5018-5022.

[40] E. Shirakawa, K. Itoh, T. Higashino, T. Hayashi, $J$. Am. Chem. Soc. 2010, 132, 15537-15539.

[41] B. S. Bhakuni, A. Yadav, S. Kumar, S. Kumar, New. J. Chem. 2014, 348, 827-836.

[42] A. Dewanji, S. Murarka, D. P. Curran, A. Studer, Org. Lett. 2013, 15, 6102-6105.

[43] a) P. Shkla, N. K. Yadav, P. Singh, F. W. Bansode, R. K. Singh, Int. J. Basic Appl. Sci. 2012, 2, 86-91; b) J. Berger, J. Appl. Biomed. 2007, 5, 125-130.

[44] For reviews on this topic, see: a) N. R. Deprez, M. S. Sanford, Inorg. Chem. 2007, 46, 1924-1935; b) E. A. Merritt, B. Olofsson, Angew. Chem. Int. Ed. 2009, 48, 905-9070; c) M. S. Yusubov, A. V. Maskaev, V. V. Zhdankin, ARKIVOC 2011, 370-409; d) S. Rousseaux, E. Vrancken, J.-M. Campagne, Angew. Chem. Int. Ed. 2012, 51, 10934-10935; e) M. S.
Yusubov, D. Yu. Svitich, M. S. Larkina, V. V. Zhdankin, ARKIVOC 2013, 364-395; f) Ref. 6a.

[45] a) Y. Kita, K. Morimoto, M. Ito, C. Ogawa, A. Goto, T. Dohi, J. Am. Chem. Soc. 2009, 131, 16681669; b) K. Morimoto, N. Yamaoka, C. Ogawa, T. Nakae, H. Fujioka, T. Dohi, Y. Kita, Org. Lett. 2010, 12, 3804-3807.

[46] L. Ackermann, M. Dell'Acqua, S. Fenner, R. Vicente, R. Sandmann, Org. Lett. 2011, 13, 23582360 .

[47] S. Lakhdar, M. Westmaier, F. Ferrier, R. Gaumont, T. Boubaker, A. R. Ofial, H. Mayr, J. Org. Chem. 2006, 71, 9088-9095.

[48] (a) F. Bellina, F. Benelli, R. Rossi, J. Org. Chem. 2008, 73, 5529-5535; b) E. David, J. Lejeune, S. Pellet-Rostaing, J. Schulz, M. Lemaire, J. Chauvin, A. Deronzier, Tetrahedron Lett. 2008, 49, 18601864; c) Z. Zhang, Z. Hu, Z. Yu, P. Lei, H. Chi, Y. Wang, R. He, Tetrahedron Lett. 2007, 48, 24152419; d) G. Cusati, L. Djakovitch, Tetrahedron Lett. 2008, 49, 2499-2502; e) B. S. Lane, M. A. Brown, D. Sames, J. Am. Chem. Soc. 2005, 127, 8050-8057; f) J. Cornells, P. Lu, I. Larrosa, Org. Lett. 2009, 11, 5506-5509; g) J. Zhou, P. Hu, M. Zhang, S. Huang, M. Wang, W. Su, Chem. Eur. J. 2010, 16, 58765881; h) S. Chen, Y. Liao, Z. Zhao, H. Qi, S. Liu, G.-J. Deng.

[49] A. M. Wagner, M. S. Sanford, Org. Lett. 2011, 13, 288-291.

[50] Y. Zhu, M. Bauer, J. Ploog, L. Ackermann, Chem. Eur. J. 2014, 20, 13099-13102.

[51] J. wen, R.-Y. Zhang, S.-Y. Chen, J. Zhang, X.-Q. Yu, J. Org. Chem. 2012, 77, 766-771.

[52] a) F. M. Beringer, R. A. Falk, M. Karniol, I. Lillien, G. Masullo, M. Mausner, E. Sommer, J. Am. Chem. Soc. 1990, 81, 342-351; b) J. J. Lubinowski, C. G. Arrieche, W. E. McEwen, J. Org. Chem. 1980, 45, 2076-2079; c) J. L. Dektar, N. P. Hacker, J. Org. Chem. 1990, 55, 639-647; d) D. Chen, K. Takai, M. Ochiai, Tetrahedron Lett.. 1997, 38, 8211-8214.

[53] a) K. J. Reszka, C. F. Chignell, Chem.-Biol. Interact. 1995, 96, 223-234: b) U. Costas-Costas, E. Gonzalez-Romero, C. Bravo-Diaz, Helv. Chim. Acta. 2001, 84, 632-648.

[54] F. P. Crisóstomo, T. Martin, R. Carrillo, Angew. Chem. Int. ed. 2014, 53, 2181-2185.

[55] For further examples diazotization of anilines with $t$-butyl nitrite in organic solvents, see: a) M. P. Doyle, B. Siegfried, J. F. Dellaria Jr. J. Org. Chem. 1977, 42, 2428-2431; b) F. Ek, O. Axelsson, L.-G. Wistrand, T. Frejd, J. Org. Chem. 2002, 67, 6736-6381; c) X.-F. Wu, H. Neumann, M. Beller, Chem. Commun. 2011, 47, 7959-7961; d) F. Le Callonnec, E. Fouquet, F.-X. Felpin, Org. Lett. 2011, 13, 2646-2649; e) R. 
Joncour, N. Susperregui, N. Pinaud, K. Miqueu, E. Fouquet, J.-M. Sotiropoulos, F.-X. Felpin, Chem. Eur. J. 2013, 19, 9291-9296; f) C. Matheis, K. Jouvin, L. J. Goossen, Org. Lett. 2014, 16, 5984 5987.

[56] N. O. Obushak, A. I. Lesyuk, Yu: I. Gorak, V. S. Matiichuk, Russ. J. Org. Chem. 2009, 45, 1375-1381.

[57] S. E. Vaillard, A. Studer in Encyclopedia of Radicals in Chemistry, Biology and Materials (Eds.: C. Chatgilialoglu, A. Studer), Wiley-VCH, 2012, pp. 1059-1095.

[58] A. Ward, M. O. Chaffman, E. M. Sorkin, Drugs 1986, 32, 130-168.

[59] C. I. N'Da, A. Petzer, J. P. Petzer, Drug Res. (Stuttg) 2015, 65, 46-51.

[60] Y. Li, W. Liu, C. Kuang, Chem. Commun. 2014, 50, 7124-7127.

[61] a) E. M. Kosower, P.-K. C. Huang, T. Tsuji, J. Am. Chem. Soc. 1969, 91, 2325-2329; b) A. G. Myers, M. Movassaghi, B. Zheng, Tetrahedron Lett. 1997, 38, 6569-6572; c) J. Hofmann, H. Jasch, M. R. Heinrich, J. Org. Chem. 2014, 79, 2314-2320.

[62] a) T. Jiang, S.-Y. Chen, H. Zhuang, R.-S. Zeng, J.P. Zou, Tetrahedron Lett. 2014, 55, 4549-4552; b) J. Hofmann, H. Jasch, M. R. Heinrich, J. Org. Chem. 2014, 79, 2314-2320, and references cited therein.

[63] For examples of radical arylation reactions with arylhydrazines, see: a) T. Jiang, S.-Y . Chen, G.-Y. Zhang, R.-S. Zeng, J.-P. Zou, Org. Biomol. Chem. 2014, 12, 6922-6926; b) Ref. 61c; c) Ref. 62a; d) A. A. S. Briquet, H.-J. Hansen, Helv. Chim. Acta 1994, 77, 1577-1584.

[64] For representative examples, see: a) S. J. Hays, M. J. Rice, D. F. Ortwine, G. Johnson, R. D. Schwarz, D. K. Boyd, L. F. Copeland, M. G. Vartanian, P. A. Boxer, J. Pharm. Sci. 1994, 83, 1425-1432; b) I. Hutchinson, M. S. Chua, H. L. Browne, V. Trapani, T. D. Bradshaw, A. D. Westwell, J. Med. Chem. 2001, 44, 1446-1449; c) H. M. Wang, M. Gao, B. Mock, K. Miller, G. Sledge, G. Hutchins, Q. Zheng, Bioorg. Med. Chem. 2006, 14, 8599-8607; d) K. Serdons, T. Verduyckt, D. Vanderghinste, J. Cleynhens, P. Borghgraef, P. Vermaelen, C. Terwinghe, F, Van Leuven, K. Van Laere, H. Kung, G. Bormans, A. Verbruggen, Bioorg. Med. Chem. Lett. 2009, 19, 602-605; e) S. Gupta, N. Moorthi, U. Sanyal, Ind. J. Pharmacy Pharm. Sci. 2010, 2, 57-62.

[65] a) J. Huang, J. Chan, Y. Chen, J. Borths, K. D. Baucom, R. D. Larsen, M. M. Faul, J. Am. Chem. Soc. 2010, 132, 3674-3675; b) H. A. Chiong, O. Daugulis, Org. Lett. 2007, 9, 1449-1451; c) W. P. Gallagher, R. E. Malecza Jr. J. Org. Chem. 2003, 68, 6775-6779.
[66] a) S. Kirchberg, S. Tani, K. Ueda, J. Yamaguchi, A. Studer, K. Itami, Angew. Chem. Int. Ed. 2011, 50, 2387-2391; b) S. Ranjit, X. Liu, Chem. Eur. J. 2011, 17, 1105-1108; c) B. Liu, X. Qin, K. Li, X. Li, Q. Guo, J. Lan, J. You, Chem. Eur. J. 2010, 16, 1183611839.

[67] T. Yamamoto, K. Muto, M. Koniyama, J. Canivet, J. Yamaguchi, K. Itami, Chem. Eur. J. 2011, 17, 10113-10122.

[68] H. Hachiya, K. Hirano, T. Satoh, M. Miura, Angew. Chem. Int. Ed. 2010, 49, 2202-2205.

[69] S. Liu, R. Chen, X. Guo, H. Yang, G. Deng, C. J. Li, Green Chem. 2012, 14, 1577-1580.

[70] Q. Shuai, L. Yang, X. Guo, O. Baslé, C.-J. Li, J. Am. Chem. Soc. 2010, 132, 12212-12213.

[71] Y. Gao, Q. Song, G. Cheng, X. Cui, Org. Biomol. Chem. 2014, 12, 1044-1047.

[72] R. S. Sánchez, F. A. Zhuravlev, J. Am. Chem. Soc. 2007, 129, 5824-5825.

[73] Y.-X.Chen, L.-F. Qian, W. Zhang, B. Han, Angew. Chem. Int. Ed. 2008, 47, 9330-9333.

[74] Z. Liu,, J. Zhang, S. Chen, E. Shi, Y. Xu, X. Wan, Angew. Chem. Int. Ed. 2012, 51, 3231-3235.

[75] For representative examples, see: a) J. Zhao, Y. Zhang, K. Cheng, J. Org. Chem. 2008, 73, 74287431; b) S.-D. Yang, C.-L. Sun, Z. Fang, B.-J. Li, Y.-Z. Li, Z.-J. Shi, Angew. Chem. Int. ed. 2008, 47, 1473-1476; c) M. Tobisu, I. Hyodo, N. Chatani, J. Am. Chem. Soc. 2009, 131, 12070-12071; d) Z. Liang, B. Yao, Y. Zhang, Org. Lett. 2010, 12, 31853187; e) I. B. Seiple, S. Su, R. A. Rodriguez, R. Gianatassio, Y. Fujiwara, A. L. Sobel, P. S. Baran, J. Am. Chem. Soc. 2010, 132, 13194-13196; f) J. Wen, S. Qin, L.-F. Ma, L. Dong, J. Zhang, S.-S. Liu, Y.-S. Duan, S.-Y. Chen, C.-W. Hu, X.-Q. Yu, Org. Lett. 2010, 12, 2694-2697; g) H. Hachiya, K. Hirano, T. Satoh, M. Miura, Angew. Chem. Int. Ed. 2010, 49, 2202-2205; h) B. Liu, X. Qin, K. Li, Q. Guo, J. Lan, J. You, Chem. Eur. J. 2010, 16, 11836-11839; i) S. Ranjit, X. Liu, Chem. Eur. J. 2011, 17, 1105-1108; j) F. Yang, Z. Xu, Z. Wang, Z. Yu, R. Wang, Chem. Eur. J. 2011, 17, 6321-6325; k) G.-P. Qu, P.-Y. Xin, H.-Y. Nu, D.-C. Wang, R. F. Ding, H.-M. Guo, Chem. Commun. 2011, 47, 111\40-11142; 1) J. Wang, S. Wang, G. Wang, J. Zhang, X.-Q. Yu, Chem. Commun. 2012, 48, 11769-11771; m) A. Deb, S. Manna, A. Maji, U. Dutta, D. Maiti, Eur. J. Org. Chem. 2013, 5251-5253; n) M.-Z. Lu, P. Lu, Y.-H. Xu, T.-P. Loh, Org. Lett. 2014, 16, 2614-2617; o) R. Giri, S. Thapa, A. Kafle, Adv. Synth. Catal. 2014, 356, 1395-1411; p) E. E. Anagnostaki, A. D. Fotiadou, V. Demertzidou, A. L. Zografos, Chem. Commun. 2014, 50, 6879-6882; q) W.-Y. Hu, P.-P. Wang, S.-L. Zhang, Synthesis 2015, 47, 42-48; r) A. 
Modaki, S. Rana, D. Maiti, J. Org. Chem. 2015, 80, 296-303.

[76] H. Andersson, F. Almqvist, R. Olsson, Org. Lett. 2007, 9, 1335-1337.

[77] H. Andersson, T. S.-L. Banchelin, S. Das, R. Olsson, F. Almqvist, Chem. Commun. 2010, 46, 3384-3386.

[78] L.-C. Campeau, F. Fagnou, Org. Synth. 2011, 88, 22-32.

[79] Y. Shen, J. Chen, M. Liu, J. Ding, W. Gao, X. Huang, H. Wu, Chem. Commun. 2014, 50, 42924295.

[80] P. P. Singh, S. K. Aithagani, M. Yadav, V. P. Singh, R. A. Vishwakarma, J. Org. Chem. 2013, 78, 2639-2648.

[81] F. Zhang, X.-F. Duan, Org. Lett. 2011, 13, 61026105.

[82] a) A. Funk, P. Divekar, Can. J. Microbiol. 1959, 5, 317-321; b) R. P. Chandran, R. Sankaran, P. V. Divekar, J. Antibiot. 1968, 21, 243.

[83] A. Krasovskiy, P. Knochel, Angew. Chem. Int. Ed. 2004, 43, 3333-3336.

[84] A. Krasovskiy, P. Knochel, Synthesis 2006, 890891.

[85] K. Chatterjee, W. Raether, N. Iyer, B. N. Ganguli, Z. Parasitenkd. 1984, 70, 569-573.

[86] A. K. Singla, R. K. Gurram, A. Chauhan, N. Khatri, R. M. Vohra, R. S. Jolly, J. N. Agrewala, PLoS ONE 2014, 9, e107051; doi: 10.1371/journal.pone. 0107051 .

[87] T. Kato, Y. Yamanaka, J. Org. Chem. 1965, 30, 910-913.

[88] J. T. van Bergen, R. M. Kellogg, J. Org. Chem. 1971, 36, 1705-1708.

[89] a) D. B. Harden, M. J. Makrosz, L. Strekowski, J. Org. Chem. 1988, 53, 4137-4140; b) L. Strekowski, D. B. harden, W. B. Grubb III, S. E. Patterson, A. Czarny, M. J. Mokrosz, M. T. Cegla, R. L. Wydra, J. Heterocyclic Chem. 1990, 27, 1393-1400.

[90] F.-F. Zho, W.-W. Xie, Y.-X. Yang, L. Zhang, P. Wang, R. Yuan, C.-S. Da, J. Org. Chem. 2013, 78, 3243-3249.

[91] X. Ren, P. Wen, X. Shi, Y. Wang, J. Li, S. Yang, H. Yan, G. Huang, Org. Lett. 2013, 15, 5194-5197.

[92] a) M. Tobisu, I. Hyodo, N. Chatani, J. Am. Chem. Soc. 2009, 131, 12070-12071; b) I. Hyodo, M. Tobisu, N. Chatani, Chem. Asian J. 2012, 7, 13571365.

[93] A. M. Berman, R. G. Bergmann, J. A. Ellman, J. Org. Chem. 2014, 79, 10682-10688.
[94] J. Zhang, J. Chen, X. Zhang, X. Lei, J. Org. Chem. 2014, 79, 10682-10688.

[95] Q. Chen, X. M. du Jourdin, P. Knochel, J. Am. Chem. Soc. 2013, 135, 4958-4961.

[96] P. Guo, J. N. Joo, S. Rakshit, D. Sames, J. Am. Chem. Soc. 2011, 133, 16338-16341.

[97] D. E. Stephens, G. Chavez, M. Valdes, M. Dovalina, H. D. Arman, O. V. Larionov, Org. Biomol. Chem. 2014, 12, 6190-6199

[98] For some paper on transition metal-free direct (hetero)arylation reactions of heteroarenes that have been published in 2015, see: a) M. Ravi, P. Chauhan, R. Kant, S. K. Shukla, P. P. Yadav, J. Org. Chem. 2015, 80, 5369-5376; b) S. Kumar, V. Rathore, A. Verma, Ch. D. Prasad, A. Kumar, A. Yadav, S. Jana, Moh. Sattar, Meenkshi, S. Kumar, Org. Lett. 2015, 17, 82-85; c) L. Wang, J. Cao, Q. Chen, M. He, J. Org. Chem. 2015, 80, 4743-4748; d) S. Mao, X. Geng, Y. Yang, X. Qian, S. Wu, J. Han, L. Wang, RSC Adv. 2015, 5, 36390-36393; e) M. Kojima, K. Oisaki, M. Kanai, Chem. Commun. 2015, 51, 97189721; f) P. Maity, D. Kundu, B. C. Ranu, Eur. J. Org. Chem. 2015, 1727-1734; g) A. P. Colleville, R. A. J. Horan, S. Olazabal, N. C. O. Tomkinson, Org. Proc. Res. Dev. DOI: 10.1021/acs.oprd.5b00231.

[98] For a review on the current debate of whether metal-free reactions are really metal-free, see: R. A. D. Arancon, C. S. K. Lin, C. Vargas, R. Luque, Org. Biomol. Chem. 2014, 12, 10-3 


\section{REVIEW}

Transition Metal-Free Direct $\mathrm{C}-\mathrm{H}$ (Hetero)arylation of Heteroarenes: A Sustainable Methodology to Access (Hetero)aryl-Substituted Heteroarenes

Adv. Synth. Catal. Year, Volume, Page - Page

Renzo Rossi,* Marco Lessi, Chiara Manzini, Giulia Marianetti, Fabio Bellina*

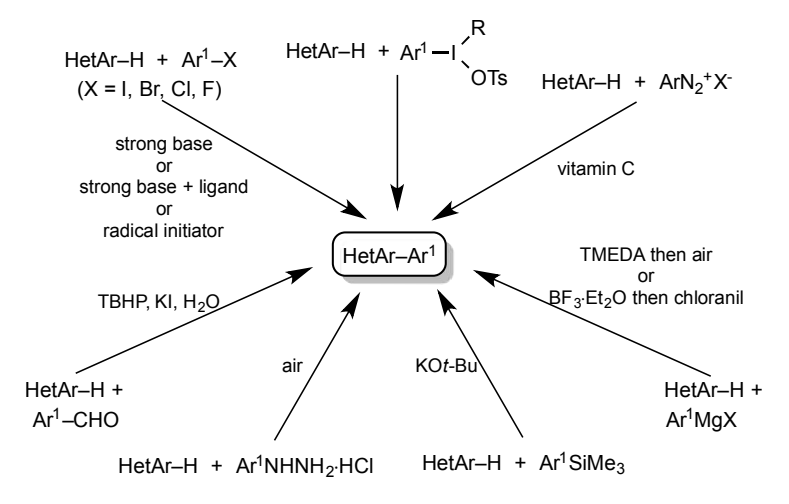

